\title{
A Galactoside-Binding Protein Tricked into Binding Unnatural Pyranose Derivatives: 3-Deoxy-3-Methyl-Gulosides Selectively Inhibit Galectin-1
}

\author{
Kumar Bhaskar Pal ${ }^{1}$, Mukul Mahanti ${ }^{1}$, Hakon Leffler ${ }^{2}\left(\mathbb{D}\right.$ and Ulf J. Nilsson ${ }^{1, *(1)}$ \\ 1 Centre for Analysis and Synthesis, Department of Chemistry, Lund University, Box 124, \\ SE-221 00 Lund, Sweden \\ 2 Section MIG, Department of Laboratory Medicine, Lund University, BMC-C1228b, Klinikgatan 28, \\ SE-221 84 Lund, Sweden \\ * Correspondence: ulf.nilsson@chem.lu.se; Tel.: +46-46-222-8218; Fax: +46-46-222-8209
}

Received: 23 June 2019; Accepted: 22 July 2019; Published: 2 August 2019

\begin{abstract}
Galectins are a family of galactoside-recognizing proteins involved in different galectinsubtype-specific inflammatory and tumor-promoting processes, which motivates the development of inhibitors that are more selective galectin inhibitors than natural ligand fragments. Here, we describe the synthesis and evaluation of 3-C-methyl-gulopyranoside derivatives and their evaluation as galectin inhibitors. Methyl 3-deoxy-3-C-(hydroxymethyl)- $\beta$-D-gulopyranoside showed 7-fold better affinity for galectin-1 than the natural monosaccharide fragment analog methyl $\beta$-D-galactopyranoside, as well as a high selectivity over galectin-2, 3, 4, 7, 8, and 9. Derivatization of the 3-C-hydroxymethyl into amides gave gulosides with improved selectivities and affinities; methyl 3-deoxy-3-C-(methyl-2,3,4,5,6-pentafluorobenzamide)- $\beta$-D-gulopyranoside had $\mathrm{K}_{\mathrm{d}} 700 \mu \mathrm{M}$ for galectin-1, while not binding any other galectin.
\end{abstract}

Keywords: galectin-1; gulopyranosides; fluorescence polarization; benzamide; selective

\section{Introduction}

Galectins are an evolutionary ancient family of small soluble proteins with affinity for $\beta$-D-galactopyranoside-containing glycoconjugates and a conserved amino acid sequence motif $[1,2]$. By their carbohydrate-binding activity they can cross-link glycoproteins, resulting in a variety of effects, such as regulation of cell adhesion, intracellular glycoprotein traffic, and cell signaling [3-5]. These effects in turn affect cell behavior in inflammation, immunity and cancer, and galectins appear to be rate limiting in some such pathophysiological conditions, e.g., based on effects in null mutant mice and other model systems [6-10]. This has stimulated development of galectin inhibitors as potential drug candidates, but different galectins have a different tissue distribution and function. Although all bind glycoconjugates containing $\beta$-galactose residues, each galectin may have a different affinities for larger natural glycans and for artificial small molecule ligands. Hence, there is an important need for selective galectin-inhibitors, that, for example, distinguish between the two most studied galectins in humans, galectin-1 and galectin-3.

The carbohydrate binding site of galectins is a concave groove and long enough to hold about a tetrasaccharide and based on this the carbohydrate binding site of galectins has been described as a combination of four subsites (A-D) together with an additional one less defined fifth subsite $\mathrm{E}$ [3]. Within this groove, subsite $\mathrm{C}$ is conserved among galectins, made up of the defining amino acid sequence motif and binds $\beta$-galactopyranosides by $\mathrm{H}$-bond interaction with $4-\mathrm{OH}, 6-\mathrm{OH}$ and the ring 
5-O, and $\mathrm{CH}-\pi$ interaction of the $\alpha$-side of the pyranose ring with a Trp residue. The neighbouring sites, however, vary among galectins, and can be targeted for selective inhibitor development. To do this, previous inhibitor design has derivatized the positions on galactose not engaged by subsite $C$, namely $\mathrm{C} 1, \mathrm{C} 2$, and C3 [11]. Gulose is a rare saccharide not found in mammals, but can potentially bind galectins because it is structurally similar to galactose with the only difference being the stereoconfiguration at $\mathrm{C} 3$. Hence, the $\mathrm{C} 3$ is epimeric with the $\mathrm{OH}$ axial instead of equatorial in the galectin bound pyranose form. Here, we show that derivatization at $\mathrm{C} 3$ in gulose offers a new space for galectin inhibitor design and surprisingly selective inhibitors of galectin-1. In particular, amide-functionalised C3-methyl gulopyranosides are shown to be apparently selective towards human galectin-1.

\section{Results and Discussion}

\subsection{Synthesis of Methyl 3-Deoxy-3-C-(methyl)- $\beta$-D-gulopyranosides and galectin inhibition evaluation}

The synthesis of the 3-C-methyl-gulo derivatives was initiated by Dess-Martin periodinane oxidation [12] of the known methyl 2,4,6-tri-O-benzyl- $\beta$-D-galactopyranoside $\mathbf{1 1}$ to afford the corresponding keto derivative 12 in $84 \%$ yield (Scheme 1). Methylenation of 12 with Petasis reagent gave the olefin $\mathbf{1 3}$ in 79\% yield. Next, the olefin $\mathbf{1 3}$ was subjected to hydroboration with 9-borabicyclo-[3.3.1]nonane (9-BBN) [12], followed by oxidative cleavage of the carbon-boron bond with alkaline hydrogen peroxide to afford the corresponding gulo and galacto isomers 14a $(36 \%)$ and $\mathbf{1 4 b}(24 \%)$, which were separated by flash column chromatography at a ratio 3:2. Both the gulo and galacto derivatives $\mathbf{1 4} \mathbf{a}$ and $\mathbf{1 4} \mathbf{b}$ were separately subjected to hydrogenation [13] in the presence of $\mathrm{Pd}(\mathrm{OH})_{2}-\mathrm{C}$ to give the desired methyl 3-deoxy-3-C-(hydroxymethyl)- $\beta$-D-gulopyranoside $1 \mathrm{a}$ and methyl 3-deoxy-3-C-(hydroxymethyl)- $\beta$-D-galactopyranoside $1 \mathrm{~b}$ in yields of $51 \%$ and $63 \%$, respectively. Evaluation of $\mathbf{1 a}$ and $\mathbf{1 b}$ as inhibitors of human galectin-1, 2, 3, $4 \mathrm{~N}$ (N-terminal domain) $4 \mathrm{C}$ (C-terminal domain), $7,8 \mathrm{~N}, 8 \mathrm{C}, 9 \mathrm{~N}$, and $9 \mathrm{C}$ in a reported competitive fluorescence anisotropy assay $[14,15]$ revealed that the gulo derivative 1a was selective for galectin- 1 with a dissociation constant of $1300 \mu \mathrm{M}$, which is about an order of magnitude better than for the virtually unselective reference compound methyl $\beta$-D-galactopyranoside 32 (Figure 1, Table 1).

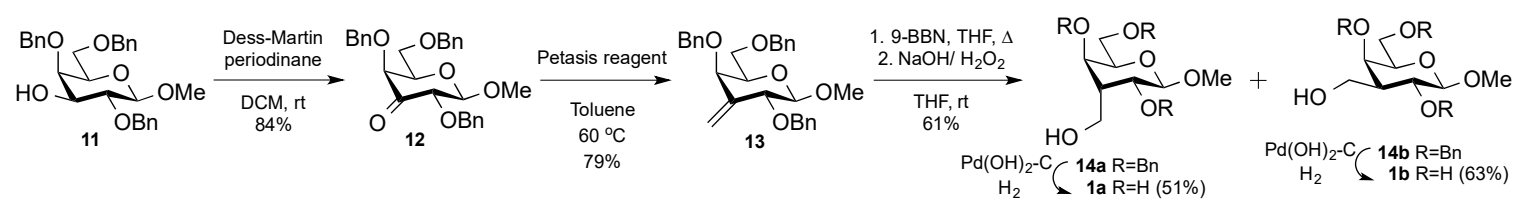

Scheme 1. Synthesis of methyl 3-deoxy-3-C-(hydroxymethyl)- $\beta$-D-gulopyranoside 1a, methyl 3-deoxy-3-C-(hydroxymethyl)- $\beta$-D-galactopyranoside $\mathbf{1 b}$.

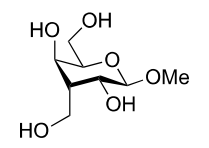

1a

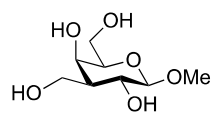

$1 b$

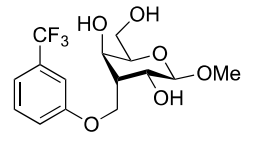

2

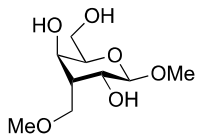

3

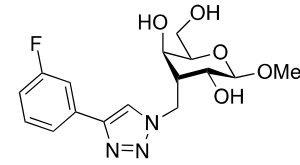

4

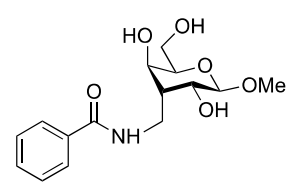

$7 a$

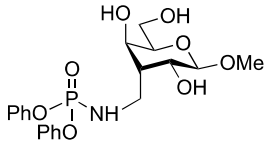

8

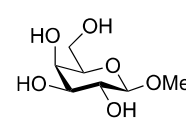

32

Figure 1. Structures of the tested compounds 1-8 and reference compound $\mathbf{3 2 .}$ 
Table 1. $K_{\mathrm{d}}$-values $(\mathrm{mM})^{\mathrm{a}}$ of compounds $\mathbf{1 a}-\mathbf{1 b}, \mathbf{2}-\mathbf{3}, \mathbf{7 a}, \mathbf{8}$, and the reference methyl $\beta$-D-galactopyranoside 32 against human galectin- $1,2,3,4 \mathrm{~N}, 4 \mathrm{C}, 7,8 \mathrm{~N}, 8 \mathrm{C}, 9 \mathrm{~N}$, and $9 \mathrm{C}$ in a competitive fluorescence polarization assay $[15,16]$.

\begin{tabular}{ccccccccccc}
\hline \multirow{2}{*}{ Compounds s } & \multicolumn{10}{c}{ Galectin } \\
\cline { 2 - 11 } & $\mathbf{1}$ & $\mathbf{2}$ & $\mathbf{3}$ & $\mathbf{4 \mathbf { N } ^ { \mathbf { b } }}$ & $\mathbf{4 \mathbf { C } ^ { \mathbf { c } }}$ & $\mathbf{7}$ & $\mathbf{8 N}^{\mathbf{b}}$ & $\mathbf{8 C}^{\mathbf{c}}$ & $\mathbf{9 N}^{\mathbf{b}}$ & $\mathbf{9 C}^{\mathbf{c}}$ \\
\hline $\mathbf{1 a}$ & $1.3 \pm 0.15$ & ND & NB & NB & ND & NB & NB & $3.7 \pm 0.02$ & NB & NB \\
$\mathbf{1 b}$ & NB & NB & NB & $>4$ & NB & NB & NB & NB & NB & NB \\
$\mathbf{2}$ & NB & NB & NB & NB & NB & NB & NB & NB & NB & NB \\
$\mathbf{3}$ & NB & ND & NB & ND & ND & ND & NB & NB & ND & ND \\
$\mathbf{4}$ & NB & NB & NB & NB & NB & NB & NB & NB & NB & NB \\
$\mathbf{5}$ & NB & NB & NB & NB & NB & NB & NB & NB & NB & NB \\
$\mathbf{6}$ & $>10$ & ND & NB & NB & NB & NB & NB & NB & ND & NB \\
$\mathbf{7 a}$ & $1.8 \pm 0.15$ & NB & NB & NB & NB & NB & NB & NB & ND & NB \\
$\mathbf{8}$ & $>10$ & ND & NB & NB & NB & NB & NB & NB & ND & $>5$ \\
$\mathbf{3 2}$ & $>10[16]$ & $13[17]$ & $4.4[16]$ & $6.6[17]$ & $10[17]$ & $4.8[16]$ & $6.3[16]$ & $>30[18]$ & $3.3[16]$ & $8.6[19]$ \\
\hline
\end{tabular}

${ }^{a}$ The data are average and SEM (standard error of mean) of 4-8 single-triple point measurements. ${ }^{\mathrm{b}} \mathrm{N}$-terminal domain. ${ }^{\mathrm{c}} \mathrm{C}$-terminal domain. ${ }^{\mathrm{d}}$ Not determined. ${ }^{\mathrm{e}}$ Not binding at the highest concentration tested: $4 \mathrm{mM}$.

In stark contrast, the galacto derivative $\mathbf{1 b}$ did not bind any galectin tested, except for a weak binding to galectin- $4 \mathrm{~N}$. This observation encouraged us to further explore the 3-C-methyl gulopyranoside scaffold for the discovery of galectin-1-selective inhibitors. Hence, we initiated synthetic efforts toward replacing the hydroxymethyl of 1a with amide, ether, urea, and triazole functionalities. An aryl ether was synthesized following a recently reported iodonium-salt mediated reaction [20] to give the aryl ether 15, which after hydrogenolysis [13] of the benzyl protecting groups gave 2 (Scheme 2). The hydroxymethyl 14a was methylated with methyl iodide to give the methyl ether 16, which after debenzylation gave the 3-methoxymethyl guloside 3. Treatment of 14a with methanesulfonyl chloride furnished the corresponding gulo mesylate, which was then directly treated with $\mathrm{NaN}_{3}$ in dry DMF at $80{ }^{\circ} \mathrm{C}$ to provide the gulo azide, 17 in $83 \%$ yield. The gulo azide 17 was treated with 1-ethynyl-3-fluorobenzene in the presence of the CuI and DIPEA catalytic system [21] in dry dichloromethane to give the triazole 18 within $48 \mathrm{~h}$ in $86 \%$ yield. Debenzylation provided the desired triazole-derived methyl guloside 4 . The urea $\mathbf{2 0}$ was obtained via reduction of the azide $\mathbf{1 7}$ to give the amine 19, followed by reaction with 3-fluorophenylisocyanate. Debenzylation [13] of 20 afforded the target gulo urea derivative 5 in $66 \%$ yield. The amine 19 was treated with benzensulfonyl chloride, benzoyl chloride, and diphenyl phosphoryl chloride in the presence of $\mathrm{Et}_{3} \mathrm{~N}$ to give the protected sulfonamide 21, amide 22a, and diphenylphosphonamide $\mathbf{2 3}$, which were subjected for hydrogenolysis [13] in the presence of $\mathrm{Pd}(\mathrm{OH})_{2}$ to get the unprotected amides $\mathbf{6}, \mathbf{7 a}$, and $\mathbf{8}$.

Evaluation of aryl ether 2 , methyl ether 3 , triazole 4, urea 5, sulfonamide 6 , benzamide $7 \mathrm{a}$, and phosphonamide 8 derived methyl gulosides' affinities for the human galectin-1, 2, 3, 4N, 4C, 7, 8N, $8 \mathrm{C}, 9 \mathrm{~N}$, and $9 \mathrm{C}$ showed that most of the gulo derivatives were inactive as ligands for galectins, the benzamide 7a displayed moderate affinity, similar to that of $\mathbf{1 a}$, for galectin-1 and with excellent selectivity (Table 1). Particularly noteworthy was that $7 \mathbf{a}$ also had a significantly better affinity for galectin- 1 than the simple reference monosaccharide methyl $\beta$-D-galactopyranoside 32 . Furthermore, the hydroxylmethyl group of 1a plays an important role in the interaction with galectin-1, as the corresponding methyl ether 3 binds galectin-1 significantly worse than 1 a does. 


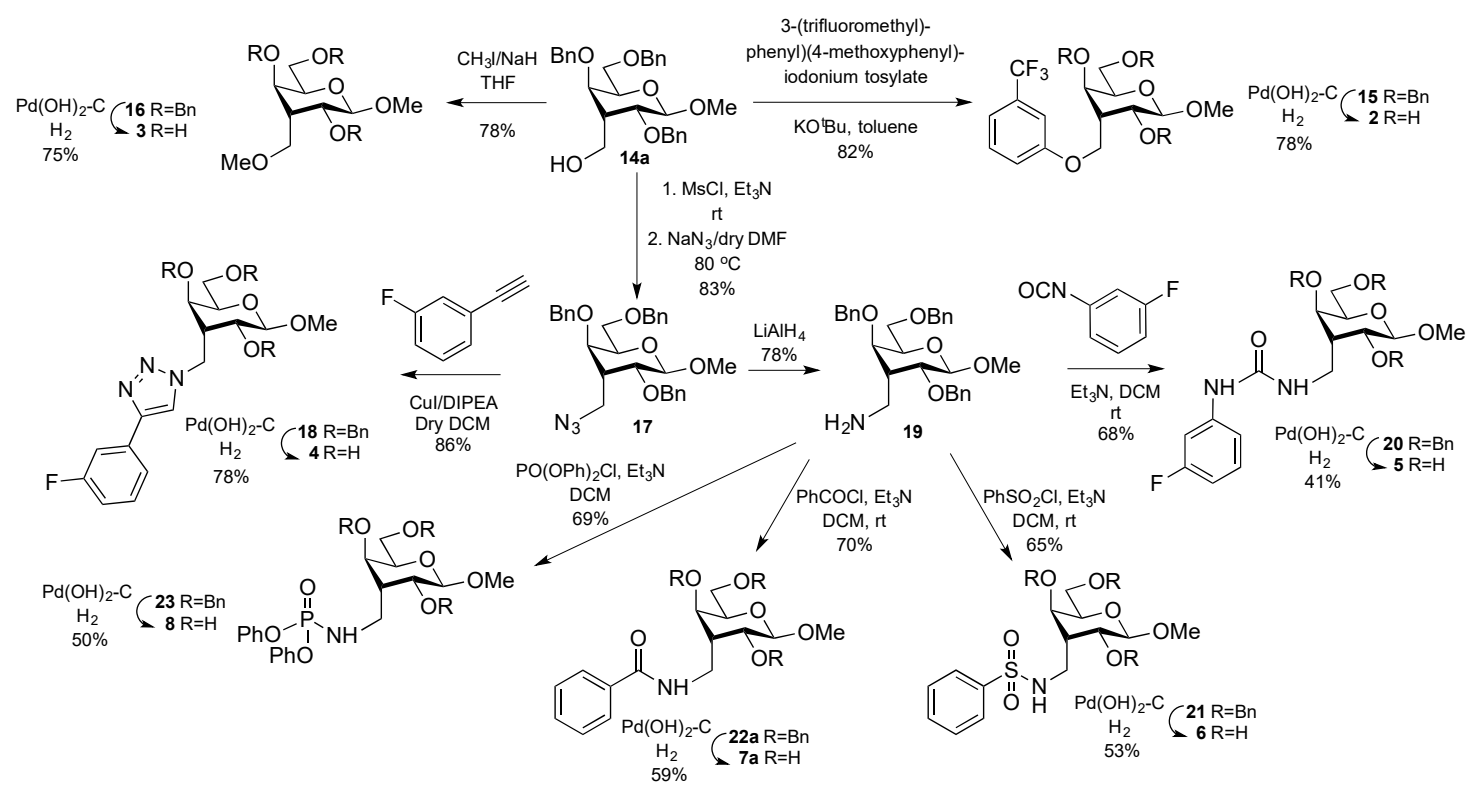

Scheme 2. Synthesis of methyl 3-deoxy-3-C-methyl- $\beta$-D-gulopyranoside ether $2-3$, triazole 4, urea 5, sulfonamide $\mathbf{6}$, amide $7 \mathbf{a}$, and phosphonamide 8 derivatives.

\subsection{Synthesis and Optimization of 3-Deoxy-3-C-Amidomethyl- $\beta$-D-Gulopyranoside Derivatives as Galectin-1 Inhibitors}

The observation that the amide 7 a showed moderate affinity but high selectivity for galectin-1 prompted us to prepare a series $\mathbf{7} \mathbf{c}-\mathbf{7 l}$ of benzamide analogs carrying selected different substituents at different positions, including four fluorbenzamide expected to possess improved metabolic stability and pharmacokinetic properties, as well as a reference acetamide analog $7 \mathbf{b}$ (Scheme 3). Furthermore, in order to investigate the role of the gulo 3-C-methyl substituent, the 3-OH 9 and 3-benzamido 10 gulosides were synthesized (Scheme 3). Hydrolysis of the known 4,6-O-benzylidene gulose derivative, 24 [22] with $80 \% \mathrm{AcOH}$ at $80{ }^{\circ} \mathrm{C}$ gave the diol 25 in $91 \%$ yield, which upon Zemplen de-O-acetylation [23] afforded the target methyl $\beta$-D-gulopyranoside 9 in $93 \%$ yield. Selective $3-O$-triflation of methyl 4,6-O-benzylidene- $\beta$-D-galactopyranoside 26 [24], followed by one-pot benzoylation of 2-O-hydroxyl gave 27 . The crude triflate 27 was subsequently converted into the 3-azido-3-deoxy-guloside 28 by treatment with sodium azide in DMF. De-benzylidenation with $80 \% \mathrm{AcOH}$ at $80{ }^{\circ} \mathrm{C}$ and subsequent benzoylation afforded $\mathbf{2 9}$ in $43 \%$ yield over four steps from $\mathbf{2 6}$. Azide hydrogenation gave 30, which upon benzoylation and de-O-benzoylation gave the benzamide $\mathbf{1 0}$.

An immediate observation upon evaluating the affinities of 7b-7l and 9-10 (Figure 2, Table 2) was that the acetamide $7 \mathbf{b}$ displays a similar affinity for galectin- 1 as the benzamides $7 \mathbf{a}$ and $\mathbf{7} \mathbf{c}-\mathbf{7 k}$. Hence, the phenyl moieties of $7 \mathbf{a}$ and $\mathbf{7 c}-\mathbf{7 k}$ do not contribute to enhancing the affinity for galectin-1. However, the phenyl moieties and substitution patterns of $7 \mathbf{a}$ and $\mathbf{7 c}-7 \mathbf{k}$ influence the selectivity over other galectins, as six substituted amides $(\mathbf{7 a}, \mathbf{7 d}$, and $\mathbf{7 f} \mathbf{f}-\mathbf{7 i})$ retained high selectivity for galectin- 1 over the other galectins. The pentafluorophenyl $7 \mathrm{~g}$ turned out to be the best $\beta$-D-gulopyranoside-based monosaccharide inhibitor for human galectin-1 with 14-fold improved affinity over the reference methyl $\beta$-D-galactopyranoside 32. The larger biphenyl 71 did not bind galectin-1, which suggests that the galectin-1 site accommodating the axial gulo substituent is limited in size. Evaluation of the guloside 9 revealed that while it is similar to the reference galactoside 32 in the affinity for galectin-1, it displays a much higher selectivity in that it is inactive against the other galectins under the evaluation conditions used. Unfortunately, extensive molecular dynamics and docking analyses to explain the selective galectin-1 binding to $3-C$-methyl-gulosides were inconclusive as such calculations cannot provide reliable relative affinities of bound ligands. Hence, it remains to find a plausible structural explanation for this selectivity. Interestingly, the benzamide $\mathbf{1 0}$ showed no binding to galectin-1 under the assay conditions but instead had improved binding to and selectivity for galectin- $4 \mathrm{~N}$. Hence, while 
3-C-methyl gulosides represent an interesting structural class for the discovery of selective galectin-1 inhibitors, 3 -C-amido gulosides may represent a novel structural class for galectin-4 inhibitor discovery.

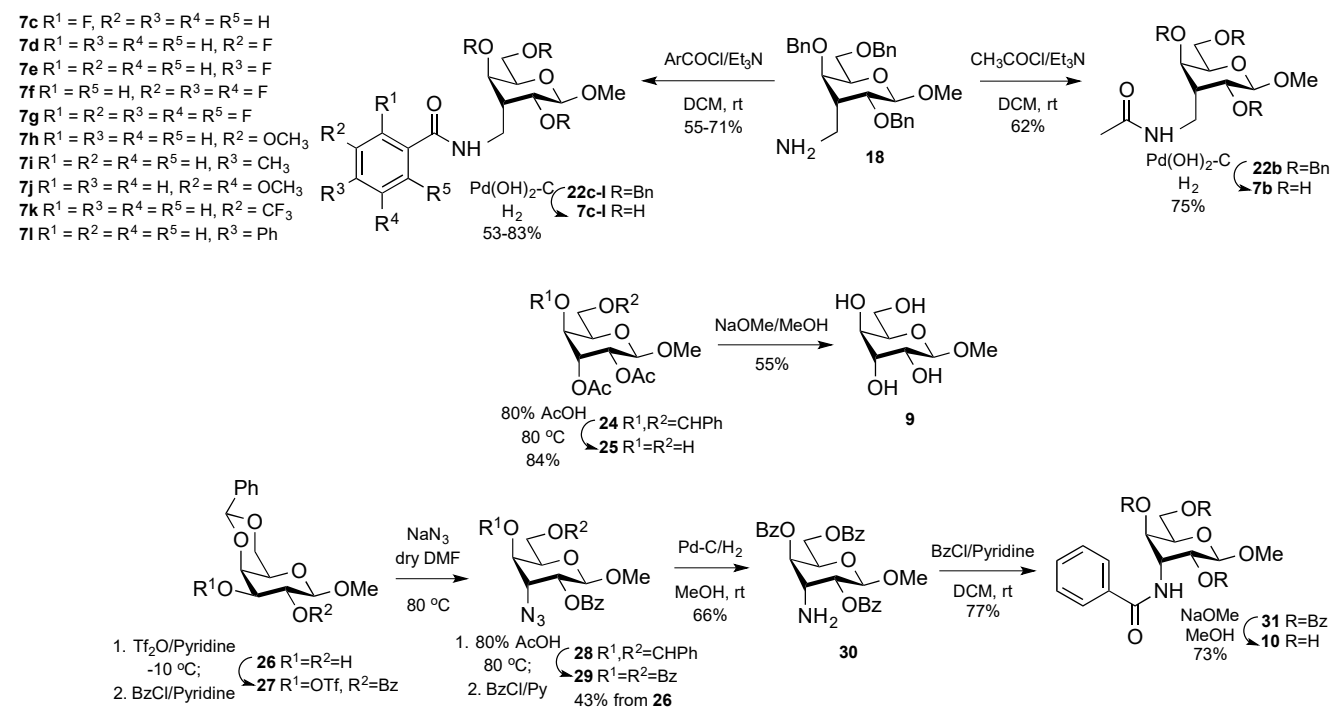

Scheme 3. Synthesis of 3-deoxy-3-C-amidomethyl- $\beta$-D-gulo derivatives 7b-7l, methyl $\beta$-D-gulopyranoside 9, and methyl 3-deoxy-3-N-benzamido- $\beta$-D-gulopyranoside 10.

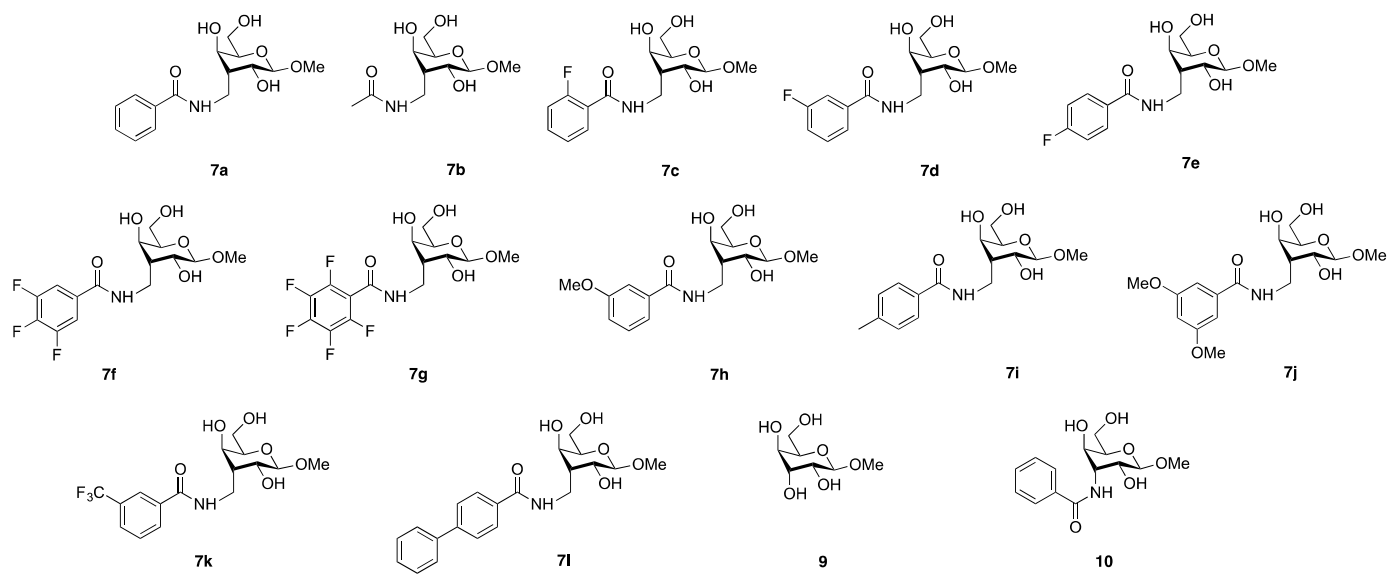

Figure 2. Structures of all tested compounds $7 \mathbf{a}-7 \mathbf{l}$ and $\mathbf{9 - 1 0}$.

Table 2. $K_{\mathrm{d}}$-values $(\mathrm{mM})^{\mathrm{a}}$ of compounds $7 \mathrm{a}-7 \mathrm{l}, \mathbf{9}$, and 10 against human galectin-1, 2, 3, 4N, 4C, 7, 8N, $8 \mathrm{C}, 9 \mathrm{~N}$, and $9 \mathrm{C}$ in a competitive fluorescence polarization assay.

\begin{tabular}{|c|c|c|c|c|c|c|c|c|c|c|}
\hline \multirow{2}{*}{ Compounds } & \multicolumn{10}{|c|}{ Galectin } \\
\hline & 1 & 2 & 3 & $4 N^{b}$ & $4 \mathrm{C}^{\mathrm{c}}$ & 7 & $8 \mathrm{~N}^{b}$ & $8 C^{c}$ & $9 N^{b}$ & $9 C^{c}$ \\
\hline $7 a$ & $1.8 \pm 0.15$ & $\mathrm{NB}^{\mathrm{d}}$ & NB & NB & NB & NB & NB & NB & $\mathrm{ND}^{\mathrm{e}}$ & NB \\
\hline $7 \mathrm{~b}$ & $1.5 \pm 0.08$ & NB & NB & $1.9 \pm 0.05$ & NB & NB & NB & $2.7 \pm 0.5$ & NB & NB \\
\hline $7 c$ & $1.9 \pm 0.04$ & NB & NB & $2.2 \pm 0.16$ & NB & NB & NB & NB & NB & NB \\
\hline $7 d$ & $1.9 \pm 0.4$ & NB & NB & NB & NB & NB & NB & NB & NB & NB \\
\hline $7 e$ & $1.7 \pm 0.06$ & NB & $1.6 \pm 0.03$ & $1.7 \pm 0.07$ & NB & NB & NB & NB & NB & NB \\
\hline $7 f$ & $2.5 \pm 0.4$ & NB & NB & NB & NB & NB & NB & NB & NB & NB \\
\hline $7 g$ & $0.7 \pm 0.005$ & NB & NB & NB & NB & NB & NB & NB & NB & NB \\
\hline $7 \mathrm{~h}$ & $3.2 \pm 0.5$ & NB & NB & NB & NB & NB & NB & NB & NB & NB \\
\hline $7 \mathbf{i}$ & $2.3 \pm 0.4$ & NB & NB & NB & NB & NB & NB & NB & NB & NB \\
\hline $7 \mathbf{j}$ & $1.8 \pm 0.04$ & NB & NB & $2 \pm 0.4$ & NB & NB & NB & $2.6 \pm 0.6$ & NB & NB \\
\hline $7 \mathbf{k}$ & $1.8 \pm 0.07$ & NB & NB & $1.9 \pm 0.1$ & NB & NB & NB & NB & NB & NB \\
\hline 71 & NB & NB & NB & NB & NB & NB & NB & NB & NB & NB \\
\hline 9 & $10 \pm 0.25$ & $10 \pm 1.5$ & NB & ND & $11 \pm 1.2$ & NB & NB & NB & NB & NB \\
\hline 10 & NB & NB & NB & $1.3 \pm 0.2$ & NB & ND & NB & NB & NB & NB \\
\hline
\end{tabular}

${ }^{a}$ The data are average and SEM of 4-8 single-triple point measurements. ${ }^{b} \mathrm{~N}$-terminal domain. ${ }^{\mathrm{c}} \mathrm{C}$-terminal domain.

${ }^{\mathrm{d}}$ Not binding at the highest concentration tested: $4 \mathrm{mM}$. ${ }^{\mathrm{e}}$ Not determined. 


\section{Materials and Methods}

\subsection{General Methods Experimental Procedures}

All reactions were carried out in oven-dried glassware. All solvents and reagents were mainly purchased from Sigma-Aldrich or Fluka and were used without further purification or synthesized via the literature protocol. TLC analysis was performed on pre-coated Merck silica gel $60 \mathrm{~F}_{254}$ plates using UV light and charring solution ( $10 \mathrm{~mL}$ conc. $\mathrm{H}_{2} \mathrm{SO}_{4} / 90 \mathrm{~mL}$ EtOH). Flash column chromatography was done on $\mathrm{SiO}_{2}$ purchased from Aldrich (technical grade, $60 \AA$ A pore size, 230-400 mesh, 40-63 $\mu \mathrm{m}$ ). All NMR spectra were recorded with the Bruker DRX $400 \mathrm{MHz}$ spectrometer $\left(400 \mathrm{MHz}\right.$ for ${ }^{1} \mathrm{H}, 100 \mathrm{MHz}$ for ${ }^{13} \mathrm{C}\left(125 \mathrm{MHz}{ }^{13} \mathrm{C}\right.$ for compound 7k with the Bruker Avance III $500 \mathrm{MHz}$ spectrometer equipped with a broadband observe SMART probe, Fällanden, Switzerland), $376 \mathrm{MHz}$ for ${ }^{19} \mathrm{~F}, 162 \mathrm{MHz}$ for $\left.{ }^{31} \mathrm{P}, \mathrm{ESI}\right)$ at ambient temperature using $\mathrm{CDCl}_{3}$ or $\mathrm{CD}_{3} \mathrm{OD}$ as solvents. Chemical shifts are given in ppm relative to the residual solvent peak ( ${ }^{1} \mathrm{H}$ NMR: $\mathrm{CDCl}_{3} \delta 7.26 ; \mathrm{CD}_{3} \mathrm{OD} \delta 3.31 ;{ }^{13} \mathrm{C} \mathrm{NMR}^{\mathrm{CDCl}} \mathrm{CD}_{3} \delta$ 77.16; $\left.\mathrm{CD}_{3} \mathrm{OD} \delta 49.00\right)$ with multiplicity ( $b=$ broad, $s=$ singlet, $d=$ doublet, $t=$ triplet, $q=$ quartet, quin = quintet, sext $=$ sextet, hept $=$ heptet, $m=$ multiplet, $t d=$ triplet of doublets, $d t=$ doublet of triplets), coupling constants (in $\mathrm{Hz}$ ) and integration. Copies of nmr spectra are provided in the supplementary information. High-resolution mass analysis was obtained using the Micromass Q-TOF mass spectrometer. Analytical data is given if the compound is novel or not fully characterized in the literature. Final compounds were further purified via HPLC before evaluation of galectin affinity. All tested compounds were $>95 \%$ pure according to the analytical HPLC analysis.

\subsection{Methyl 2,4,6-Tri-O-Benzyl- $\beta$-D-Xylo-Hex-3-Ulopyranoside $\mathbf{1 2}$}

Into a solution of alcohol $11(8.1 \mathrm{~g}, 17.45 \mathrm{mmol})$ in dry dichloromethane $(250 \mathrm{~mL})$ Dess-Martin periodinane ( $9.62 \mathrm{~g}, 22.68 \mathrm{mmol}, 1.3$ equiv.) was added, under nitrogen atmosphere and the reaction mixture was stirred for $4 \mathrm{~h}$ (TLC heptane/EtOAc, 3:1, $\mathrm{R}_{\mathrm{f}} 0.5$ ). After that, a saturated $\mathrm{NaHCO}_{3}$ solution $(400 \mathrm{~mL})$ was added and the mixture was stirred for $30 \mathrm{~min}$. Then, the organic layer was collected and washed successively with the saturated $\mathrm{Na}_{2} \mathrm{~S}_{2} \mathrm{O}_{3}$ solution $(2 \times 250 \mathrm{~mL})$. The organic layer was collected, dried over $\mathrm{Na}_{2} \mathrm{SO}_{4}$, filtered and concentrated in vacuo. Flash chromatography of the crude material (heptane/EtOAc, 7:2) afforded ketone 12 (6.45 g, $13.955 \mathrm{mmol}$, yield 80\%) as a white solid. $[\alpha]_{\mathrm{D}}^{25}-72.3\left(\mathrm{c} 1.4, \mathrm{CHCl}_{3}\right) .{ }^{1} \mathrm{H}$ NMR $\left(\mathrm{CDCl}_{3}, 400 \mathrm{MHz}\right): 7.47-7.21(\mathrm{~m}, 15 \mathrm{H}, \mathrm{ArH}), 4.76(\mathrm{~d}, 1 \mathrm{H}, J 12.0 \mathrm{~Hz}$, $\left.\mathrm{CH}_{2} \mathrm{Ph}\right), 4.73\left(\mathrm{~d}, 1 \mathrm{H}, \mathrm{J} 12.0 \mathrm{~Hz}, \mathrm{CH}_{2} \mathrm{Ph}\right), 4.58\left(\mathrm{~d}, 1 \mathrm{H}, J 12.0 \mathrm{~Hz}, \mathrm{CH}_{2} \mathrm{Ph}\right), 4.51\left(\mathrm{~d}, 1 \mathrm{H}, J 12.0 \mathrm{~Hz}, \mathrm{CH}_{2} \mathrm{Ph}\right.$ ), $4.48\left(\mathrm{~d}, 1 \mathrm{H}, J_{1,2} 7.6 \mathrm{~Hz}, \mathrm{H}-1\right), 4.44\left(\mathrm{~d}, 1 \mathrm{H}, J_{1,2} 7.6 \mathrm{~Hz}, \mathrm{H}-2\right), 4.43\left(\mathrm{~d}, 1 \mathrm{H}, J 11.6 \mathrm{~Hz}, \mathrm{CH}_{2} \mathrm{Ph}\right), 4.35(\mathrm{~d}, 1 \mathrm{H}, J$ $11.6 \mathrm{~Hz}, \mathrm{CH}_{2} \mathrm{Ph}$ ), 3.95 (d, 1H, J $\left.1.2 \mathrm{~Hz}, \mathrm{H}-4\right), 3.83-3.75$ (m, 3H, H-5, H-6a, H-6b), 3.61 (s, 3H, OCH ) . ${ }^{13} \mathrm{C} \mathrm{NMR}\left(\mathrm{CDCl}_{3}, 100 \mathrm{MHz}\right): 203.8,137.7,137.2,136.4,128.29,128.27,127.26,128.0,127.8,127.6,127.5$, $104.9,82.1,80.7,73.5,73.4,72.3,72.1,67.5,57.1$. HRMS calcd for $\mathrm{C}_{28} \mathrm{H}_{30} \mathrm{O}_{6}{ }^{+} \mathrm{NH}_{4}{ }^{+}\left(\mathrm{M}+\mathrm{NH}_{4}\right)^{+}$: 480.2386, found: 480.2378 .

\subsection{Methyl 2,4,6-Tri-O-Benzyl-3-Deoxy-3-C-Methylene- $\beta$-D-Xylo-Hex-3-Ulopyranoside $\mathbf{1 3}$}

Into a solution of ketone $\mathbf{1 2}(6.3 \mathrm{~g}, 13.63 \mathrm{mmol})$ in dry toluene $(100 \mathrm{~mL})$ bis (cyclopentadienyl) dimethyltitanium was added, $5 \mathrm{wt} \%$ in toluene $(125 \mathrm{~mL}, 30 \mathrm{mmol}, 2.2$ equiv.), under nitrogen atmosphere and the reaction mixture was stirred for $48 \mathrm{~h}$ at $65^{\circ} \mathrm{C}$ in the dark. After that, the reaction mixture (TLC heptane/EtOAc, 4:1, $\mathrm{R}_{\mathrm{f}} 0.47$ ) was concentrated in vacuo and flash chromatography of the crude material (heptane/EtOAc, 10:1-5:1) afforded methylene derivative 13 (4.6 g, 9.99 mmol, yield $71 \%)$ as a light-yellow oil. $[\alpha]_{\mathrm{D}}^{25}-40.3\left(\mathrm{c} 1.1, \mathrm{CHCl}_{3}\right) .{ }^{1} \mathrm{H} \mathrm{NMR}\left(\mathrm{CDCl}_{3}, 400 \mathrm{MHz}\right): 7.49-7.28(\mathrm{~m}, 15 \mathrm{H}$, $\mathrm{ArH}), 5.61\left(\mathrm{t}, 1 \mathrm{H}, \mathrm{J}_{2, \mathrm{H}-7 \mathrm{a}} 2.0 \mathrm{~Hz}, \mathrm{CH}_{2}\right), 5.20\left(\mathrm{t}, 1 \mathrm{H}, \mathrm{J}_{2, \mathrm{H}-7 \mathrm{~b}} 2.0 \mathrm{~Hz}, \mathrm{CH}_{2}\right), 5.00\left(\mathrm{~d}, 1 \mathrm{H}, J 12.0 \mathrm{~Hz}, \mathrm{CH}_{2} \mathrm{Ph}\right)$, $4.78\left(\mathrm{~d}, 1 \mathrm{H}, \mathrm{J} 12.0 \mathrm{~Hz}, \mathrm{CH}_{2} \mathrm{Ph}\right.$ ), $4.65\left(\mathrm{~d}, 1 \mathrm{H}, \mathrm{J} 12.0 \mathrm{~Hz}, \mathrm{CH}_{2} \mathrm{Ph}\right), 4.58$ (d, $1 \mathrm{H}, J 12.0 \mathrm{~Hz}, \mathrm{CH}_{2} \mathrm{Ph}$ ), 4.56 (d, $\left.1 \mathrm{H}, J 12.0 \mathrm{~Hz}, \mathrm{CH}_{2} \mathrm{Ph}\right), 4.36(\mathrm{~d}, 1 \mathrm{H}, J 7.6 \mathrm{~Hz}, \mathrm{H}-1), 4.28$ (d, $\left.1 \mathrm{H}, J 12.0 \mathrm{~Hz}, \mathrm{CH}_{2} \mathrm{Ph}\right), 4.14\left(\mathrm{dt}, 1 \mathrm{H}, J_{1,2}\right.$ $\left.7.6 \mathrm{~Hz}, J_{2, \mathrm{H}-7 \mathrm{a}}, J_{2, \mathrm{H}-7 \mathrm{~b}} 2.0 \mathrm{~Hz}, \mathrm{H}-2\right), 4.03$ (d, 1H, J 0.4 Hz, H-4), 3.91-3.79 (m, 3H, H-5, H-6a, H-6b), 3.65 (s, 3H, $\left.\mathrm{OCH}_{3}\right) .{ }^{13} \mathrm{C} \mathrm{NMR}\left(\mathrm{CDCl}_{3}, 100 \mathrm{MHz}\right): 142.2,138.5,138.2,137.9,128.4,128.3,128.2,128.0,127.9$, 
127.7, 127.62, 127.59, 127.5, 113.7, 104.9, 77.7, 77.3, 76.6, 73.7, 73.6, 69.2, 69.0, 56.7. HRMS calcd for $\mathrm{C}_{29} \mathrm{H}_{32} \mathrm{O}_{5}+\mathrm{NH}_{4}{ }^{+}\left(\mathrm{M}+\mathrm{NH}_{4}\right)^{+}: 478.2593$, found: 478.2607 .

3.4. Methyl 2,4,6-Tri-O-Benzyl-3-Deoxy-3-C-Hydroxymethyl- $\beta$-D-Gulopyranoside 14a and Methyl 2,4,6-Tri-O-Benzyl-3-Deoxy-3-C-Hydroxymethyl- $\beta$-D-Galactopyranoside 14b

A solution of $13(4.6 \mathrm{~g}, 9.99 \mathrm{mmol})$ in dry THF $(150 \mathrm{~mL})$ was treated with a 9-BBN solution in THF $(0.5 \mathrm{M}, 125 \mathrm{~mL})$ and heated to reflux for $24 \mathrm{~h}$. After that, the solution was cooled to $0{ }^{\circ} \mathrm{C}$ and a $10 \%$ aqueous sodium hydroxide solution $(100 \mathrm{~mL})$ and a $30 \%$ hydrogen peroxide solution $(100 \mathrm{~mL})$ were added simultaneously within $5 \mathrm{~min}$ and stirring continued for another $30 \mathrm{~min}$. Then, diethyl ether $(200 \mathrm{~mL})$ was added followed by careful addition of a $20 \%$ aqueous sodium hydrogen sulfite solution (7 mL). This mixture was stirred further for $60 \mathrm{~min}$ and extracted with diethyl ether, and the combined organic layers were dried with $\mathrm{Na}_{2} \mathrm{SO}_{4}$, filtered, and concentrated in vacuo (TLC heptane/EtOAc, 2:1 (double run), $\mathrm{R}_{\mathrm{f}} 0.48$ for $\mathbf{1 4 a}, \mathrm{R}_{\mathrm{f}} 0.4$ for $\mathbf{1 4 b}$ ). Flash chromatography (Heptane/EtOAc, 8:1 to 2:1) of the residue afforded a gulo-isomer, 14a $(1.74 \mathrm{~g}, 3.638 \mathrm{mmol})$ and galacto-isomer, 14b $(1.16 \mathrm{~g}, 2.426 \mathrm{mmol})$ to be $\approx 3: 2$ in favor of the guloisomer at an overall yield of $61 \%(2.9 \mathrm{~g}, 6.064 \mathrm{mmol})$. Gulo-isomer 14a: $[\alpha]_{\mathrm{D}}^{25}-25.7\left(\mathrm{c} 1.3, \mathrm{CHCl}_{3}\right) .{ }^{1} \mathrm{H}$ NMR $\left(\mathrm{CDCl}_{3}, 400 \mathrm{MHz}\right): 7.36-7.20(\mathrm{~m}, 15 \mathrm{H}, \mathrm{ArH}), 4.82(\mathrm{~d}, 1 \mathrm{H}, J 12.0 \mathrm{~Hz}$, $\left.\mathrm{CH}_{2} \mathrm{Ph}\right), 4.65(\mathrm{~d}, 1 \mathrm{H}, \mathrm{J} 6.4 \mathrm{~Hz}, \mathrm{H}-1), 4.57\left(\mathrm{~d}, 1 \mathrm{H}, J 11.6 \mathrm{~Hz}, \mathrm{CH}_{2} \mathrm{Ph}\right), 4.54\left(\mathrm{~d}, 1 \mathrm{H}, J 11.6 \mathrm{~Hz}, \mathrm{CH}_{2} \mathrm{Ph}\right), 4.52$ (d, $\left.1 \mathrm{H}, J 11.6 \mathrm{~Hz}, \mathrm{CH}_{2} \mathrm{Ph}\right), 4.47$ (d, 1H, J $\left.12.0 \mathrm{~Hz}, \mathrm{CH}_{2} \mathrm{Ph}\right), 4.41$ (d, $\left.1 \mathrm{H}, J 11.6 \mathrm{~Hz}, \mathrm{CH}_{2} \mathrm{Ph}\right), 3.95-3.88$ (m, 2H, H-4, H-5), 3.73 (dd, 1H, J1,2 6.4 Hz, J2,3 5.2 Hz, H-2), 3.74-3.57 (m, 4H, H-6a, H-6b, CH ${ }_{2} \mathrm{OH}$ ), 3.54 (s,

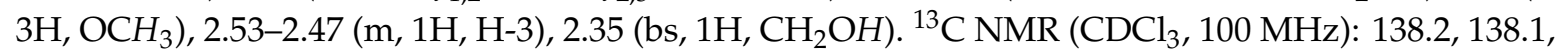
138.0, 128.6, 128.52, 128.47, 128.2, 128.1, 128.03, 127.96, 127.9, 127.8, 101.2, 77.2, 74.8, 73.8, 73.6, 73.4, 71.9, 69.5, 62.0, 56.5, 41.6. HRMS calcd for $\mathrm{C}_{29} \mathrm{H}_{34} \mathrm{O}_{6}+\mathrm{NH}_{4}{ }^{+}\left(\mathrm{M}+\mathrm{NH}_{4}\right)^{+}: 496.2699$, found: 496.2700 . Galacto-isomer 14b: $[\alpha]_{\mathrm{D}}^{25}-13.4$ (c $\left.0.9, \mathrm{CHCl}_{3}\right) .{ }^{1} \mathrm{H} \mathrm{NMR}\left(\mathrm{CDCl}_{3}, 400 \mathrm{MHz}\right)$ : 7.39-7.28 (m, $\left.15 \mathrm{H}, \mathrm{ArH}\right)$, $4.92\left(\mathrm{~d}, 1 \mathrm{H}, J 11.2 \mathrm{~Hz}, \mathrm{CH}_{2} \mathrm{Ph}\right), 4.65\left(\mathrm{~d}, 1 \mathrm{H}, J 11.2 \mathrm{~Hz}, \mathrm{CH}_{2} \mathrm{Ph}\right), 4.60-4.52\left(\mathrm{~m}, 4 \mathrm{H}, \mathrm{CH}_{2} \mathrm{Ph}\right), 4.41(\mathrm{~d}, 1 \mathrm{H}$, $\left.J_{1,2} 7.6 \mathrm{~Hz}, \mathrm{H}-1\right), 3.90\left(\mathrm{~d}, 1 \mathrm{H}, J_{3,4} 2.8 \mathrm{~Hz}, \mathrm{H}-4\right), 3.82\left(\mathrm{dd}, 1 \mathrm{H}, J 4.8 \mathrm{~Hz}, J 7.2 \mathrm{~Hz}, \mathrm{CH}_{2} \mathrm{OH}\right), 3.73-3.55$ (m, 8H, H-5, H-6a, H-6b, H-2, $\left.\mathrm{CH}_{2} \mathrm{OH}, \mathrm{OCH}_{3}\right), 2.04$ (bs, $\left.1 \mathrm{H}, \mathrm{CH}_{2} \mathrm{OH}\right), 1.87-1.82$ (m, 1H, H-3). ${ }^{13} \mathrm{C}$ NMR $\left(\mathrm{CDCl}_{3}, 100 \mathrm{MHz}\right): 138.5,138.1,137.8,128.6,128.53,128.52,128.4,128.3,128.03,127.98,127.8,106.4$, 76.5, 76.2, 74.8, 74.7, 74.6, 73.7, 68.6, 62.2, 56.8, 47.3. HRMS calcd for $\mathrm{C}_{29} \mathrm{H}_{34} \mathrm{O}_{6}+\mathrm{H}^{+}(\mathrm{M}+\mathrm{H})^{+}:$: 479.2434, found: 479.2434 .

\subsection{Methyl 2,4,6-Tri-O-Benzyl-3-Deoxy-3-C-(3-Trifluoromethylphenoxymethyl)- $\beta$-D-Gulopyranoside 15}

Compound 14a ( $80 \mathrm{mg}, 0.17 \mathrm{mmol})$ was stirred in a $25 \mathrm{~mL}$ round-bottom flask in toluene $(2 \mathrm{~mL})$ for $3 \mathrm{~min}$. A mixture of 3-(trifluoromethyl)phenyl)(4-methoxyphenyl)iodonium tosylate (140 mg, $0.25 \mathrm{mmol})$ and potassium tert-butoxide $(28.5 \mathrm{mg}, 0.25 \mathrm{mmol})$ were added under air and the mixture turned yellow. The reaction was stirred for $3 \mathrm{~h}$, when the TLC showed almost complete consumption of the starting material (TLC heptane/EtOAc, 3:1, $\mathrm{R}_{\mathrm{f}}$ 0.48). The mixture was then diluted with EtOAc $(10 \mathrm{~mL})$ and filtered. Then the volatiles were removed under reduced pressure, and the residue was subjected to column chromatography (heptane/EtOAc, 8:1 to 4:1) to provide the purified product 15 (92.6 mg, $0.15 \mathrm{mmol}, 89 \%$ ) as a colorless oil. $[\alpha]_{\mathrm{D}}^{25}-70.9\left(\mathrm{c} 0.8, \mathrm{CHCl}_{3}\right) .{ }^{1} \mathrm{H} \mathrm{NMR}\left(\mathrm{CDCl}_{3}, 400 \mathrm{MHz}\right)$ : 7.40-7.22 (m, 17H, ArH), 7.08 (bs, 1H, ArH), $7.02(\mathrm{dd}, 1 \mathrm{H}, J 8.0$ Hz, J $2.4 \mathrm{~Hz}, \mathrm{ArH}), 4.79$ (d, 1H, J $12.0 \mathrm{~Hz}$, $\left.\mathrm{CH}_{2} \mathrm{Ph}\right), 4.62(\mathrm{~d}, 1 \mathrm{H}, J 6.0 \mathrm{~Hz}, \mathrm{H}-1), 4.58\left(\mathrm{~d}, 1 \mathrm{H}, J 12.0 \mathrm{~Hz}, \mathrm{CH}_{2} \mathrm{Ph}\right), 4.57\left(\mathrm{~d}, 1 \mathrm{H}, J 11.6 \mathrm{~Hz}, \mathrm{CH}_{2} \mathrm{Ph}\right), 4.54$ $\left(\mathrm{d}, 1 \mathrm{H}, J 12.4 \mathrm{~Hz}, \mathrm{CH}_{2} \mathrm{Ph}\right), 4.50\left(\mathrm{~s}, 2 \mathrm{H}, \mathrm{CH}_{2} \mathrm{Ph}\right), 4.24$ (dd, 1H, J $\left.6.0 \mathrm{~Hz}, J 9.6 \mathrm{~Hz}, \mathrm{H}-3 \mathrm{a}^{\prime}\right), 4.19-4.15$ (m, 1H, H-5), 4.08 (dd, 1H, J $\left.9.6 \mathrm{~Hz}, J 8.0 \mathrm{~Hz}, \mathrm{H}-3 \mathrm{~b}^{\prime}\right), 3.87$ (dd, 1H, J $\left.5.2 \mathrm{~Hz}, J 2.8 \mathrm{~Hz}, \mathrm{H}-4\right), 3.85$ (t, 1H, J $6.0 \mathrm{~Hz}, \mathrm{H}-2), 3.80$ (dd, 1H, J 10.0 Hz, J $6.8 \mathrm{~Hz}, \mathrm{H}-6 \mathrm{a}), 3.72$ (dd, 1H, J $10.0 \mathrm{~Hz}, J 5.2 \mathrm{~Hz}, \mathrm{H}-6 \mathrm{~b}), 3.57$ (s, 1H, $\left.\mathrm{OCH}_{3}\right), 2.76-2.70(\mathrm{~m}, 1 \mathrm{H}, \mathrm{H}-3) .{ }^{13} \mathrm{C} \mathrm{NMR}\left(\mathrm{CDCl}_{3}, 100 \mathrm{MHz}\right): 158.8,138.30,138.27,137.9,131.9$ (q, $J$ $32.1 \mathrm{~Hz}), 130.0,128.49,128.46,128.3,128.0,127.9,127.83,127.77,124.1(\mathrm{q}, J 271 \mathrm{~Hz}), 118.0,117.6(\mathrm{q}, J$ $3.8 \mathrm{~Hz}), 111.5(\mathrm{q}, J 3.7 \mathrm{~Hz}), 101.3,74.7,73.6,73.5,73.3,72.8,71.9,69.8,64.6,56.4,39.6 .{ }^{19} \mathrm{~F} \mathrm{NMR}\left(\mathrm{CDCl}_{3}\right.$, $376 \mathrm{MHz})$ : -62.6. HRMS calcd for $\mathrm{C}_{36} \mathrm{H}_{41} \mathrm{~F}_{3} \mathrm{NO}_{6}+\mathrm{NH}_{4}{ }^{+}\left(\mathrm{M}+\mathrm{NH}_{4}\right)^{+}:$640.2886, found: 640.2895. 


\subsection{Methyl 2,4,6-Tri-O-Benzyl-3-Deoxy-3-C-Methoxymethyl- $\beta$-D-Gulopyranoside 16}

Compound 14a ( $57 \mathrm{mg}, 0.12 \mathrm{mmol})$ was stirred in a $5 \mathrm{~mL}$ round-bottom flask in dry THF $(2 \mathrm{~mL})$ for $5 \mathrm{~min}$ at $0{ }^{\circ} \mathrm{C}$. Into the solution, $\mathrm{NaH}(6 \mathrm{mg}, 0.24 \mathrm{mmol})$ was added and the stirring was continued at $0{ }^{\circ} \mathrm{C}$ for $5 \mathrm{~min}$. Then, into the reaction mixture iodomethane dropwise was added and the reaction temperature increased to rt gradually. Stirring continued overnight when the TLC showed almost complete consumption of the starting material (TLC heptane/EtOAc, 3:2, $R_{f} 0.53$ ). Then, NaH was quenched with EtOAc and the volatiles were removed under reduced pressure. The residue was subjected to column chromatography (heptane/EtOAc, 6:1 to 3:1) to provide the purified product 16 (46 mg, $0.09 \mathrm{mmol}, 78 \%)$. $[\alpha]_{\mathrm{D}}^{25}-62.5$ (c 1.2, $\left.\mathrm{CHCl}_{3}\right) .{ }^{1} \mathrm{H}$ NMR $\left(\mathrm{CDCl}_{3}, 400 \mathrm{MHz}\right): 7.35-7.20(\mathrm{~m}, 15 \mathrm{H}$, $\mathrm{ArH}), 4.76\left(\mathrm{~d}, 1 \mathrm{H}, J 12.0 \mathrm{~Hz}, \mathrm{CH}_{2} \mathrm{Ph}\right), 4.58\left(\mathrm{~d}, 1 \mathrm{H}, J 12.0 \mathrm{~Hz}, \mathrm{CH}_{2} \mathrm{Ph}\right), 4.57\left(\mathrm{~d}, 1 \mathrm{H}, J 11.6 \mathrm{~Hz}, \mathrm{CH}_{2} \mathrm{Ph}\right)$, $4.53\left(\mathrm{~d}, 1 \mathrm{H}, J_{1,2} 6.4 \mathrm{~Hz}, \mathrm{H}-1\right), 4.48$ (d, 2H, J $\left.12.4 \mathrm{~Hz}, \mathrm{CH}_{2} \mathrm{Ph}\right), 4.37$ (d, $\left.1 \mathrm{H}, J 11.6 \mathrm{~Hz}, \mathrm{CH}_{2} \mathrm{Ph}\right), 4.11-4.07$ (m, 1H, H-5), 3.75-3.71 (m, 3H, H-2, H-4, H-6a), 3.67-3.61 (m, 2H, H-6b, $\left.\mathrm{CH}_{2} \mathrm{OCH}_{3}\right), 3.56-3.50$ (m, 4H,

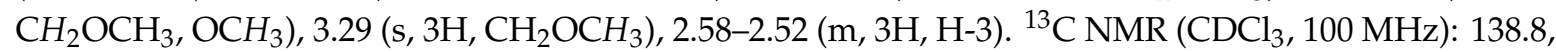
138.43, 138.39, 128.5, 128.43, 128.36, 128.1, 127.94, 128.90, 127.8, 127.74, 127.69, 127.66, 101.8, 75.1, 74.7, 73.7, 73.3, 73.2, 71.8, 70.2, 69.2, 59.0, 56.4, 40.2. HRMS calcd for $\mathrm{C}_{17} \mathrm{H}_{21} \mathrm{NO}_{6}+\mathrm{H}^{+}(\mathrm{M}+\mathrm{H})^{+}: 335.1369$, found: 335.1369 .

\subsection{Methyl 2,4,6-Tri-O-Benzyl-3-Deoxy-3-C-Azidomethyl- $\beta$-D-Gulopyranoside $\mathbf{1 7}$}

Into a stirred solution of $14 \mathrm{a}(1.6 \mathrm{~g}, 3.35 \mathrm{mmol})$ in $\mathrm{DCM}(25 \mathrm{~mL})$ containing $\mathrm{Et}_{3} \mathrm{~N}(890 \mu \mathrm{L}, 6.69 \mathrm{mmol})$ at $0{ }^{\circ} \mathrm{C} \mathrm{MsCl}(390 \mu \mathrm{L}, 5.02 \mathrm{mmol})$ was added dropwise over $5 \mathrm{~min}$, and the solution was stirred for $4 \mathrm{~h}$ at $\mathrm{rt}$ (TLC heptane/EtOAc, 1:1, $\left.\mathrm{R}_{\mathrm{f}} 0.31\right)$. The solution was extracted with $1 \mathrm{~N} \mathrm{HCl}(2 \times 50 \mathrm{~mL})$ followed by sat'd $\mathrm{NaHCO}_{3}(2 \times 50 \mathrm{~mL})$, and the organic layer was dried $\left(\mathrm{Na}_{2} \mathrm{SO}_{4}\right)$. The solvent was removed by rotary evaporation to give a yellow liquid that was dissolved in dry DMF $(10 \mathrm{~mL})$. Sodium azide $(1.3 \mathrm{~g}$, $20.08 \mathrm{mmol}$ ) was added and the solution was heated at $80^{\circ} \mathrm{C}$ for $6 \mathrm{~h}$ to give a yellowish-brown mixture. The mixture was cooled at $\mathrm{rt}$, water $(50 \mathrm{~mL})$ was added, and the mixture was extracted with EtOAc (2 $\times 40 \mathrm{~mL})$. The organic layer was washed with brine $(50 \mathrm{~mL})$ and dried $\left(\mathrm{Na}_{2} \mathrm{SO}_{4}\right)$. The solvent was removed by rotary evaporation to give a yellow liquid that was then purified by flash chromatography (Heptane/EtOAc 8:1 to 3:1) to give compound 17 (1.4 g, $2.78 \mathrm{mmol}, 83 \%$ from 14a) as a colorless liquid. $[\alpha]_{\mathrm{D}}^{25}-5.2\left(\mathrm{c} 0.8, \mathrm{CHCl}_{3}\right) .{ }^{1} \mathrm{H}$ NMR $\left(\mathrm{CDCl}_{3}, 400 \mathrm{MHz}\right): 7.38-7.20(\mathrm{~m}, 15 \mathrm{H}, \mathrm{ArH}), 4.76(\mathrm{~d}, 1 \mathrm{H}, J 12.0 \mathrm{~Hz}$, $\left.\mathrm{CH}_{2} \mathrm{Ph}\right), 4.56\left(\mathrm{~d}, 1 \mathrm{H}, J 12.0 \mathrm{~Hz}, \mathrm{CH}_{2} \mathrm{Ph}\right), 4.55\left(\mathrm{~d}, 1 \mathrm{H}, J 11.6 \mathrm{~Hz}, \mathrm{CH}_{2} \mathrm{Ph}\right), 4.51$ (d, $\left.1 \mathrm{H}, J_{1,2} 6.4 \mathrm{~Hz}, \mathrm{H}-1\right)$, $4.48\left(\mathrm{~d}, 1 \mathrm{H}, J 12.4 \mathrm{~Hz}, \mathrm{CH}_{2} \mathrm{Ph}\right), 4.44\left(\mathrm{~d}, 1 \mathrm{H}, J 12.0 \mathrm{~Hz}, \mathrm{CH}_{2} \mathrm{Ph}\right), 4.41\left(\mathrm{~d}, 1 \mathrm{H}, J 12.0 \mathrm{~Hz}, \mathrm{CH}_{2} \mathrm{Ph}\right), 4.09-4.05$ (m, 1H, H-5), 3.77-3.64 (m, 5H, H-2, H-4, H-6a, H-6b, $\left.\mathrm{CH}_{2} \mathrm{~N}_{3}\right), 3.50$ (s, 3H, OCH $\left.\mathrm{H}_{3}\right), 3.39$ (dd, 1H, J $\left.12.4 \mathrm{~Hz}, J 8.4 \mathrm{~Hz}, \mathrm{CH}_{2} \mathrm{~N}_{3}\right), 2.42-2.36$ (m, $\left.1 \mathrm{H}, \mathrm{H}-3\right) .{ }^{13} \mathrm{C} \mathrm{NMR}\left(\mathrm{CDCl}_{3}, 100 \mathrm{MHz}\right): 138.4,138.3,137.9$, $128.53,128.52,128.50,128.2,128.02,127.95,127.9,127.8,100.8,75.0,73.7,73.6,73.4,72.5,72.0,69.6,56.4$, 48.6, 39.7. HRMS calcd for $\mathrm{C}_{29} \mathrm{H}_{33} \mathrm{~N}_{3} \mathrm{O}_{5}+\mathrm{NH}_{4}{ }^{+}\left(\mathrm{M}+\mathrm{NH}_{4}\right)^{+}$: 521.2764, found: 521.2775.

\subsection{Methyl 2,4,6-Tri-O-Benzyl-3-Deoxy-3-C-[4-(3-Fluorophenyl)-1H-1,2,3-Triazol-1-Yl-Methyl]-} $\beta$-D-Gulopyranoside 18

A solution of azide $17(53 \mathrm{mg}, 0.10 \mathrm{mmol})$ in dichloromethane $(2 \mathrm{~mL})$, 1-Ethynyl-3-fluorobenzene $(18.1 \mu \mathrm{L}, 0.16 \mathrm{mmol}), \mathrm{CuI}(10 \mathrm{~mol} \%, 2 \mathrm{mg})$ and DIPEA $(28 \mu \mathrm{L}, 0.16 \mathrm{mmol})$ were added and the mixture was stirred at room temperature for $48 \mathrm{~h}$ (TLC heptane/EtOAc, 2:1, $\mathrm{R}_{\mathrm{f}} 0.58$ ). The solvent was removed under reduced pressure, and the residue was dissolved in EtOAc $(10 \mathrm{~mL})$ and the solution was washed with sat. $\mathrm{NH}_{4} \mathrm{Cl}(10 \mathrm{~mL})$, brine $(10 \mathrm{~mL})$, dried over $\mathrm{Na}_{2} \mathrm{SO}_{4}$ and concentrated in vacuo. The product was purified by flash column chromatography (heptane/EtOAc, 6:1 to 1:1) to give the corresponding triazole, 18 as white amorphous solid $(56.4 \mathrm{mg}, 0.09 \mathrm{mmol}, 86 \%)$. $[\alpha]_{\mathrm{D}}^{25}-63$ (c $\left.0.6, \mathrm{CHCl}_{3}\right) .{ }^{1} \mathrm{H} \mathrm{NMR}$ $\left(\mathrm{CDCl}_{3}, 400 \mathrm{MHz}\right): 7.52-7.04(\mathrm{~m}, 20 \mathrm{H}, \mathrm{ArH}), 4.80\left(\mathrm{~d}, 1 \mathrm{H}, J 11.6 \mathrm{~Hz}, \mathrm{CH}_{2} \mathrm{Ph}\right), 4.63(\mathrm{dd}, 1 \mathrm{H}, J 6.8 \mathrm{~Hz}$, J 14.0 Hz, H-3'), 4.60-4.44 (m, 7H, H-1, H-3', $\left.\mathrm{CH}_{2} \mathrm{Ph}\right), 4.35$ (d, $\left.1 \mathrm{H}, J 11.6 \mathrm{~Hz}, \mathrm{CH}_{2} \mathrm{Ph}\right), 4.26-4.22$ (m, 1H, H-5), 3.79 (dd, 1H, J 10.0 Hz, J 7.2 Hz, H-6a), 3.74 (dd, 1H, J 6.4 Hz, J 3.2 Hz, H-4), 3.71 (dd, 1H, J $10.0 \mathrm{~Hz}, J 5.2 \mathrm{~Hz}, \mathrm{H}-6 \mathrm{~b}), 3.79$ (t, 1H, J 4.8 Hz, H-2), 3.51 (s, 1H, OCH 3 ), 2.68-2.61 (m, 1H, H-3). ${ }^{13} \mathrm{C}$ NMR $\left(\mathrm{CDCl}_{3}, 100 \mathrm{MHz}\right): 163.3$ (d, J $\left.244 \mathrm{~Hz}\right), 146.8,138.19,138.16,137.4,132.8$ (d, J 8.3 Hz), 130.5 (d, J 8.4 Hz), 
128.7, 128.52, 128.51, 128.3, 128.2, 128.0, 127.9, 127.8, 121.3 (d, J 2.7 Hz), 120.6, 115.0 (d, J $22 \mathrm{~Hz}), 112.7$ (d, J $23 \mathrm{~Hz}), 100.1,75.2,73.52,73.47,73.1,72.5,72.2,69.4,56.4,47.4,41.1 .{ }^{19} \mathrm{~F} \mathrm{NMR}\left(\mathrm{CDCl}_{3}, 376 \mathrm{MHz}\right)$ : -112.7. HRMS calcd for $\mathrm{C}_{37} \mathrm{H}_{38} \mathrm{FN}_{3} \mathrm{O}_{5}+\mathrm{H}^{+}(\mathrm{M}+\mathrm{H})^{+}$: 624.2874, found: 624.2884 .

\subsection{Methyl 2,4,6-Tri-O-Benzyl-3-Deoxy-3-C-(Aminomethyl)- $\beta$-D-Gulopyranoside $\mathbf{1 9}$}

Into a stirred solution of $\mathbf{1 7}(1.31 \mathrm{~g}, 2.60 \mathrm{mmol})$ in dry THF $(20 \mathrm{~mL})$ at $0{ }^{\circ} \mathrm{C}, \mathrm{LiAlH}_{4}(148 \mathrm{mg}$, $3.9 \mathrm{mmol}$ ) was added in portions over $5 \mathrm{~min}$ under nitrogen atmosphere, and the solution was stirred for $1 \mathrm{~h}$ at $\mathrm{rt}$ (TLC DCM/MeOH, 15:1, $\mathrm{R}_{\mathrm{f}}$ 0.44). After $30 \mathrm{~min}$, TLC was checked which shows complete conversion of the azide into amine. Then, the reaction was quenched EtOAc and the reaction mixture was filtered through a pad of Celite ${ }^{\circledR}$ (St. Louis, MO, USA). Then, the filtrate was concentrated in vacuo and the crude was purified by column chromatography (DCM:MeOH 25:1) to give compound 19 (969 mg, $2.03 \mathrm{mmol}$, yield $78 \%$ ) as a colorless oil. $[\alpha]_{\mathrm{D}}^{25}-36.2$ (c 1.1, $\left.\mathrm{CHCl}_{3}\right) .{ }^{1} \mathrm{H} \mathrm{NMR}\left(\mathrm{CDCl}_{3}\right.$, $400 \mathrm{MHz}): 7.35-7.22(\mathrm{~m}, 15 \mathrm{H}, \mathrm{ArH}), 4.80\left(\mathrm{~d}, 1 \mathrm{H}, \mathrm{J} 12.0 \mathrm{~Hz}, \mathrm{CH}_{2} \mathrm{Ph}\right), 4.57-4.54\left(\mathrm{~m}, 3 \mathrm{H}, \mathrm{H}-1, \mathrm{CH}_{2} \mathrm{Ph}\right), 4.51$ $\left(\mathrm{d}, 1 \mathrm{H}, J 12.0 \mathrm{~Hz}, \mathrm{CH}_{2} \mathrm{Ph}\right), 4.47\left(\mathrm{~d}, 1 \mathrm{H}, J 12.0 \mathrm{~Hz}, \mathrm{CH}_{2} \mathrm{Ph}\right), 4.42\left(\mathrm{~d}, 1 \mathrm{H}, J 11.6 \mathrm{~Hz}, \mathrm{CH}_{2} \mathrm{Ph}\right), 3.97-3.93(\mathrm{~m}$, 1H, H-5), 3.74-3.65 (m, 4H, H-2, H-4, H-6a, H-6b), 3.52 (s, 3H, OCH $), 3.08$ (dd, 1H, J 6.4 Hz, J $12.8 \mathrm{~Hz}$, $\mathrm{CH}_{2} \mathrm{NH}_{2}$ ), $2.68\left(\mathrm{dd}, 1 \mathrm{H}, \mathrm{J} 12.8 \mathrm{~Hz}, \mathrm{~J} 6.4 \mathrm{~Hz}, \mathrm{CH}_{2} \mathrm{NH}_{2}\right), 2.32-2.27(\mathrm{~m}, 1 \mathrm{H}, \mathrm{H}-3), 1.99$ (bs, $2 \mathrm{H}, \mathrm{CH}_{2} \mathrm{NH}_{2}$ ). ${ }^{13} \mathrm{C} \mathrm{NMR}\left(\mathrm{CDCl}_{3}, 100 \mathrm{MHz}\right): 138.6,138.3,138.1,128.53,128.49,128.4,128.2,128.0,127.9,127.83,127.81$, 127.77, 101.3, 76.2, 75.2, 73.6, 73.4, 72.9, 71.7, 69.7, 56.4, 42.7, 39.7. HRMS calcd for $\mathrm{C}_{29} \mathrm{H}_{35} \mathrm{NO}_{5}+\mathrm{H}^{+}$ $(\mathrm{M}+\mathrm{H})^{+}:$478.2593, found: 478.2603 .

\subsection{Methyl 2,4,6-Tri-O-Benzyl-3-Deoxy-3-C-(3-Fluorophenylureidomethyl)- $\beta$-D-Gulopyranoside 20}

A solution of amine $19(61 \mathrm{mg}, 0.13 \mathrm{mmol})$ in dry dichloromethane $(2 \mathrm{~mL}), \mathrm{Et}_{3} \mathrm{~N}(35.6 \mu \mathrm{L}, 0.26 \mathrm{mmol})$ was added and the mixture was stirred at room temperature for 5 min under $\mathrm{N}_{2}$ atmosphere. Then into the solution phenyl isocyanate $(29.2 \mu \mathrm{L}, 0.26 \mathrm{mmol})$ was added and the solution was stirred at $\mathrm{rt}$ for $12 \mathrm{~h}$ (TLC heptane/EtOAc, 1:1, $\mathrm{R}_{\mathrm{f}}$ 0.32). The solvent was removed under reduced pressure, and the residue was dissolved in EtOAc $(10 \mathrm{~mL})$ and the solution was washed with brine $(10 \mathrm{~mL})$, dried over $\mathrm{Na}_{2} \mathrm{SO}_{4}$ and concentrated in vacuo. The product was purified by flash column chromatography (heptane/EtOAc, 5:1 to 2:1) to give the corresponding semicarbazide 20 as a colorless oil $(53.4 \mathrm{mg}$, $0.09 \mathrm{mmol}$, yield $68 \%)$. $[\alpha]_{\mathrm{D}}^{25}-83.1$ (c $\left.0.8, \mathrm{CHCl}_{3}\right) .{ }^{1} \mathrm{H} \mathrm{NMR}\left(\mathrm{CDCl}_{3}, 400 \mathrm{MHz}\right): 7.39-7.12(\mathrm{~m}, 17 \mathrm{H}$, $\mathrm{ArH}), 6.85(\mathrm{dd}, 1 \mathrm{H}, J 1.2 \mathrm{~Hz}, J 8.0 \mathrm{~Hz}, \mathrm{ArH}), 6.71-6.66(\mathrm{~m}, 1 \mathrm{H}, \mathrm{ArH}), 6.11$ (bs, 1H, NHCONHC$\left.{ }_{6} \mathrm{H}_{4} \mathrm{~F}\right)$, 5.30 (bs, $\left.1 \mathrm{H}, \mathrm{NHCONHC}_{6} \mathrm{H}_{4} \mathrm{~F}\right), 4.79$ (d, $\left.1 \mathrm{H}, J 11.6 \mathrm{~Hz}, \mathrm{CH}_{2} \mathrm{Ph}\right), 4.59$ (d, 1H, J 6.0 Hz, H-1), 4.55 (d, $\left.1 \mathrm{H}, J 12.0 \mathrm{~Hz}, \mathrm{CH}_{2} \mathrm{Ph}\right), 4.49$ (d, $\left.1 \mathrm{H}, J 12.4 \mathrm{~Hz}, \mathrm{CH}_{2} \mathrm{Ph}\right), 4.48-4.42\left(\mathrm{~m}, 3 \mathrm{H}, \mathrm{CH}_{2} \mathrm{Ph}\right), 4.03-3.99(\mathrm{~m}, 1 \mathrm{H}$, H-5), 3.74-3.65 (m, 4H, H-2, H-4, H-6a, H-6b), 3.51 (s, 1H, OCH $)_{3}, 3.42$ (dd, 1H, J 14.0 Hz, J $5.6 \mathrm{~Hz}$, $\left.\mathrm{CH}_{2} \mathrm{NHCONHC}_{6} \mathrm{H}_{4} \mathrm{~F}\right), 3.34\left(\mathrm{dd}, 1 \mathrm{H}, J 14.0 \mathrm{~Hz}, J 7.6 \mathrm{~Hz}, \mathrm{CH}_{2} \mathrm{NHCONHC}_{6} \mathrm{H}_{4} \mathrm{~F}\right), 2.42-2.36(\mathrm{~m}, 1 \mathrm{H}, \mathrm{H}-3)$. ${ }^{13} \mathrm{C}$ NMR (CDCl $\left.3,100 \mathrm{MHz}\right): 163.3(\mathrm{~d}, J 243 \mathrm{~Hz}), 154.9,140.6$ (d, J $\left.11 \mathrm{~Hz}\right), 138.4,138.2,137.9,130.2$ (d, J $9.5 \mathrm{~Hz}), 128.8,128.5,128.3,128.2,128.0,127.9,127.8,114.8$ (d, J $2.7 \mathrm{~Hz}), 109.7$ (d, J $21.2 \mathrm{~Hz}), 106.9$ (d, J $26 \mathrm{~Hz}), 100.7,75.3,73.54,73.49,73.0,72.1,69.4,56.5,39.8,39.1 .{ }^{19} \mathrm{~F} \mathrm{NMR}\left(\mathrm{CDCl}_{3}, 376 \mathrm{MHz}\right):-111.6$. HRMS calcd for $\mathrm{C}_{36} \mathrm{H}_{40} \mathrm{FN}_{2} \mathrm{O}_{6}+\mathrm{H}^{+}(\mathrm{M}+\mathrm{H})^{+}: 615.2886$, found: 615.2870 .

\subsection{General Procedure for the Synthesis of Amides 21, 22a-221, and $\mathbf{2 3}$}

To a solution of the amine (1 eq) in dry DCM ( $2 \mathrm{~mL}$ per $0.1 \mathrm{mmol}) \mathrm{Et}_{3} \mathrm{~N}$ (2 eq) was added. Into the solution, acid chloride or anhydride (1.5 eq) was added and the solution was stirred at $\mathrm{rt}$ for $8 \mathrm{~h}$. After that, $1(\mathrm{~N}) \mathrm{HCl}$ solution was added to the reaction mixture and extracted with DCM and washed successively with saturated $\mathrm{NaHCO}_{3}$. After evaporating the solvents in vacuo, the crude material thus obtained was purified by flash chromatography using heptane-EtOAc (5:1 to 1:1) to give pure amides as colorless oils.

\subsubsection{Methyl 2,4,6-Tri-O-Benzyl-3-Deoxy-3-C-Phenylsulfonamidomethyl- $\beta$-D-Gulopyranoside 21}

Compound 21 (TLC heptane/EtOAc, 2:1, $\mathrm{R}_{\mathrm{f}} 0.21$ ) was prepared according to the general procedure 3.11 from the amine 19 ( $55 \mathrm{mg}, 0.12 \mathrm{mmol}$ ). Obtained as a colorless oil in $65 \%$ yield ( $46.2 \mathrm{mg}, 0.07 \mathrm{mmol}$ ). 
$[\alpha]_{\mathrm{D}}^{25}-55.7\left(\mathrm{c} 0.7, \mathrm{CHCl}_{3}\right) .{ }^{1} \mathrm{H} \mathrm{NMR}\left(\mathrm{CDCl}_{3}, 400 \mathrm{MHz}\right): 7.73-7.17(\mathrm{~m}, 20 \mathrm{H}, \mathrm{ArH}), 5.23(\mathrm{dd}, 1 \mathrm{H}, J 5.2 \mathrm{~Hz}$, $\left.J 6.8 \mathrm{~Hz}, \mathrm{CH}_{2} \mathrm{NHSO}\right), 4.75\left(\mathrm{~d}, 1 \mathrm{H}, J 11.6 \mathrm{~Hz}, \mathrm{CH}_{2} \mathrm{Ph}\right), 4.53\left(\mathrm{~d}, 1 \mathrm{H}, J 12.0 \mathrm{~Hz}, \mathrm{CH}_{2} \mathrm{Ph}\right), 4.50(\mathrm{~d}, 1 \mathrm{H}, J$ $\left.12.0 \mathrm{~Hz}, \mathrm{CH}_{2} \mathrm{Ph}\right), 4.45$ (d, 1H, J $\left.12.0 \mathrm{~Hz}, \mathrm{CH}_{2} \mathrm{Ph}\right), 4.42$ (d, 1H, J $\left.6.0 \mathrm{~Hz}, \mathrm{H}-1\right), 4.39$ (d, 1H, J $11.2 \mathrm{~Hz}$, $\mathrm{CH}_{2} \mathrm{Ph}$ ), 4.36 (d, 1H, J 11.2 Hz, $\mathrm{CH}_{2} \mathrm{Ph}$ ), 3.90-3.87 (m, 1H, H-5), 3.70-3.60 (m, 4H, H-2, H-4, H-6a, H-6b), 3.47 (s, 3H, $\left.\mathrm{OCH}_{3}\right), 3.17-3.10\left(\mathrm{~m}, 1 \mathrm{H}, \mathrm{CH}_{2} \mathrm{NHSO}\right), 3.00-2.93\left(\mathrm{~m}, 1 \mathrm{H}, \mathrm{CH}_{2} \mathrm{NHSO}\right), 2.41-2.35(\mathrm{~m}, 1 \mathrm{H}$, H-3). ${ }^{13} \mathrm{C}$ NMR $\left(\mathrm{CDCl}_{3}, 100 \mathrm{MHz}\right): 139.7,138.1,137.9,137.6,132.6,129.1,128.7,128.5,128.2,128.1$, 127.94, 127.91, 127.8, 127.1, 100.5, 76.3, 74.8, 73.54, 73.50, 72.8, 71.8, 69.3, 56.3, 42.2, 39.1. HRMS calcd for $\mathrm{C}_{35} \mathrm{H}_{39} \mathrm{NO}_{7} \mathrm{~S}+\mathrm{NH}_{4}{ }^{+}\left(\mathrm{M}+\mathrm{NH}_{4}\right)^{+}: 635.2788$, found: 635.2791 .

\subsubsection{Methyl 2,4,6-Tri-O-Benzyl-3-Deoxy-3-C-(Benzamidomethyl)- $\beta$-D-Gulopyranoside 22a}

Compound 22a (TLC heptane/EtOAc, 2:1, $\mathrm{R}_{\mathrm{f}} 0.27$ ) was prepared according to the general procedure 3.11 from the amine 19 ( $43 \mathrm{mg}, 0.09 \mathrm{mmol})$. Obtained as a colorless oil in $70 \%$ yield $(37 \mathrm{mg}, 0.06 \mathrm{mmol})$. $[\alpha]_{\mathrm{D}}^{25}-42.4\left(\mathrm{c} 0.8, \mathrm{CHCl}_{3}\right) .{ }^{1} \mathrm{H}$ NMR $\left(\mathrm{CDCl}_{3}, 400 \mathrm{MHz}\right): 7.43-7.22(\mathrm{~m}, 20 \mathrm{H}, \mathrm{ArH}), 7.03(\mathrm{t}, 1 \mathrm{H}, J 5.6 \mathrm{~Hz}$, $\left.\mathrm{CH}_{2} \mathrm{NHCO}\right), 4.89\left(\mathrm{~d}, 1 \mathrm{H}, J 11.2 \mathrm{~Hz}, \mathrm{CH}_{2} \mathrm{Ph}\right), 4.69\left(\mathrm{~d}, 1 \mathrm{H}, J_{1,2} 6.0 \mathrm{~Hz}, \mathrm{H}-1\right), 4.57\left(\mathrm{~d}, 1 \mathrm{H}, J 12.0 \mathrm{~Hz}, \mathrm{CH}_{2} \mathrm{Ph}\right)$, 4.55-4.46 (m, 4H, CH $\mathrm{CH}_{2} \mathrm{Ph}$ ), 4.07-4.03 (m, 1H, H-5), 3.82 (dd, 1H, J1,2 6.0 Hz, J2,3 4.8 Hz, H-2), 3.79-3.68 (m, 4H, H-4, H-6a, H-6b, $\mathrm{CH}_{2} \mathrm{NHCO}$ ), 3.60-3.53 (m, 4H, OCH $\left.\mathrm{CH}_{2} \mathrm{NHCO}\right), 2.51-2.46$ (m, 1H, H-3). ${ }^{13} \mathrm{C} \mathrm{NMR}\left(\mathrm{CDCl}_{3}, 100 \mathrm{MHz}\right): 166.8,138.3,138.2,137.8,134.2,131.2,128.7,128.53,128.51,128.47,128.3$, 128.2, 128.0, 127.8, 126.9, 100.9, 77.9, 75.9, 74.3, 73.5, 73.1, 72.2, 69.4, 56.5, 39.8, 39.3. HRMS calcd for $\mathrm{C}_{36} \mathrm{H}_{39} \mathrm{NO}_{6}+\mathrm{H}^{+}(\mathrm{M}+\mathrm{H})^{+}$: 582.2856, found: 582.2851.

\subsubsection{Methyl 2,4,6-Tri-O-Benzyl-3-Deoxy-3-C-(Acetamidomethyl)- $\beta$-D-Gulopyranoside 22b}

Compound 22b (TLC heptane/EtOAc, 1:1, $\mathrm{R}_{\mathrm{f}} 0.4$ ) was prepared according to the general procedure 3.11 from the amine $19(49 \mathrm{mg}, 0.10 \mathrm{mmol})$. Obtained as a colorless oil in $62 \%$ yield $(33 \mathrm{mg}, 0.06 \mathrm{mmol})$. $[\alpha]_{\mathrm{D}}^{25}-31.6\left(\mathrm{c} 0.8, \mathrm{CHCl}_{3}\right) .{ }^{1} \mathrm{H} \mathrm{NMR}\left(\mathrm{CDCl}_{3}, 400 \mathrm{MHz}\right): 7.39-7.21(\mathrm{~m}, 15 \mathrm{H}, \mathrm{ArH}), 6.05$ (bs, $1 \mathrm{H}$, $\left.\mathrm{NHCOCH}_{3}\right), 4.83\left(\mathrm{~d}, 1 \mathrm{H}, J 11.6 \mathrm{~Hz}, \mathrm{CH}_{2} \mathrm{Ph}\right), 4.59\left(\mathrm{~d}, 1 \mathrm{H}, J_{1,2} 6.4 \mathrm{~Hz}, \mathrm{H}-1\right), 4.55\left(\mathrm{~d}, 1 \mathrm{H}, J 12.0 \mathrm{~Hz}, \mathrm{CH}_{2} \mathrm{Ph}\right)$, 4.52-4.42 (m, 4H, CH $\left.\mathrm{CH}_{2} \mathrm{Ph}\right), 3.98$ (td, 1H, J $\left.6.0 \mathrm{~Hz}, J 2.8 \mathrm{~Hz}, \mathrm{H}-5\right), 3.74-3.64$ (m, 4H, H-2, H-4, H-6a, H-6b), $3.53\left(\mathrm{~s}, 3 \mathrm{H}, \mathrm{OCH}_{3}\right), 3.51-3.45\left(\mathrm{~m}, 1 \mathrm{H}, \mathrm{CH}_{2} \mathrm{NHCO}\right), 3.32-3.26\left(\mathrm{~s}, 1 \mathrm{H}, \mathrm{CH}_{2} \mathrm{NHCO}\right), 2.36-2.30(\mathrm{~m}, 1 \mathrm{H}$, $\mathrm{H}-3), 1.74$ (s, 3H, $\left.\mathrm{NHCOCH}_{3}\right) .{ }^{13} \mathrm{C} \mathrm{NMR}\left(\mathrm{CDCl}_{3}, 100 \mathrm{MHz}\right): 169.9,138.4,138.3,137.9,128.7,128.5$, 128.2, 128.12, 128.09, 127.94, 127.86, 127.7, 100.8, 77.1, 75.4, 73.8, 73.5, 73.0, 72.0, 69.4, 56.5, 39.7, 38.4, 23.2. HRMS calcd for $\mathrm{C}_{31} \mathrm{H}_{37} \mathrm{NO}_{6}+\mathrm{H}^{+}(\mathrm{M}+\mathrm{H})^{+}$: 520.2699 , found: 520.2704 .

3.11.4. Methyl 2,4,6-Tri-O-Benzyl-3-Deoxy-3-C-(2-Fluorobenzamidomethyl)- $\beta$-D-Gulopyranoside 22c

Compound 22c (TLC heptane/EtOAc, 2:1, $\mathrm{R}_{\mathrm{f}} 0.19$ ) was prepared according to the general procedure 3.11 from the amine 19 ( $49 \mathrm{mg}, 0.10 \mathrm{mmol})$. Obtained as a colorless oil in $59 \%$ yield ( $31.5 \mathrm{mg}, 0.06 \mathrm{mmol})$. $[\alpha]_{\mathrm{D}}^{25}-41.7\left(\mathrm{c} 0.7, \mathrm{CHCl}_{3}\right) .{ }^{1} \mathrm{H}$ NMR $\left(\mathrm{CDCl}_{3}, 400 \mathrm{MHz}\right): 8.05-8.01(\mathrm{td}, 1 \mathrm{H}, J 8.0 \mathrm{~Hz}, J 1.6 \mathrm{~Hz}, \mathrm{ArH})$, 7.48-7.43 (m, 1H, ArH), 7.36-7.16 (m, 17H, ArH), 7.07-7.02 (m, 1H, ArH), $4.84\left(\mathrm{~d}, 1 \mathrm{H}, J 11.6 \mathrm{~Hz}, \mathrm{CH}_{2} \mathrm{Ph}\right)$, $4.65\left(\mathrm{~d}, 1 \mathrm{H}, J_{1,2} 6.8 \mathrm{~Hz}, \mathrm{H}-1\right), 4.62\left(\mathrm{~d}, 1 \mathrm{H}, J 12.0 \mathrm{~Hz}, \mathrm{CH}_{2} \mathrm{Ph}\right), 4.57\left(\mathrm{~d}, 1 \mathrm{H}, J 12.0 \mathrm{~Hz}, \mathrm{CH}_{2} \mathrm{Ph}\right), 4.48(\mathrm{~d}, 1 \mathrm{H}$, $\left.J 12.0 \mathrm{~Hz}, \mathrm{CH}_{2} \mathrm{Ph}\right), 4.46\left(\mathrm{~d}, 1 \mathrm{H}, J 11.6 \mathrm{~Hz}, \mathrm{CH}_{2} \mathrm{Ph}\right), 4.40\left(\mathrm{~d}, 1 \mathrm{H}, J 11.6 \mathrm{~Hz}, \mathrm{CH}_{2} \mathrm{Ph}\right), 4.07(\mathrm{td}, 1 \mathrm{H}, J 6.0 \mathrm{~Hz}$, J $2.8 \mathrm{~Hz}, \mathrm{H}-5), 3.79-3.58$ (m, 6H, H-2, H-4, H-6a, H-6b, $\mathrm{CH}_{2} \mathrm{NHCO}$ ), 3.54 (s, 3H, OCH $), 2.49-2.43$ (m, 1H, H-3). $\left.{ }^{13} \mathrm{C} \mathrm{NMR} \mathrm{(CDCl} 3,100 \mathrm{MHz}\right): 163.2$ (d, J $\left.3.0 \mathrm{~Hz}\right), 160.6$ (d, J $\left.247 \mathrm{~Hz}\right), 138.3,138.2,137.8$, 133.1 (d, J $9.0 \mathrm{~Hz}), 132.0$ (d, J 2.0 Hz), 128.46, 128.45, 128.4, 128.3, 128.2, 127.9, 127.8, 127.7, 124.7 (d, J 3.1 Hz), 121.4 (d, J $12 \mathrm{~Hz}), 116.1$ (d, J $24 \mathrm{~Hz}), 101.0,76.3,75.1,73.6,73.5,72.9,72.0$, 69.5, 56.5, 40.0, 38.5. ${ }^{19} \mathrm{~F} \mathrm{NMR}\left(\mathrm{CDCl}_{3}, 376 \mathrm{MHz}\right)$ : -113.4. HRMS calcd for $\mathrm{C}_{36} \mathrm{H}_{38} \mathrm{FNO}_{6}+\mathrm{NH}_{4}{ }^{+}\left(\mathrm{M}+\mathrm{NH}_{4}\right)^{+}$: 617.3027, found: 617.3025 .

3.11.5. Methyl 2,4,6-Tri-O-Benzyl-3-Deoxy-3-C-(3-Fluorobenzamidomethyl)- $\beta$-D-Gulopyranoside 22d

Compound 22d (TLC heptane/EtOAc, 2:1, $\mathrm{R}_{\mathrm{f}} 0.24$ ) was prepared according to the general procedure 3.11 from the amine $19(46 \mathrm{mg}, 0.10 \mathrm{mmol})$. Obtained as a colorless oil in $67 \%$ yield $(48 \mathrm{mg}, 0.06 \mathrm{mmol})$. $[\alpha]_{\mathrm{D}}^{25}-61.8\left(\mathrm{c} 0.7, \mathrm{CHCl}_{3}\right) .{ }^{1} \mathrm{H}$ NMR $\left(\mathrm{CDCl}_{3}, 400 \mathrm{MHz}\right): 7.36-6.99(\mathrm{~m}, 20 \mathrm{H}, \mathrm{NHCO}, \mathrm{ArH}), 4.89(\mathrm{~d}, 1 \mathrm{H}, J$ $\left.11.2 \mathrm{~Hz}, \mathrm{CH}_{2} \mathrm{Ph}\right), 4.69$ (d, $\left.1 \mathrm{H}, J_{1,2} 6.0 \mathrm{~Hz}, \mathrm{H}-1\right), 4.58\left(\mathrm{~d}, 1 \mathrm{H}, \mathrm{J} 12.0 \mathrm{~Hz}, \mathrm{CH}_{2} \mathrm{Ph}\right), 4.54-4.47\left(\mathrm{~m}, 4 \mathrm{H}, \mathrm{CH}_{2} \mathrm{Ph}\right)$, 
4.07 (td, 1H, J $6.4 \mathrm{~Hz}, J 2.8 \mathrm{~Hz}, \mathrm{H}-5), 3.82\left(\mathrm{dd}, 1 \mathrm{H}, J_{1,2} 6.0 \mathrm{~Hz}, J_{2,3} 4.8 \mathrm{~Hz}, \mathrm{H}-2\right), 3.81-3.66(\mathrm{~m}, 4 \mathrm{H}, \mathrm{H}-4$, $\left.\mathrm{H}-6 \mathrm{a}, \mathrm{H}-6 \mathrm{~b}, \mathrm{CH}_{2} \mathrm{NHCO}\right), 3.60-3.54\left(\mathrm{~m}, 4 \mathrm{H}, \mathrm{CH}_{2} \mathrm{NHCO}, \mathrm{OCH}_{3}\right), 2.50-2.44(\mathrm{~m}, 1 \mathrm{H}, \mathrm{H}-3) .{ }^{13} \mathrm{C}$ NMR $\left(\mathrm{CDCl}_{3}, 100 \mathrm{MHz}\right): 165.5(\mathrm{~d}, J 2.2 \mathrm{~Hz}), 162.7(\mathrm{~d}, J 246 \mathrm{~Hz}), 138.2,138.0,137.7,136.6(\mathrm{~d}, J 6.8 \mathrm{~Hz}), 130.0(\mathrm{~d}$, J 7.8 Hz), 128.7, 128.53, 128.50, 128.4, 128.29, 128.25, 128.0, 127.9, 127.8, 122.1 (d, J 3.0 Hz), 118.2 (d, J $22 \mathrm{~Hz}), 114.4(\mathrm{~d}, J 23 \mathrm{~Hz}), 100.8,78.8,75.8,74.3,73.5,73.0,72.2,69.3,56.5,39.6,39.5 .{ }^{19} \mathrm{~F} \mathrm{NMR}\left(\mathrm{CDCl}_{3}\right.$, $376 \mathrm{MHz})$ : -111.9. HRMS calcd for $\mathrm{C}_{36} \mathrm{H}_{38} \mathrm{FNO}_{6}+\mathrm{H}^{+}(\mathrm{M}+\mathrm{H})^{+}: 600.2761$, found: 600.2772 .

3.11.6. Methyl 2,4,6-Tri-O-Benzyl-3-Deoxy-3-C-(4-Fluorobenzamidomethyl)- $\beta$-D-Gulopyranoside 22e

Compound 22e (TLC heptane/EtOAc, 2:1, $\mathrm{R}_{\mathrm{f}} 0.2$ ) was prepared according to the general procedure 3.11 from the amine 19 (51 mg, $0.11 \mathrm{mmol})$. Obtained as a colorless oil in $71 \%$ yield $(45.4 \mathrm{mg}, 0.08 \mathrm{mmol}$ ). $[\alpha]_{\mathrm{D}}^{25}+51.9\left(\mathrm{c} 0.6, \mathrm{CHCl}_{3}\right) .{ }^{1} \mathrm{H}$ NMR $\left(\mathrm{CDCl}_{3}, 400 \mathrm{MHz}\right): 7.36-7.23(\mathrm{~m}, 17 \mathrm{H}, \mathrm{ArH}), 7.05(\mathrm{t}, 1 \mathrm{H}, J 5.6 \mathrm{~Hz}$, NHCO), 6.89-6.84 (m, 2H, ArH), 4.90 (d, 1H, J 11.2 Hz, CH $\mathrm{CH}_{2} \mathrm{Ph}, 4.70\left(\mathrm{~d}, 1 \mathrm{H}, J_{1,2} 6.0 \mathrm{~Hz}, \mathrm{H}-1\right), 4.58$ (d, $\left.1 \mathrm{H}, J 12.0 \mathrm{~Hz}, \mathrm{CH}_{2} \mathrm{Ph}\right), 4.54-4.48\left(\mathrm{~m}, 4 \mathrm{H}, \mathrm{CH}_{2} \mathrm{Ph}\right), 4.05$ (td, $\left.1 \mathrm{H}, J 6.0 \mathrm{~Hz}, J 2.8 \mathrm{~Hz}, \mathrm{H}-5\right), 3.83\left(\mathrm{dd}, 1 \mathrm{H}, J_{1,2}\right.$ $\left.6.0 \mathrm{~Hz}, J_{2,3} 4.8 \mathrm{~Hz}, \mathrm{H}-2\right), 3.80-3.67$ (m, 4H, H-4, H-6a, H-6b, $\left.\mathrm{CH}_{2} \mathrm{NHCO}\right), 3.59-3.52$ (m, 4H, CH $\mathrm{CH}_{2} \mathrm{NHC}$,

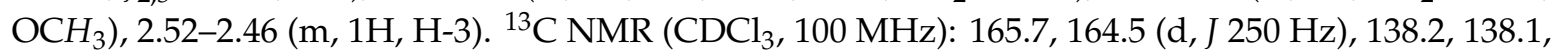
$130.3(\mathrm{~d}, J 3.0 \mathrm{~Hz}), 129.1$ (d, J 8.9 Hz), 128.8, 128.6, 128.53, 128.52, 128.33, 128.28, 128.0, 127.9, 127.8, 115.4 (d, J $22 \mathrm{~Hz}), 100.8,78.1,76.0,74.4,73.5,73.1,72.2,69.3,56.5,39.61,39.58 .{ }^{19} \mathrm{~F} \mathrm{NMR}\left(\mathrm{CDCl}_{3}, 376 \mathrm{MHz}\right)$ : -108.8. HRMS calcd for $\mathrm{C}_{36} \mathrm{H}_{38} \mathrm{FNO}_{6}+\mathrm{NH}_{4}{ }^{+}\left(\mathrm{M}+\mathrm{NH}_{4}\right)^{+}$: 617.3027, found: 617.3038.

3.11.7. Methyl2,4,6-Tri-O-Benzyl-3-Deoxy-3-C-(3,4,5-Trifluorobenzamidomethyl)$\beta$-D-Gulopyranoside 22f

Compound 22f (TLC heptane/EtOAc, 2:1, $\mathrm{R}_{\mathrm{f}} 0.18$ ) was prepared according to the general procedure 3.11 from the amine $19(49 \mathrm{mg}, 0.10 \mathrm{mmol})$. Obtained as a colorless oil in $53 \%$ yield $(34.6 \mathrm{mg}, 0.06 \mathrm{mmol})$. $[\alpha]_{\mathrm{D}}^{25}-73.6\left(\mathrm{c} 0.8, \mathrm{CHCl}_{3}\right) .{ }^{1} \mathrm{H}$ NMR $\left(\mathrm{CDCl}_{3}, 400 \mathrm{MHz}\right): 7.36-6.93(\mathrm{~m}, 18 \mathrm{H}, \mathrm{ArH}), 4.87(\mathrm{~d}, 1 \mathrm{H}, J 11.2 \mathrm{~Hz}$, $\left.\mathrm{CH}_{2} \mathrm{Ph}\right), 4.68\left(\mathrm{~d}, 1 \mathrm{H}, J_{1,2} 5.6 \mathrm{~Hz}, \mathrm{H}-1\right), 4.58\left(\mathrm{~d}, 1 \mathrm{H}, \mathrm{J} 11.6 \mathrm{~Hz}, \mathrm{CH}_{2} \mathrm{Ph}\right), 4.51-4.48\left(\mathrm{~m}, 4 \mathrm{H}, \mathrm{CH}_{2} \mathrm{Ph}\right), 4.07$ (td, 1H, J 6.4 Hz, J 3.6 Hz, H-5), 3.82-3.53 (m, 9H, H-2, H-4, H-6a, H-6b, OCH, $\mathrm{CH}_{2} \mathrm{NHCO}$ ), 2.46-2.40 (m, 1H, H-3). ${ }^{13} \mathrm{C}$ NMR (CDCl, $\left.100 \mathrm{MHz}\right): 163.7,151.0$ (ddd, J $\left.3.4 \mathrm{~Hz}, J 10.2 \mathrm{~Hz}, J 251 \mathrm{~Hz}\right), 141.9$ (dt, $J$ J $15.2 \mathrm{~Hz}, J 255 \mathrm{~Hz}), 138.2,137.9,137.7,130.4-130.2$ (m), 128.8, 128.6, 128.53, 128.47, 128.29, 128.27, 128.2, 127.90, 127.85, 111.5 (dd, J $6.1 \mathrm{~Hz}, J 16 \mathrm{~Hz}), 100.5,78.1,75.8,74.3,73.6,73.0,72.3,69.3,56.5$, 40.0, 39.3. ${ }^{19} \mathrm{~F} \mathrm{NMR}\left(\mathrm{CDCl}_{3}, 376 \mathrm{MHz}\right):-132.1(\mathrm{~d}, J 20 \mathrm{~Hz}),-155.7(\mathrm{t}, J 20 \mathrm{~Hz})$. HRMS calcd for $\mathrm{C}_{36} \mathrm{H}_{36} \mathrm{~F}_{3} \mathrm{NO}_{6}+\mathrm{NH}_{4}{ }^{+}\left(\mathrm{M}+\mathrm{NH}_{4}\right)^{+}: 653.2838$, found: 653.2845 .

3.11.8. Methyl 2,4,6-Tri-O-Benzyl-3-Deoxy-3-C-(2,3,4,5,6-Pentafluorobenzamidomethyl)$\beta$-D-Gulopyranoside 22g

Compound 22g (TLC heptane/EtOAc, 2:1, $\mathrm{R}_{\mathrm{f}} 0.17$ ) was prepared according to the general procedure 3.11 from the amine 19 ( $45 \mathrm{mg}, 0.09 \mathrm{mmol})$. Obtained as a colorless oil in $49 \%$ yield ( $31 \mathrm{mg}, 0.05 \mathrm{mmol})$. $[\alpha]_{\mathrm{D}}^{25}-75.7\left(\mathrm{c} 0.5, \mathrm{CHCl}_{3}\right) .{ }^{1} \mathrm{H}$ NMR $\left(\mathrm{CDCl}_{3}, 400 \mathrm{MHz}\right): 7.36-7.20(\mathrm{~m}, 15 \mathrm{H}, \mathrm{ArH}), 6.81(\mathrm{t}, 1 \mathrm{H}, J 5.6 \mathrm{~Hz}$, $\left.\mathrm{CH}_{2} \mathrm{NHCO}\right), 4.89\left(\mathrm{~d}, 1 \mathrm{H}, J 11.2 \mathrm{~Hz}, \mathrm{CH}_{2} \mathrm{Ph}\right), 4.65\left(\mathrm{~d}, 1 \mathrm{H}, J_{1,2} 6.0 \mathrm{~Hz}, \mathrm{H}-1\right), 4.57\left(\mathrm{~d}, 1 \mathrm{H}, J 12.0 \mathrm{~Hz}, \mathrm{CH}_{2} \mathrm{Ph}\right.$ ), $4.51\left(\mathrm{~d}, 1 \mathrm{H}, J 11.2 \mathrm{~Hz}, \mathrm{CH}_{2} \mathrm{Ph}\right), 4.48\left(\mathrm{~d}, 1 \mathrm{H}, J 12.0 \mathrm{~Hz}, \mathrm{CH}_{2} \mathrm{Ph}\right), 4.47\left(\mathrm{~d}, 1 \mathrm{H}, J 12.0 \mathrm{~Hz}, \mathrm{CH}_{2} \mathrm{Ph}\right), 4.42$ $\left(\mathrm{d}, 1 \mathrm{H}, J 12.0 \mathrm{~Hz}, \mathrm{CH}_{2} \mathrm{Ph}\right), 4.06(\mathrm{td}, 1 \mathrm{H}, J 6.8 \mathrm{~Hz}, J 3.6 \mathrm{~Hz}, \mathrm{H}-5), 3.81\left(\mathrm{dd}, 1 \mathrm{H}, J_{1,2} 6.0 \mathrm{~Hz}, J_{2,3} 3.6 \mathrm{~Hz}\right.$, H-2), 3.78-3.69 (m, 3H, H-4, H-6a, H-6b), 3.63-3.58 (m, 2H, CH $\left.{ }_{2} \mathrm{NHCO}\right), 3.54$ (s, 1H, $\left.\mathrm{OCH}_{3}\right), 2.45-3.39$ (m, 1H, H-3). ${ }^{13} \mathrm{C} \mathrm{NMR}\left(\mathrm{CDCl}_{3}, 100 \mathrm{MHz}\right): 156.9,145.1-144.9$ (m), 142.6-142.4 (m), 140.9-140.6 (m), 138.8-138.5 (m), 138.2, 137.9, 137.7, 136.3-136.0 (m), 128.5, 128.2, 128.1, 128.0, 127.9, 127.8, 111.9-111.5

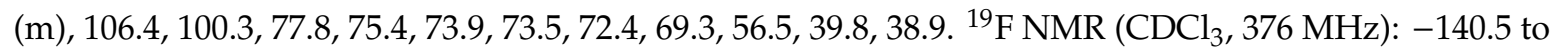
$-140.6(\mathrm{~m}, 2 \mathrm{~F}),-151.7(\mathrm{t}, 1 \mathrm{~F}, \mathrm{~J} 2 \mathrm{~Hz}),-160.1$ to $-160.3(\mathrm{~m}, 2 \mathrm{~F})$. HRMS calcd for $\mathrm{C}_{36} \mathrm{H}_{34} \mathrm{~F}_{5} \mathrm{NO}_{6}+\mathrm{NH}_{4}{ }^{+}$ $\left(\mathrm{M}+\mathrm{NH}_{4}\right)^{+}: 689.2650$, found: 689.2656 .

3.11.9. Methyl 2,4,6-Tri-O-Benzyl-3-Deoxy-3-C-(3-Methoxybenzamidomethyl)- $\beta$-D-Gulopyranoside 22h

Compound 22h (TLC heptane/EtOAc, 1:1, $\mathrm{R}_{\mathrm{f}} 0.45$ ) was prepared according to the general procedure 3.11 from the amine $19(47 \mathrm{mg}, 0.10 \mathrm{mmol})$. Obtained as a colorless oil in $51 \%$ yield $(30.7 \mathrm{mg}, 0.05 \mathrm{mmol})$. 
$[\alpha]_{\mathrm{D}}^{25}-43.2\left(\mathrm{c} 0.5, \mathrm{CHCl}_{3}\right) .{ }^{1} \mathrm{H}$ NMR $\left(\mathrm{CDCl}_{3}, 400 \mathrm{MHz}\right): 7.35-7.21(\mathrm{~m}, 17 \mathrm{H}, \mathrm{ArH}), 7.08(\mathrm{t}, 1 \mathrm{H}, J 8.0 \mathrm{~Hz}$, $\mathrm{ArH}), 7.00\left(\mathrm{~m}, 2 \mathrm{H}, \mathrm{CH}_{2} \mathrm{NHCO}, \mathrm{ArH}\right), 6.75-6.72(\mathrm{~m}, 1 \mathrm{H}, \mathrm{ArH}), 4.87\left(\mathrm{~d}, 1 \mathrm{H}, J 11.6 \mathrm{~Hz}, \mathrm{CH}_{2} \mathrm{Ph}\right), 4.68$ $\left(\mathrm{d}, 1 \mathrm{H}, J_{1,2} 6.4 \mathrm{~Hz}, \mathrm{H}-1\right), 4.57\left(\mathrm{~d}, 1 \mathrm{H}, J 11.6 \mathrm{~Hz}, \mathrm{CH}_{2} \mathrm{Ph}\right), 4.54\left(\mathrm{~d}, 1 \mathrm{H}, J 11.6 \mathrm{~Hz}, \mathrm{CH}_{2} \mathrm{Ph}\right), 4.51(\mathrm{~d}, 1 \mathrm{H}, J$ $\left.12.8 \mathrm{~Hz}, \mathrm{CH}_{2} \mathrm{Ph}\right), 4.48\left(\mathrm{~d}, 1 \mathrm{H}, J 11.2 \mathrm{~Hz}, \mathrm{CH}_{2} \mathrm{Ph}\right), 4.45\left(\mathrm{~d}, 1 \mathrm{H}, J 11.2 \mathrm{~Hz}, \mathrm{CH}_{2} \mathrm{Ph}\right), 4.05(\mathrm{td}, 1 \mathrm{H}, J 6.4 \mathrm{~Hz}, J$ $2.8 \mathrm{~Hz}, \mathrm{H}-5), 3.83\left(\mathrm{dd}, 1 \mathrm{H}, J_{1,2} 6.4 \mathrm{~Hz}, J_{2,3} 5.2 \mathrm{~Hz}, \mathrm{H}-2\right), 3.79\left(\mathrm{~s}, 3 \mathrm{H}, \mathrm{C}_{6} \mathrm{H}_{4} \mathrm{OCH}_{3}\right), 3.78-3.67(\mathrm{~m}, 5 \mathrm{H}, \mathrm{H}-2$, $\left.\mathrm{H}-4, \mathrm{H}-6 \mathrm{a}, \mathrm{H}-6 \mathrm{~b}, \mathrm{CH}_{2} \mathrm{NHCO}\right), 3.59-3.53\left(\mathrm{~m}, 4 \mathrm{H}, \mathrm{CH}_{2} \mathrm{NHCO}, \mathrm{OCH}_{3}\right), 2.50-2.45$ (m, 1H, H-3). ${ }^{13} \mathrm{C} \mathrm{NMR}$ ( $\left.\mathrm{CDCl}_{3}, 100 \mathrm{MHz}\right): 166.8,159.9,138.3,138.2,137.8,129.5,128.7,128.5,128.4,128.3,128.1,128.0,127.9$, $127.8,118.4,117.7,112.3,100.9,77.6,75.8,74.2,73.5,73.1,72.1,69.4,56.5,55.5,39.8,39.2$. HRMS calcd for $\mathrm{C}_{37} \mathrm{H}_{41} \mathrm{NO}_{7}+\mathrm{H}^{+}(\mathrm{M}+\mathrm{H})^{+}$: 612.2961, found: 612.2972.

\subsubsection{Methyl 2,4,6-Tri-O-Benzyl-3-Deoxy-3-C-(p-Toluamidomethyl)- $\beta$-D-Gulopyranoside 22i}

Compound 22i (TLC heptane/EtOAc, 2:1, $\mathrm{R}_{\mathrm{f}} 0.24$ ) was prepared according to the general procedure 3.11 from the amine $19(51 \mathrm{mg}, 0.11 \mathrm{mmol})$. Obtained as a colorless oil in $61 \%$ yield $(38.8 \mathrm{mg}, 0.07 \mathrm{mmol})$. $[\alpha]_{\mathrm{D}}^{25}-56.2\left(\mathrm{c} 0.5, \mathrm{CHCl}_{3}\right) .{ }^{1} \mathrm{H}$ NMR $\left(\mathrm{CDCl}_{3}, 400 \mathrm{MHz}\right): 7.35-7.21(\mathrm{~m}, 17 \mathrm{H}, \mathrm{ArH}), 7.04(\mathrm{~d}, 1 \mathrm{H}, J 7.6 \mathrm{~Hz}$, $\mathrm{ArH}), 6.96\left(\mathrm{t}, 1 \mathrm{H}, J 6.0 \mathrm{~Hz}, \mathrm{CH}_{2} \mathrm{NHCO}\right), 4.88\left(\mathrm{~d}, 1 \mathrm{H}, J 11.2 \mathrm{~Hz}, \mathrm{CH}_{2} \mathrm{Ph}\right), 4.68\left(\mathrm{~d}, 1 \mathrm{H}, J_{1,2} 6.4 \mathrm{~Hz}, \mathrm{H}-1\right)$, $4.57\left(\mathrm{~d}, 1 \mathrm{H}, \mathrm{J} 12.0 \mathrm{~Hz}, \mathrm{CH}_{2} \mathrm{Ph}\right), 4.53\left(\mathrm{~d}, 1 \mathrm{H}, J 11.2 \mathrm{~Hz}, \mathrm{CH}_{2} \mathrm{Ph}\right), 4.51$ (d, $\left.1 \mathrm{H}, J 12.0 \mathrm{~Hz}, \mathrm{CH}_{2} \mathrm{Ph}\right), 4.48$ (d, $\left.1 \mathrm{H}, J 12.0 \mathrm{~Hz}, \mathrm{CH}_{2} \mathrm{Ph}\right), 4.45\left(\mathrm{~d}, 1 \mathrm{H}, J 11.6 \mathrm{~Hz}, \mathrm{CH}_{2} \mathrm{Ph}\right), 4.04(\mathrm{td}, 1 \mathrm{H}, J 6.4 \mathrm{~Hz}, J 2.8 \mathrm{~Hz}, \mathrm{H}-5), 3.82$ (dd, $\left.1 \mathrm{H}, J_{1,2} 6.4 \mathrm{~Hz}, J_{2,3} 5.2 \mathrm{~Hz}, \mathrm{H}-2\right), 3.78-3.67$ (m, 3H, H-4, H-6a, H-6b, $\mathrm{CH}_{2} \mathrm{NHCO}$ ), 3.58-3.52 (m,

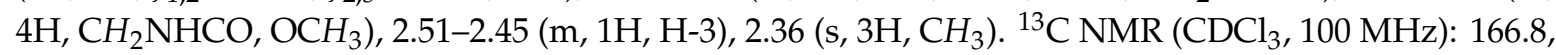
141.6, 138.3, 138.2, 137.9, 131.4, 130.3, 129.24, 129.16, 128.7, 128.52, 128.51, 128.4, 128.3, 128.1, 128.0, $127.9,127.8,126.9,101.0,77.8,75.9,74.2,73.5,73.1,72.1,69.4,56.5,39.9,39.2,21.5$. HRMS calcd for $\mathrm{C}_{37} \mathrm{H}_{41} \mathrm{NO}_{6}+\mathrm{H}^{+}(\mathrm{M}+\mathrm{H})^{+}$: 596.3012, found: 596.3019.

3.11.11. Methyl 2,4,6-Tri-O-Benzyl-3-Deoxy-3-C-(3,5-Dimethoxybenzamidomethyl)$\beta$-D-Gulopyranoside 22j

Compound 22j (TLC heptane/EtOAc, 2:1, $\mathrm{R}_{\mathrm{f}} 0.22$ ) was prepared according to the general procedure 3.11 from the amine $19(53 \mathrm{mg}, 0.11 \mathrm{mmol})$. Obtained as a colorless oil in $67 \%$ yield $(48 \mathrm{mg}, 0.07 \mathrm{mmol})$. $[\alpha]_{\mathrm{D}}^{25}-39.5\left(\mathrm{c} 0.8, \mathrm{CHCl}_{3}\right) .{ }^{1} \mathrm{H}$ NMR $\left(\mathrm{CDCl}_{3}, 400 \mathrm{MHz}\right): 7.35-7.18(\mathrm{~m}, 15 \mathrm{H}, \mathrm{ArH}), 6.82(\mathrm{t}, 1 \mathrm{H}, \mathrm{J} 6.0 \mathrm{~Hz}$, NHCO), $6.72(\mathrm{~d}, 2 \mathrm{H}, J 2.4 \mathrm{~Hz}, \operatorname{ArH}), 6.54(\mathrm{t}, 1 \mathrm{H}, J 2.4 \mathrm{~Hz}, \mathrm{ArH}), 4.84\left(\mathrm{~d}, 1 \mathrm{H}, J 11.6 \mathrm{~Hz}, \mathrm{CH}_{2} \mathrm{Ph}\right), 4.65$ (d, $\left.1 \mathrm{H}, J_{1,2} 6.4 \mathrm{~Hz}, \mathrm{H}-1\right), 4.57\left(\mathrm{~d}, 1 \mathrm{H}, J 12.0 \mathrm{~Hz}, \mathrm{CH}_{2} \mathrm{Ph}\right), 4.56\left(\mathrm{~d}, 1 \mathrm{H}, J 12.0 \mathrm{~Hz}, \mathrm{CH}_{2} \mathrm{Ph}\right), 4.48(\mathrm{~d}, 1 \mathrm{H}, J$ $\left.11.6 \mathrm{~Hz}, \mathrm{CH}_{2} \mathrm{Ph}\right), 4.47\left(\mathrm{~d}, 1 \mathrm{H}, J 11.6 \mathrm{~Hz}, \mathrm{CH}_{2} \mathrm{Ph}\right), 4.43\left(\mathrm{~d}, 1 \mathrm{H}, J 11.6 \mathrm{~Hz}, \mathrm{CH}_{2} \mathrm{Ph}\right), 4.03(\mathrm{td}, 1 \mathrm{H}, J 6.4 \mathrm{~Hz}, J$ $2.8 \mathrm{~Hz}, \mathrm{H}-5), 3.78$ (dd, $\left.1 \mathrm{H}, J_{1,2} 6.0 \mathrm{~Hz}, J_{2,3} 4.8 \mathrm{~Hz}, \mathrm{H}-2\right), 3.75-3.65$ (m, 10H, H-4, H-6a, H-6b, $\mathrm{CH}_{2} \mathrm{NHCO}$, $\left.2 \times \mathrm{OCH}_{3}\right), 3.57-3.52\left(\mathrm{~m}, 4 \mathrm{H}, \mathrm{CH}_{2} \mathrm{NHCO}, \mathrm{OCH}_{3}\right), 2.47-2.41(\mathrm{~m}, 1 \mathrm{H}, \mathrm{H}-3) .{ }^{13} \mathrm{C} \mathrm{NMR}\left(\mathrm{CDCl}_{3}, 100 \mathrm{MHz}\right)$ : $167.1,160.9,163.3,138.3,138.2,137.8,136.8,128.7,128.5,128.2,128.1,128.0,127.93,127.88,127.8,104.9$, 103.6, 100.9, 77.2, 75.6, 73.9, 73.5, 73.1, 72.1, 69.5, 56.5, 55.6, 39.9, 39.0. HRMS calcd for $\mathrm{C}_{38} \mathrm{H}_{43} \mathrm{NO}_{8}+\mathrm{H}^{+}$ $(\mathrm{M}+\mathrm{H})^{+}:$642.3066, found: 642.3067 .

3.11.12. Methyl 2,4,6-tri-O-Benzyl-3-Deoxy-3-C-(3-Trifluoromethylbenzamidomethyl)$\beta$-D-Gulopyranoside 22k

Compound 22k (TLC heptane/EtOAc, 2:1, $\mathrm{R}_{\mathrm{f}} 0.25$ ) was prepared according to the general procedure 3.11 from the amine 19 ( $43 \mathrm{mg}, 0.09 \mathrm{mmol})$. Obtained as a colorless oil in $55 \%$ yield $(32.2 \mathrm{mg}, 0.05 \mathrm{mmol})$. $[\alpha]_{\mathrm{D}}^{25}-38.7\left(\mathrm{c} \mathrm{0.8}, \mathrm{CHCl}_{3}\right) .{ }^{1} \mathrm{H}$ NMR $\left(\mathrm{CDCl}_{3}, 400 \mathrm{MHz}\right): 8.00(\mathrm{~s}, 1 \mathrm{H}, \mathrm{ArH}), 7.69-7.66(\mathrm{~m}, 1 \mathrm{H}, \mathrm{ArH})$, 7.34-7.21 (m, 17H, ArH), 7.09 (t, 1H, J $\left.6.0 \mathrm{~Hz}, \mathrm{CH}_{2} \mathrm{NHCO}\right), 4.88\left(\mathrm{~d}, 1 \mathrm{H}, J 11.6 \mathrm{~Hz}, \mathrm{CH}_{2} \mathrm{Ph}\right), 4.69$ (d, $\left.1 \mathrm{H}, J_{1,2} 6.0 \mathrm{~Hz}, \mathrm{H}-1\right), 4.58$ (d, $\left.1 \mathrm{H}, J 12.0 \mathrm{~Hz}, \mathrm{CH}_{2} \mathrm{Ph}\right), 4.53\left(\mathrm{~d}, 1 \mathrm{H}, J 11.2 \mathrm{~Hz}, \mathrm{CH}_{2} \mathrm{Ph}\right), 4.51-4.47(\mathrm{~m}, 3 \mathrm{H}$, $\left.\mathrm{CH}_{2} \mathrm{Ph}\right), 4.07$ (s td, 1H, J $\left.6.4 \mathrm{~Hz}, J 3.2 \mathrm{~Hz}, \mathrm{H}-5\right), 3.83$ (dd, 1H, J $\left.6.0 \mathrm{~Hz}, J 4.8 \mathrm{~Hz}, \mathrm{H}-2\right), 3.81-3.68$ (m, 4H, H-2, H-4, H-6a, H-6b, CH $\mathrm{CH}_{2} \mathrm{NCO}$ ), 3.62-3.59 (m, 1H, $\mathrm{CH}_{2} \mathrm{NHCO}$ ), 3.56 (s, 3H, OCH $)$, 2.50-2.45 (m, 1H, H-3). ${ }^{13} \mathrm{C}$ NMR (CDCl, $\left.100 \mathrm{MHz}\right): 165.5,138.2,138.1,137.8,135.1,133.4131 .2$ (q, J $\left.32 \mathrm{~Hz}\right), 129.5$, 129.2, 129.1, 128.7, 128.54, 128.52, 128.4, 128.31, 128.25, 128.0, 127.9, 127.8, 125.2, 124.6 (q, J 3.7 Hz), 123.7 (q, J $271 \mathrm{~Hz}), 100.8,77.8,75.8,74.3,73.6,73.1,72.2,69.3,56.5,39.62,39.61 .{ }^{19} \mathrm{~F} \mathrm{NMR}\left(\mathrm{CDCl}_{3}, 376 \mathrm{MHz}\right)$ : -62.7. HRMS calcd for $\mathrm{C}_{37} \mathrm{H}_{38} \mathrm{~F}_{3} \mathrm{NO}_{6}+\mathrm{H}^{+}(\mathrm{M}+\mathrm{H})^{+}: 650.2729$, found: 650.2727. 
3.11.13. Methyl 2,4,6-Tri-O-Benzyl-3-Deoxy-3-C-(4-Phenylbenzamidomethyl)- $\beta$-D-Gulopyranoside 221

Compound 221 (TLC heptane/EtOAc, 2:1, $\mathrm{R}_{\mathrm{f}} 0.32$ ) was prepared according to the general procedure 3.11 from the amine $19(60 \mathrm{mg}, 0.13 \mathrm{mmol})$. Obtained as a colorless oil in $55 \%$ yield $(45.5 \mathrm{mg}, 0.07 \mathrm{mmol})$. $[\alpha]_{\mathrm{D}}^{25}-47.8\left(\mathrm{c} 0.9, \mathrm{CHCl}_{3}\right) .{ }^{1} \mathrm{H}$ NMR $\left(\mathrm{CDCl}_{3}, 400 \mathrm{MHz}\right): 7.61-7.24(\mathrm{~m}, 24 \mathrm{H}, \mathrm{ArH}), 7.10(\mathrm{t}, 1 \mathrm{H}, \mathrm{J} 6.0 \mathrm{~Hz}$, $\left.\mathrm{CH}_{2} \mathrm{NHCO}\right), 4.92\left(\mathrm{~d}, 1 \mathrm{H}, J 11.2 \mathrm{~Hz}, \mathrm{CH}_{2} \mathrm{Ph}\right), 4.72\left(\mathrm{~d}, 1 \mathrm{H}, J_{1,2} 6.4 \mathrm{~Hz}, \mathrm{H}-1\right), 4.59\left(\mathrm{~d}, 1 \mathrm{H}, J 12.0 \mathrm{~Hz}, \mathrm{CH}_{2} \mathrm{Ph}\right)$, $4.57-4.48\left(\mathrm{~m}, 4 \mathrm{H}, \mathrm{CH}_{2} \mathrm{Ph}\right), 4.08(\mathrm{td}, 1 \mathrm{H}, J 6.0 \mathrm{~Hz}, J 2.8 \mathrm{~Hz}, \mathrm{H}-5), 3.85\left(\mathrm{dd}, 1 \mathrm{H}, J_{1,2} 6.0 \mathrm{~Hz}, J_{2,3} 4.8 \mathrm{~Hz}, \mathrm{H}-2\right)$, 3.82-3.70 (m, 4H, H-4, H-6a, H-6b, $\left.\mathrm{CH}_{2} \mathrm{NHCO}\right), 3.64-3.59$ (m, 1H, $\left.\mathrm{CH}_{2} \mathrm{NHCO}\right), 3.58$ (s, 3H, $\mathrm{OCH}_{3}$ ), 2.55-2.50 (m, 1H, H-3). ${ }^{13} \mathrm{C} \mathrm{NMR}\left(\mathrm{CDCl}_{3}, 100 \mathrm{MHz}\right): 166.5,143.9,140.3,138.3,138.2,137.9,132.9,129.0$, 128.7, 128.53, 128,49, 128.3, 128.2, 128.02, 127.98, 127.9, 127.8, 127.4, 127.24, 127.15, 100.9, 77.9, 75.9, 74.3, 73.5, 73.1, 72.2, 69.4, 56.5, 39.8, 39.4. HRMS calcd for $\mathrm{C}_{42} \mathrm{H}_{43} \mathrm{NO}_{6}+\mathrm{NH}_{4}{ }^{+}\left(\mathrm{M}+\mathrm{NH}_{4}\right)^{+}:$675.3434, found: 675.3433 .

3.11.14. Methyl 2,4,6-tri-O-Benzyl-3-Deoxy-3-C-(Diphenylphosphonamidomethyl)$\beta$-D-Gulopyranoside 23

Compound 23 (TLC heptane/EtOAc, 2:1, $\mathrm{R}_{\mathrm{f}} 0.26$ ) was prepared according to the general procedure 3.11 from the amine $19(52 \mathrm{mg}, 0.11 \mathrm{mmol})$. Obtained as a colorless oil in $69 \%$ yield ( $53.3 \mathrm{mg}, 0.08 \mathrm{mmol})$. $[\alpha]_{\mathrm{D}}^{25}-77.8\left(\mathrm{c} 0.7, \mathrm{CHCl}_{3}\right) .{ }^{1} \mathrm{H}$ NMR $\left(\mathrm{CDCl}_{3}, 400 \mathrm{MHz}\right): 7.36-7.13(\mathrm{~m}, 20 \mathrm{H}, \mathrm{ArH}), 4.76(\mathrm{~d}, 1 \mathrm{H}, J 12.0 \mathrm{~Hz}$, $\left.\mathrm{CH}_{2} \mathrm{Ph}\right), 4.55-49\left(\mathrm{~m}, 3 \mathrm{H}, \mathrm{H}-1, \mathrm{CH}_{2} \mathrm{Ph}\right), 4.45\left(\mathrm{~d}, 1 \mathrm{H}, J 12.0 \mathrm{~Hz}, \mathrm{CH}_{2} \mathrm{Ph}\right), 4.34\left(\mathrm{~d}, 1 \mathrm{H}, J 11.6 \mathrm{~Hz}, \mathrm{CH}_{2} \mathrm{Ph}\right), 4.28$ (d, $\left.1 \mathrm{H}, J 11.6 \mathrm{~Hz}, \mathrm{CH}_{2} \mathrm{Ph}\right), 3.95-92$ (m, 1H, H-5), 3.71-3.58 (m, 5H, H-2, H-4, H-6a, H-6b, NHPO(OPh) 2 ), 3.47 (s, 3H, OCH $\left.\mathrm{O}_{3}\right), 3.40-3.31$ (m, 1H, $\left.\mathrm{CH}_{2} \mathrm{NHSO}\right), 3.15-3.09$ (m, 1H, $\left.\mathrm{CH}_{2} \mathrm{NHSO}\right), 2.33-2.27(\mathrm{~m}, 1 \mathrm{H}$, H-3). ${ }^{13} \mathrm{C} \mathrm{NMR}\left(\mathrm{CDCl}_{3}, 100 \mathrm{MHz}\right): 150.9$ (dd, J $\left.6.7 \mathrm{~Hz}, J 2.4 \mathrm{~Hz}\right), 138.22,138.21,137.9,128.6,128.51$, 128.45, 128.1, 128.0, 127.93, 127.87, 127.8, 125.0 (d, J 4.3 Hz), 120.3 (d, J 5.0 Hz, J 8.0 Hz), 100.8, 76.1, 74.9, 73.6, 73.4, 72.8, 71.8, 69.5, 56.5, 42.1 (d, J 1.8 Hz), 40.2. ${ }^{31} \mathrm{P} \mathrm{NMR}\left(\mathrm{CDCl}_{3}, 162 \mathrm{MHz}\right):-1.01$. HRMS calcd for $\mathrm{C}_{41} \mathrm{H}_{44} \mathrm{PNO}_{8}+\mathrm{H}^{+}(\mathrm{M}+\mathrm{H})^{+}$: 710.2883 , found: 710.2889 .

\subsection{General Procedure the Synthesis of $\mathbf{1 a}, \mathbf{1} \mathbf{b}, \mathbf{2}-\mathbf{6}, \mathbf{7 a}-\mathbf{7 1}$, and $\mathbf{8}$}

A solution of crude in EtOAc/isopropanol (1:3) was stirred with $\mathrm{Pd}(\mathrm{OH})_{2} / \mathrm{C}(10 \%$ wt., $1 \mathrm{mg}$ per $4 \mathrm{mg}$ of crude) under hydrogen atmosphere at room temperature for $12 \mathrm{~h}$. All the hydrogenation reactions were carried out in an EtOAc-isopropanol mixture (1:3, $4 \mathrm{~mL})$. After the completion of the reaction (as indicated by TLC), the reaction mixture was filtered through a Celite bed and washed with methanol. The filtrate was concentrated under reduced pressure and purified through the flash column (DCM:MeOH) to get the desired compounds as white amorphous solids or colorless oils.

\subsubsection{Methyl 3-Deoxy-3-C-Hydroxymethyl- $\beta$-D-Gulopyranoside 1a}

Compound 1a (TLC, DCM/MeOH, 5:1, $\mathrm{R}_{\mathrm{f}} 0.41$ ) was prepared according to the general procedure 3.12 from the alcohol 14a $(63 \mathrm{mg}, 0.13 \mathrm{mmol})$. Obtained as a white amorphous solid in $51 \%$ yield (14 mg, $0.07 \mathrm{mmol}$ ) from flash column chromatography (DCM:MeOH 12:1-5:1). [ $\alpha]_{\mathrm{D}}^{25}-50.7$ (c 0.6 , $\left.\mathrm{CH}_{3} \mathrm{OH}\right) .{ }^{1} \mathrm{H}$ NMR $\left(\mathrm{CD}_{3} \mathrm{OD}, 400 \mathrm{MHz}\right): 4.39$ (d, $\left.1 \mathrm{H}, J 7.6 \mathrm{~Hz}, \mathrm{H}-1\right), 3.96\left(\mathrm{dd}, 1 \mathrm{H}, J_{3,4} 4.0 \mathrm{~Hz}, J_{4,5} 2.0 \mathrm{~Hz}\right.$, $\mathrm{H}-4), 3.92\left(\mathrm{dd}, 1 \mathrm{H}, J 11.2 \mathrm{~Hz}, J 5.6 \mathrm{~Hz}, \mathrm{CH}_{2} \mathrm{OH}\right), 3.86$ (dd, $\left.1 \mathrm{H}, J_{1,2} 7.6 \mathrm{~Hz}, J_{2,3} 6.0 \mathrm{~Hz} \mathrm{H}-2\right), 3.84-3.74$ (m, 3H, H-5, H-6a, H-6b), 3.67 (dd, 1H, J $\left.11.2 \mathrm{~Hz}, J 8.4 \mathrm{~Hz}, \mathrm{CH}_{2} \mathrm{OH}\right), 3.51$ (s, 3H, OCH $), 2.32-2.26$ (m, 1H, H-3). ${ }^{13} \mathrm{C}$ NMR (CD $\left.{ }_{3} \mathrm{OD}, 125 \mathrm{MHz}\right): 104.0,76.1,69.0,68.3,63.1,59.6,56.8,49.0$. HRMS calcd for $\mathrm{C}_{8} \mathrm{H}_{16} \mathrm{O}_{6}-\mathrm{H}^{+}(\mathrm{M}-\mathrm{H})^{+}:$207.0869, found: 207.0865.

\subsubsection{Methyl 3-Deoxy-3-C-Hydroxymethyl- $\beta$-D-Galactopyranoside $\mathbf{1 b}$}

Compound $\mathbf{1 b}$ (TLC, DCM/MeOH, 5:1, $\mathrm{R}_{\mathrm{f}} 0.40$ ) was prepared according to the general procedure 3.12 from the alcohol $14 \mathbf{b}(46 \mathrm{mg}, 0.10 \mathrm{mmol})$. Obtained as a white amorphous solid in $63 \%$ yield $(12.6 \mathrm{mg}, 0.06 \mathrm{mmol} \text { ) from flash column chromatography (DCM:MeOH 12:1-6:1). [ } \alpha]_{\mathrm{D}}^{25}-32.1$ (c 0.5, $\left.\mathrm{CH}_{3} \mathrm{OH}\right) .{ }^{1} \mathrm{H}$ NMR $\left(\mathrm{CD}_{3} \mathrm{OD}, 500 \mathrm{MHz}\right): 4.16(\mathrm{~d}, 1 \mathrm{H}, J 7.6 \mathrm{~Hz}, \mathrm{H}-1), 3.97\left(\mathrm{~d}, 1 \mathrm{H}, J_{3,4} 2.4 \mathrm{~Hz}, \mathrm{H}-4\right), 3.90$ (dd, $\left.1 \mathrm{H}, J 10.4 \mathrm{~Hz}, J 4.4 \mathrm{~Hz}, \mathrm{CH}_{2} \mathrm{OH}\right), 3.78$ (dd, 1H, J $\left.10.8 \mathrm{~Hz}, J 8.4 \mathrm{~Hz}, \mathrm{H}-2\right), 3.72$ (dd, 1H, J $5.6 \mathrm{~Hz}$, 
H-6a, H-6b), 3.55-3.51 (m, 4H, H-5, OCH ( $_{3}, 3.44$ (dd, 1H, J 10.8 Hz, J 7.6 Hz, CH $\left.\mathrm{CH}_{2} \mathrm{OH}\right), 1.73-1.66$ (m, 1H, H-3). ${ }^{13} \mathrm{C}$ NMR $\left(\mathrm{CD}_{3} \mathrm{OD}, 125 \mathrm{MHz}\right): 107.6,79.8,68.8,67.1,62.7,61.2,57.1$, 49.0. HRMS calcd for $\mathrm{C}_{8} \mathrm{H}_{16} \mathrm{O}_{6}+\mathrm{Na}^{+}(\mathrm{M}+\mathrm{Na})^{+}: 231.0845$, found: 231.0840 .

\subsubsection{Methyl 3-Deoxy-3-C-(3-Trifluoromethylphenoxymethyl)- $\beta$-D-Galactopyranoside 2}

Compound 2 (TLC, DCM/MeOH, 10:1, $\mathrm{R}_{\mathrm{f}} 0.5$ ) was prepared according to the general procedure 3.12 from the ether 15 ( $53 \mathrm{mg}, 0.09 \mathrm{mmol})$. Obtained as a colorless oil in $75 \%$ yield $(22.5 \mathrm{mg}, 0.06 \mathrm{mmol})$ from flash column chromatography (DCM:MeOH 20:1-12:1). $[\alpha]_{\mathrm{D}}^{25}-12.8\left(\mathrm{c} 0.7, \mathrm{CH}_{3} \mathrm{OH}\right) .{ }^{1} \mathrm{H}$ NMR ( $\left.\mathrm{CD}_{3} \mathrm{OD}, 400 \mathrm{MHz}\right): 7.46(\mathrm{t}, 1 \mathrm{H}, J 8.0 \mathrm{~Hz}, \mathrm{ArH}), 7.23-7.21(\mathrm{~m}, 3 \mathrm{H}, \mathrm{ArH}), 4.50(\mathrm{~d}, 1 \mathrm{H}, J 7.2 \mathrm{~Hz}, \mathrm{H}-1), 4.35$ $\left(\mathrm{dd}, 1 \mathrm{H}, J 4.8 \mathrm{~Hz}, J 10.0 \mathrm{~Hz}, \mathrm{CH}_{2} \mathrm{OH}\right), 4.22\left(\mathrm{t}, 1 \mathrm{H}, J 8.8 \mathrm{~Hz}, \mathrm{CH}_{2} \mathrm{OH}\right), 4.08$ (bs, 1H, H-4), 3.97-3.94 (m, 2H, H-2, H-5), 3.78 (d, 2H, J 6.0 Hz, H-6a, H-6b), 3.54 (s, 3H, OCH $), 2.64-2.58$ (m, 1H, H-3). ${ }^{13} \mathrm{C}$ NMR ( $\left.\mathrm{CD}_{3} \mathrm{OD}, 100 \mathrm{MHz}\right): 160.6,132.8\left(\mathrm{q}^{*}, J 32 \mathrm{~Hz}\right), 131.4,125.5\left(\mathrm{q}^{*}, J 270 \mathrm{~Hz}\right), 119.3,118.3$ (br q, J $\left.3.7 \mathrm{~Hz}\right)$, 112.4 (br q, J 3.8 Hz), 104.1, 76.1, 68.2, 68.1, 65.9, 62.9, 56.8, 46.1. $\left.{ }^{19} \mathrm{~F} \mathrm{NMR} \mathrm{CD}_{3} \mathrm{OD}, 376 \mathrm{MHz}\right):-64.2$. HRMS calcd for $\mathrm{C}_{15} \mathrm{H}_{20} \mathrm{~F}_{3} \mathrm{O}_{6}+\mathrm{H}^{+}(\mathrm{M}+\mathrm{H})^{+}$: 353.1212, found: 353.1208 .

*Only two peaks from the $\mathrm{q}$ are observed: See Supplementary information page S43)

\subsubsection{Methyl 3-Deoxy-3-C-Methoxymethyl- $\beta$-D-Galactopyranoside 3}

Compound 3 (TLC, DCM/MeOH, 10:1, $\mathrm{R}_{\mathrm{f}} 0.5$ ) was prepared according to the general procedure 3.12 from 16 (36 mg, $0.07 \mathrm{mmol})$. Obtained as a colorless oil in $64 \%$ yield $(10.4 \mathrm{mg}, 0.05 \mathrm{mmol})$. $[\alpha]_{\mathrm{D}}^{25}$ -33.4 (c $0.5, \mathrm{CH}_{3} \mathrm{OH}$ ) from flash column chromatography (DCM:MeOH 15:1-9:1). ${ }^{1} \mathrm{H}$ NMR $\left(\mathrm{CD}_{3} \mathrm{OD}\right.$, $400 \mathrm{MHz}$ ): 4.41 (d, 1H, J 7.6 Hz, H-1), 3.93 (dd, 1H, J, $\left.3.2 \mathrm{~Hz}, J_{3,4} 2.0 \mathrm{~Hz}, \mathrm{H}-4\right), 3.88-3.82$ (m, 2H, H-2, H-5), 3.73 (d, 2H, J 6.0 Hz, H-6a, H-6b), 3.65 (dd, 1H, J $\left.10.0 \mathrm{~Hz}, J 4.8 \mathrm{~Hz}, \mathrm{CH}_{2} \mathrm{OCH}_{3}\right), 3.57$ (dd, $1 \mathrm{H}, J$ $\left.10.0 \mathrm{~Hz}, J 4.8 \mathrm{~Hz}, \mathrm{CH}_{2} \mathrm{OCH}_{3}\right), 3.50\left(\mathrm{~s}, 3 \mathrm{H}, \mathrm{OCH}_{3}\right), 3.33\left(\mathrm{~s}, 3 \mathrm{H}, \mathrm{OCH}_{3}\right), 2.38-2.34(\mathrm{~m}, 1 \mathrm{H}, \mathrm{H}-3) .{ }^{13} \mathrm{C} \mathrm{NMR}$ $\left(\mathrm{CD}_{3} \mathrm{OD}, 100 \mathrm{MHz}\right):$ 104.1, 76.3, 70.2, 68.7, 68.5, 63.1, 59.1, 56.8, 46.6. HRMS calcd for $\mathrm{C}_{9} \mathrm{H}_{18} \mathrm{O}_{6}+\mathrm{Na}^{+}$ $(\mathrm{M}+\mathrm{Na})^{+}:$245.1001, found: 245.1004 .

\subsubsection{Methyl 3-Deoxy-3-C-[4-(3-Fluorophenyl)-1H-1,2,3-Triazol-1-Ylmethyl]- $\beta$-D-Galactopyranoside 4}

Compound 4 (TLC, DCM/MeOH, 10:1, $\mathrm{R}_{\mathrm{f}} 0.43$ ) was prepared according to the general procedure 3.12 from triazole 18 ( $55 \mathrm{mg}, 0.09 \mathrm{mmol})$. Obtained as a colorless oil in $78 \%$ yield $(24.3 \mathrm{mg}, 0.07 \mathrm{mmol})$ from flash column chromatography (DCM:MeOH 20:1-9:1). $[\alpha]_{\mathrm{D}}^{25}-20.5\left(\right.$ c $\left.0.7, \mathrm{CH}_{3} \mathrm{OH}\right) .{ }^{1} \mathrm{H}$ NMR (CD $\left.\mathrm{CD}_{3} \mathrm{OD}, 400 \mathrm{MHz}\right): 8.40$ (s, 1H, ArH), 7.65-7.05 (m, 4H, ArH), 4.80 (dd, 1H, J $14.4 \mathrm{~Hz}, J 6.0 \mathrm{~Hz}$, $\left.\mathrm{CH}_{2} \mathrm{~N}_{3} \mathrm{C}_{8} \mathrm{H}_{5} \mathrm{~F}\right), 4.63\left(\mathrm{dd}, 1 \mathrm{H}, J 14.4 \mathrm{~Hz}, J 9.2 \mathrm{~Hz}, \mathrm{CH}_{2} \mathrm{OH}\right), 4.48(\mathrm{~d}, 1 \mathrm{H}, J 6.4 \mathrm{~Hz}, \mathrm{H}-1), 4.02-3.99(\mathrm{~m}, 1 \mathrm{H}$, $\mathrm{H}-5), 3.82-3.78$ (m, 4H, H-2, H-4, H-6a, H-6b), 3.53 (s, 3H, OCH 3 ), 2.72-2.66 (m, 1H, H-3). ${ }^{13} \mathrm{C}$ NMR (CD 3 OD, $100 \mathrm{MHz}): 164.3$ (d, J $243 \mathrm{~Hz}), 147.7$ (d, J 3.1 Hz), 134.0 (d, J 8.3 Hz), 131.8 (d, J 8.4 Hz), 123.4, $122.4(\mathrm{~d}, J 2.5 \mathrm{~Hz}), 115.9$ (d, J $21 \mathrm{~Hz}), 113.2(\mathrm{~d}, J 23 \mathrm{~Hz}), 103.6,75.8,68.0,67.4,62.8,56.8,48.2,46.8$. HRMS calcd for $\mathrm{C}_{16} \mathrm{H}_{20} \mathrm{FN}_{3} \mathrm{O}_{5}+\mathrm{H}^{+}(\mathrm{M}+\mathrm{H})^{+}$: 354.1465, found: 354.1462 .

\subsubsection{Methyl 3-Deoxy-3-C-(3-Fluorophenylureido)Methyl- $\beta$-D-Galactopyranoside 5}

Compound 5 (TLC, $\mathrm{DCM} / \mathrm{MeOH}, 10: 1, \mathrm{R}_{\mathrm{f}} 0.44$ ) was prepared according to the general procedure 3.12 from 20 ( $50 \mathrm{mg}, 0.0814 \mathrm{mmol})$. Obtained as a colorless oil in $41 \%$ yield ( $11.5 \mathrm{mg}, 0.03 \mathrm{mmol}$ ) from flash column chromatography (DCM:MeOH 12:1-5:1). $[\alpha]_{\mathrm{D}}^{25}-17.3$ (c $\left.0.6, \mathrm{CH}_{3} \mathrm{OH}\right) .{ }^{1} \mathrm{H} \mathrm{NMR}\left(\mathrm{CD}_{3} \mathrm{OD}\right.$, $400 \mathrm{MHz}): 7.34(\mathrm{dt}, 1 \mathrm{H}, J 12.0 \mathrm{~Hz}, J 2.0 \mathrm{~Hz}, \mathrm{ArH}), 7.24-6.64(\mathrm{~m}, 3 \mathrm{H}, \mathrm{ArH}), 4.44(\mathrm{~d}, 1 \mathrm{H}, J 7.2 \mathrm{~Hz}, \mathrm{H}-1)$, 3.90-3.83 (m, 3H, H-2, H-4, H-5), 4.22 (t, 1H, J 8.8 Hz, CH $\left.{ }_{2} \mathrm{OH}\right), 4.08$ (bs, 1H, H-4), 3.97-3.94 (m, 2H, H-2, $\mathrm{H}-5), 3.78-3.76$ (d, 2H, H-6a, H-6b), 3.52 (s, 3H, OCH $)_{3}, 3.47$ (dd, 1H, J 14.4 Hz, J 6.4 Hz, CH $\left.\mathrm{CH}_{2} \mathrm{NCONH}\right)$, $3.41\left(\mathrm{dd}, 1 \mathrm{H}, J 14.4 \mathrm{~Hz}, J 7.6 \mathrm{~Hz}, \mathrm{CH}_{2} \mathrm{NHCONH}\right), 2.27-2.21$ (m, 1H, H-3). ${ }^{13} \mathrm{C}$ NMR $\left(\mathrm{CD}_{3} \mathrm{OD}, 100 \mathrm{MHz}\right)$ : $164.5(\mathrm{~d}, J 240 \mathrm{~Hz}), 158.0,143.0(\mathrm{~d}, J 11 \mathrm{~Hz}), 131.0(\mathrm{~d}, J 9.8 \mathrm{~Hz}), 115.2(\mathrm{~d}, J 3.2 \mathrm{~Hz}), 109.4$ (d, J $22 \mathrm{~Hz}), 106.7$ (d, $J 22 \mathrm{~Hz}), 103.8,76.1,69.2,69.0,63.0,56.9,46.8$, 38.0. HRMS calcd for $\mathrm{C}_{15} \mathrm{H}_{21} \mathrm{FN}_{2} \mathrm{O}_{6}+\mathrm{H}^{+}(\mathrm{M}+\mathrm{H})^{+}$: 354.1462, found: 345.1459 . 


\subsubsection{Methyl 3-Deoxy-3-C-(Phenylsufonamido)Methyl- $\beta$-D-Galactopyranoside 6}

Compound 6 (TLC, DCM/MeOH, 10:1, $\mathrm{R}_{\mathrm{f}}$ 0.45) was prepared according to the general procedure 3.12 from amide 21 ( $39 \mathrm{mg}, 0.06 \mathrm{mmol})$. Obtained as a colorless oil in $53 \%$ yield ( $11.6 \mathrm{mg}, 0.03 \mathrm{mmol})$ from flash column chromatography (DCM:MeOH 20:1-10:1). $[\alpha]_{\mathrm{D}}^{25}-21.4$ (c $\left.0.6, \mathrm{CH}_{3} \mathrm{OH}\right) .{ }^{1} \mathrm{H}$ NMR $\left(\mathrm{CD}_{3} \mathrm{OD}, 400 \mathrm{MHz}\right): 7.88-7.56(\mathrm{~m}, 5 \mathrm{H}, \mathrm{ArH}), 4.26(\mathrm{~d}, 1 \mathrm{H}, J 7.2 \mathrm{~Hz}, \mathrm{H}-1), 3.93(\mathrm{~d}, 1 \mathrm{H}, J 3.6 \mathrm{~Hz}, \mathrm{H}-4)$, 3.80 (dd, 1H, J1,2 7.2 Hz, J2,3 6.0 Hz, H-2), 3.76-3.70 (m, 3H, H-5, H-6a, H-6b), 3.20 (dd, 1H, J 5.2 Hz, $\left.J 11.2 \mathrm{~Hz}, \mathrm{CH}_{2} \mathrm{NH}\right), 3.20\left(\mathrm{dd}, 1 \mathrm{H}, J 11.2 \mathrm{~Hz}, J 10.0 \mathrm{~Hz}, \mathrm{CH}_{2} \mathrm{NH}\right), 2.26-2.21(\mathrm{~m}, 1 \mathrm{H}, \mathrm{H}-3) .{ }^{13} \mathrm{C} \mathrm{NMR}$ ( $\mathrm{CD}_{3} \mathrm{OD}, 100 \mathrm{MHz}$ ): 141.7, 133.7, 130.3, 128.0, 103.5, 75.7, 68.4, 67.9, 63.2, 56.8, 46.3, 40.6. HRMS calcd for $\mathrm{C}_{14} \mathrm{H}_{21} \mathrm{NO}_{7} \mathrm{~S}+\mathrm{H}^{+}(\mathrm{M}+\mathrm{H})^{+}$: 348.1117, found: 348.1115 .

\subsubsection{Methyl 3-Deoxy-3-C-Benzamidomethyl- $\beta$-D-Gulopyranoside 7a}

Compound $7 \mathrm{a}$ (TLC, $\mathrm{DCM} / \mathrm{MeOH}, 10: 1, \mathrm{R}_{\mathrm{f}}$ 0.41) was prepared according to the general procedure 3.12 from the amide 22a ( $35 \mathrm{mg}, 0.05 \mathrm{mmol})$. Obtained as a colorless oil in $59 \%$ yield $(11 \mathrm{mg}, 0.04 \mathrm{mmol})$ from flash column chromatography (DCM:MeOH 20:1-10:1). $[\alpha]_{\mathrm{D}}^{25}-6.5$ (c $\left.0.6, \mathrm{CH}_{3} \mathrm{OH}\right) .{ }^{1} \mathrm{H}$ NMR ( $\left.\mathrm{CD}_{3} \mathrm{OD}, 400 \mathrm{MHz}\right)$ : 7.82-7.80 (m, 2H, ArH), 7.56-7.52 (m, 1H, ArH), 7.49-7.44 (m, 2H, ArH), $4.48(\mathrm{~d}$, $\left.1 \mathrm{H}, J_{1,2} 6.8 \mathrm{~Hz}, \mathrm{H}-1\right), 3.95(\mathrm{td}, 1 \mathrm{H}, J 6.0 \mathrm{~Hz}, J 2.4 \mathrm{~Hz}, \mathrm{H}-5), 3.89-3.86(\mathrm{~m}, 2 \mathrm{H}, \mathrm{H}-2, \mathrm{H}-4), 3.79\left(\mathrm{~d}, 1 \mathrm{H}, J_{6 \mathrm{a}, 6 \mathrm{~b}}\right.$ $\left.12.4 \mathrm{~Hz}, J_{5,6 \mathrm{a}} 5.6 \mathrm{~Hz}, \mathrm{H}-6 \mathrm{a}\right), 3.75\left(\mathrm{dd}, 1 \mathrm{H}, J_{6 \mathrm{a}, 6 \mathrm{~b}} 12.4 \mathrm{~Hz}, J_{5,6 \mathrm{~b}} 5.6 \mathrm{~Hz}, \mathrm{H}-6 \mathrm{~b}\right), 3.68$ (dd, $1 \mathrm{H}, J 14.0 \mathrm{~Hz}, J$ $\left.6.4 \mathrm{~Hz}, \mathrm{CH}_{2} \mathrm{NH}\right), 3.61\left(\mathrm{dd}, 1 \mathrm{H}, \mathrm{J} 11.2 \mathrm{~Hz}, J 6.4 \mathrm{~Hz}, \mathrm{CH}_{2} \mathrm{NH}\right), 3.54\left(\mathrm{~s}, 3 \mathrm{H}, \mathrm{OCH}_{3}\right), 2.42-2.35(\mathrm{~m}, 1 \mathrm{H}, \mathrm{H}-3)$. ${ }^{13} \mathrm{C}$ NMR (CD $\left.{ }_{3} \mathrm{OD}, 100 \mathrm{MHz}\right): 170.5,135.6,132.7,129.6,128.2,103.7,76.0,69.0,68.7,63.1,56.8,46.4$, 37.8. HRMS calcd for $\mathrm{C}_{14} \mathrm{H}_{19} \mathrm{NO}_{6}+\mathrm{H}^{+}(\mathrm{M}+\mathrm{H})^{+}$: 289.1291, found: 298.1289 .

\subsubsection{Methyl 3-Deoxy-3-C-Acetamidomethyl- $\beta$-D-Gulopyranoside 7b}

Compound $\mathbf{7 b}$ (TLC, $\mathrm{DCM} / \mathrm{MeOH}, 10: 1, \mathrm{R}_{\mathrm{f}} 0.42$ ) was prepared according to the general procedure 3.12 from the amide $\mathbf{2 2} \mathbf{b}(27 \mathrm{mg}, 0.05 \mathrm{mmol})$. Obtained as a colorless oil in $75 \%$ yield $(9.7 \mathrm{mg}, 0.04 \mathrm{mmol})$ from flash column chromatography (DCM:MeOH 15:1-7:1). $[\alpha]_{\mathrm{D}}^{25}-1.5$ (c 0.6, $\left.\mathrm{CH}_{3} \mathrm{OH}\right) .{ }^{1} \mathrm{H}$ NMR $\left(\mathrm{CD}_{3} \mathrm{OD}, 400 \mathrm{MHz}\right): 4.40$ (d, 1H, J, $\left.J_{1,2} 6.8 \mathrm{~Hz}, \mathrm{H}-1\right), 3.88-3.84(\mathrm{~m}, 1 \mathrm{H}, \mathrm{H}-5), 3.82-371$ (m, 4H, H-2, H-4, H-6a, H-6b), 3.51 (s, 3H, OCH $), 3.44$ (dd, 1H, J $\left.14.0 \mathrm{~Hz}, J 6.0 \mathrm{~Hz}, \mathrm{CH}_{2} \mathrm{NH}\right), 3.38$ (dd, $1 \mathrm{H}, J 14.0 \mathrm{~Hz}, J$

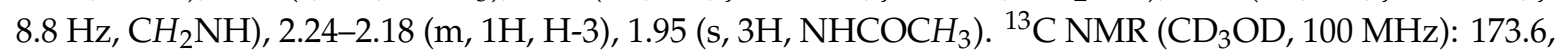
103.6, 75.9, 68.7, 68.5, 63.1, 56.8, 46.3, 37.1, 22.6. HRMS calcd for $\mathrm{C}_{10} \mathrm{H}_{19} \mathrm{NO}_{6}+\mathrm{H}^{+}(\mathrm{M}+\mathrm{H})^{+}: 250.1291$, found: 250.1291 .

\subsubsection{Methyl 3-Deoxy-3-C-(2-Fluorobenzamidomethyl)- $\beta$-D-Galactopyranoside 7c}

Compound $7 \mathrm{c}$ (TLC, DCM/MeOH, 10:1, $\mathrm{R}_{\mathrm{f}} 0.4$ ) was prepared according to the general procedure 3.12 from the amide $22 \mathrm{c}(33 \mathrm{mg}, 0.06 \mathrm{mmol})$. Obtained as a colorless oil in $69 \%$ yield $(12.5 \mathrm{mg}$, $0.04 \mathrm{mmol}$ ) from flash column chromatography (DCM:MeOH 20:1-9:1). $[\alpha]_{\mathrm{D}}^{25}-9.3\left(\mathrm{c} 0.5, \mathrm{CH}_{3} \mathrm{OH}\right.$ ). ${ }^{1} \mathrm{H}$ NMR (CD $\left.\mathrm{CD}_{3} \mathrm{OD}, 400 \mathrm{MHz}\right): 7.76(\mathrm{td}, 1 \mathrm{H}, J 7.6 \mathrm{~Hz}, J 2.0 \mathrm{~Hz}, \mathrm{ArH}), 7.56-7.50(\mathrm{~m}, 1 \mathrm{H}, \mathrm{ArH}), 7.28(\mathrm{td}$, $1 \mathrm{H}, J 7.6 \mathrm{~Hz}, J 0.8 \mathrm{~Hz}, \mathrm{ArH}), 7.20(\mathrm{ddd}, 1 \mathrm{H}, J 11.2 \mathrm{~Hz}, J 8.4 \mathrm{~Hz}, J 0.8 \mathrm{~Hz}, \mathrm{ArH}), 4.48\left(\mathrm{~d}, 1 \mathrm{H}, J_{1,2} 7.2 \mathrm{~Hz}\right.$, H-1), 3.93-3.86 (m, 3H, H-2, H-4, H-5), 3.77 (d, 2H, J5,6a $\left., J_{5,6 \mathrm{~b}} 5.6 \mathrm{~Hz}, \mathrm{H}-6 \mathrm{a}, \mathrm{H}-6 \mathrm{~b}\right), 3.66$ (d, 2H, J 7.2 $\left.\mathrm{CH}_{2} \mathrm{NH}\right), 3.53\left(\mathrm{~s}, 3 \mathrm{H}, \mathrm{OCH}_{3}\right), 2.42-2.34(\mathrm{~m}, 1 \mathrm{H}, \mathrm{H}-3) .{ }^{13} \mathrm{C}$ NMR $\left(\mathrm{CD}_{3} \mathrm{OD}, 100 \mathrm{MHz}\right): 166.7,161.4(\mathrm{~d}, J$ $248 \mathrm{~Hz}), 134.2(\mathrm{~d}, J 8.8 \mathrm{~Hz}), 131.6(\mathrm{~d}, J 2.3 \mathrm{~Hz}), 125.7(\mathrm{~d}, J 3.4 \mathrm{~Hz}), 123.9(\mathrm{~d}, J 14 \mathrm{~Hz}), 131.6(\mathrm{~d}, J 23 \mathrm{~Hz})$, 103.7, 76.0, 69.0, 68.8, 63.1, 56.9, 46.1, 38.1. ${ }^{19} \mathrm{~F}$ NMR ( $\left.\mathrm{CD}_{3} \mathrm{OD}, 376 \mathrm{MHz}\right)$ : -116.0. HRMS calcd for $\mathrm{C}_{15} \mathrm{H}_{20} \mathrm{FNO}_{6}+\mathrm{H}^{+}(\mathrm{M}+\mathrm{H})^{+}: 330.1353$, found: 330.1352 .

\subsubsection{Methyl 3-Deoxy-3-C-(3-Fluorobenzamidomethyl)- $\beta$-D-Galactopyranoside 7d}

Compound $7 \mathbf{d}$ (TLC, DCM/MeOH, 10:1, $\mathrm{R}_{\mathrm{f}} 0.45$ ) was prepared according to the general procedure 3.12 from the amide $22 \mathrm{~d}$ ( $35 \mathrm{mg}, 0.06 \mathrm{mmol})$. Obtained as a colorless oil in $59 \%$ yield $(11.3 \mathrm{mg}$, $0.03 \mathrm{mmol}$ ) from flash column chromatography (DCM:MeOH 20:1-10:1). $[\alpha]_{\mathrm{D}}^{25}-14.6$ (c $0.6, \mathrm{CH}_{3} \mathrm{OH}$ ). ${ }^{1} \mathrm{H}$ NMR $\left(\mathrm{CD}_{3} \mathrm{OD}, 400 \mathrm{MHz}\right): 7.65-7.26(\mathrm{~m}, 4 \mathrm{H}, \mathrm{ArH}), 4.47(\mathrm{~d}, 1 \mathrm{H}, J 7.2 \mathrm{~Hz}, \mathrm{H}-1), 3.94(\mathrm{td}, 1 \mathrm{H}, J 6.0 \mathrm{~Hz}$, J 2.0 Hz, H-5), 3.88-3.85 (m, 2H, H-2, H-4), 3.77 (d, 2H, J 5.6 Hz, H-6a, H-6b), 3.67 (dd, 1H, J 14.0 Hz, J 
$\left.6.4 \mathrm{~Hz}, \mathrm{CH}_{2} \mathrm{OH}\right), 3.67\left(\mathrm{dd}, 1 \mathrm{H}, \mathrm{J} 14.0 \mathrm{~Hz}, J 9.2 \mathrm{~Hz}, \mathrm{CH}_{2} \mathrm{OH}\right), 3.53\left(\mathrm{~s}, 3 \mathrm{H}, \mathrm{OCH}_{3}\right), 2.41-2.35(\mathrm{~m}, 1 \mathrm{H}, \mathrm{H}-3)$. ${ }^{13} \mathrm{C}$ NMR (CD $\left.{ }_{3} \mathrm{OD}, 100 \mathrm{MHz}\right): 168.9$ (d, J $\left.2.7 \mathrm{~Hz}\right), 164.1$ (d, J $\left.244 \mathrm{~Hz}\right), 138.0$ (d, J 6.8 Hz), 131.6 (d, J $7.9 \mathrm{~Hz}), 124.0(\mathrm{~d}, J 2.9 \mathrm{~Hz}), 119.4$ (d, J $22 \mathrm{~Hz}), 115.2$ (d, J $23 \mathrm{~Hz}), 103.6,75.9,68.9$, 68.6, 63.1, 56.8, 46.4, 37.8. HRMS calcd for $\mathrm{C}_{15} \mathrm{H}_{20} \mathrm{FNO}_{6}+\mathrm{H}^{+}(\mathrm{M}+\mathrm{H})^{+}: 330.1353$, found: 330.1354 .

\subsubsection{Methyl 3-Deoxy-3-C-(4-Fluorobenzamidomethyl)- $\beta$-D-Galactopyranoside 7e}

Compound $7 \mathrm{e}$ (TLC, DCM/MeOH, 10:1, $\mathrm{R}_{\mathrm{f}} 0.44$ ) was prepared according to the general procedure 3.12 from the amide $22 \mathrm{e}(40 \mathrm{mg}, 0.07 \mathrm{mmol})$. Obtained as a colorless oil in $53 \%$ yield $(11.6 \mathrm{mg}$, $0.04 \mathrm{mmol}$ ) from flash column chromatography (DCM:MeOH 20:1-9:1). $[\alpha]_{\mathrm{D}}^{25}-16.4\left(\mathrm{c} 0.5, \mathrm{CH}_{3} \mathrm{OH}\right)$. ${ }^{1} \mathrm{H}$ NMR (CD $\left.{ }_{3} \mathrm{OD}, 400 \mathrm{MHz}\right)$ : 7.89-7.84 (m, 2H, ArH), 7.22-7.16 (m, 2H, ArH), $4.47\left(\mathrm{~d}, 1 \mathrm{H}, J_{1,2} 7.2 \mathrm{~Hz}\right.$, H-1), 3.94 (td, 1H, J 6.0 Hz, J 3.0 Hz, H-5), 3.88-3.85 (m, 2H, H-2, H-4), 3.78 (d, 1H, J6a,6b 11.6 Hz, J5,6a $5.6 \mathrm{~Hz}, \mathrm{H}-6 \mathrm{a}), 3.75$ (d, 1H, J6a,6b $\left.11.6 \mathrm{~Hz}, J_{5,6 \mathrm{~b}} 5.6 \mathrm{~Hz}, \mathrm{H}-6 \mathrm{~b}\right), 3.66$ (d, $\left.1 \mathrm{H}, J 14.0 \mathrm{~Hz}, J 6.4 \mathrm{~Hz}, \mathrm{CH}_{2} \mathrm{NH}\right)$, $3.61\left(\mathrm{~d}, 1 \mathrm{H}, J 14.0 \mathrm{~Hz}, J 6.4 \mathrm{~Hz}, \mathrm{CH}_{2} \mathrm{NH}\right), 3.53\left(\mathrm{~s}, 3 \mathrm{H}, \mathrm{OCH}_{3}\right), 2.40-2.34(\mathrm{~m}, 1 \mathrm{H}, \mathrm{H}-3) .{ }^{13} \mathrm{C} \mathrm{NMR}\left(\mathrm{CD}_{3} \mathrm{OD}\right.$, $100 \mathrm{MHz}): 169.3,166.2$ (d, J $249 \mathrm{~Hz}), 131.9$ (d, J $3.0 \mathrm{~Hz}), 130.8$ (d, J $8.9 \mathrm{~Hz}), 116.4$ (d, J $22 \mathrm{~Hz}), 103.7,75.9$, 69.0, 68.6, 63.1, 56.8, 46.4, 37.8. ${ }^{19} \mathrm{~F} \mathrm{NMR}\left(\mathrm{CD}_{3} \mathrm{OD}, 376 \mathrm{MHz}\right)$ : -110.7 . HRMS calcd for $\mathrm{C}_{15} \mathrm{H}_{20} \mathrm{FNO}_{6}+\mathrm{H}^{+}$ $(\mathrm{M}+\mathrm{H})^{+}: 330.1353$, found: 330.1354 .

\subsubsection{Methyl 3-Deoxy-3-C-(3,4,5-Trifluorobenzamidomethyl)- 3 -D-Galactopyranoside $7 f$}

Compound $7 f\left(T L C, D C M / M e O H, 10: 1, R_{f} 0.47\right.$ ) was prepared according to the general procedure 3.12 from the amide $22 \mathrm{f}(31 \mathrm{mg}, 0.05 \mathrm{mmol})$. Obtained as a colorless oil in $70 \%$ yield $(12.5 \mathrm{mg}, 0.03 \mathrm{mmol})$ from flash column chromatography (DCM:MeOH 20:1-9:1). [ $\alpha]_{\mathrm{D}}^{25}-13.5\left(\mathrm{c} 0.6, \mathrm{CH}_{3} \mathrm{OH}\right) .{ }^{1} \mathrm{H}$ NMR (CD $\left.\mathrm{CD}_{3} \mathrm{OD}, 400 \mathrm{MHz}\right): 7.66-7.59$ (m, 2H, ArH), $4.45(\mathrm{~d}, 1 \mathrm{H}, J 6.8 \mathrm{~Hz}, \mathrm{H}-1), 4.00(\mathrm{td}, 1 \mathrm{H}, J 6.0 \mathrm{~Hz}, J 2.0 \mathrm{~Hz}$, H-5), 3.87-3.84 (m, 2H, H-2, H-4), 3.76 (d, 2H, J 5.6 Hz, H-6a, H-6b), 3.66 (dd, 1H, J 14.0 Hz, J 6.0 Hz, $\left.\mathrm{CH}_{2} \mathrm{NH}\right), 3.59\left(\mathrm{dd}, 1 \mathrm{H}, J 14.0 \mathrm{~Hz}, J 9.2 \mathrm{~Hz}, \mathrm{CH}_{2} \mathrm{NH}\right), 3.53\left(\mathrm{~s}, 3 \mathrm{H}, \mathrm{OCH}_{3}\right), 2.40-2.40-2.34(\mathrm{~m}, 1 \mathrm{H}, \mathrm{H}-3)$. ${ }^{13} \mathrm{C}$ NMR (CD $\left.\mathrm{OD}, 100 \mathrm{MHz}\right): 166.7,152.3$ (ddd, $\left.248.3 \mathrm{~Hz}, J 9.8 \mathrm{~Hz}, J 3.8 \mathrm{~Hz}\right), 143.0$ (dt, J $254 \mathrm{~Hz}, J$ $16 \mathrm{~Hz}$ ), $132.2-132.0(\mathrm{~m}), 113.1(\mathrm{dd}, J 17 \mathrm{~Hz}, J 6.1 \mathrm{~Hz}), 103.7,75.9,68.8,68.5,63.1,56.8,46.3,38.0 .{ }^{19} \mathrm{~F}$ NMR (CD 3 OD, $376 \mathrm{MHz}):-135.7(\mathrm{~d}, J 20 \mathrm{~Hz}) .-159.1(\mathrm{t}, J 20 \mathrm{~Hz})$. HRMS calcd for $\mathrm{C}_{15} \mathrm{H}_{18} \mathrm{~F}_{3} \mathrm{NO}_{6}+\mathrm{H}^{+}$ $(\mathrm{M}+\mathrm{H})^{+}: 366.1164$, found: 366.1161 .

\subsubsection{Methyl 3-Deoxy-3-C-(2,3,4,5,6-Pentafluorobenzamidomethyl)- $\beta$-D-Galactopyranoside 7g}

Compound $7 \mathrm{~g}$ (TLC, DCM/MeOH, 10:1, $\mathrm{R}_{\mathrm{f}} 0.38$ ) was prepared according to the general procedure 3.12 from the amide $22 \mathrm{~g}$ ( $30 \mathrm{mg}, 0.04 \mathrm{mmol})$. Obtained as a colorless oil in $83 \%$ yield $(14.9 \mathrm{mg}$, $0.04 \mathrm{mmol}$ ) from flash column chromatography (DCM:MeOH 20:1-8:1). $[\alpha]_{\mathrm{D}}^{25}-18.9$ (c $0.6, \mathrm{CH}_{3} \mathrm{OH}$ ). ${ }^{1} \mathrm{H}$ NMR $\left(\mathrm{CD}_{3} \mathrm{OD}, 400 \mathrm{MHz}\right): 4.46(\mathrm{~d}, 1 \mathrm{H}, J 6.4 \mathrm{~Hz}, \mathrm{H}-1), 3.94-3.85$ (m, 4H, H-2, H-4, H-5), 3.79 (dd, $1 \mathrm{H}, J 6.0 \mathrm{~Hz}, J 11.2 \mathrm{~Hz}, \mathrm{H}-6 \mathrm{a}), 3.79$ (dd, 1H, J $5.2 \mathrm{~Hz}, J 11.2 \mathrm{~Hz}, \mathrm{H}-6 \mathrm{a}), 3.68$ (dd, 1H, J $6.4 \mathrm{~Hz}, J 14.4 \mathrm{~Hz}$, $\mathrm{CH}_{2} \mathrm{NHCO}$ ), $3.62\left(\mathrm{dd}, 1 \mathrm{H}, J 14.4 \mathrm{~Hz}, J 8.8 \mathrm{~Hz}, \mathrm{CH}_{2} \mathrm{NHCO}\right), 3.53\left(\mathrm{~s}, 3 \mathrm{H}, \mathrm{OCH}_{3}\right), 2.38-2.32(\mathrm{~m}, 1 \mathrm{H}, \mathrm{H}-3)$. ${ }^{13} \mathrm{C}$ NMR (CD $\left.{ }_{3} \mathrm{OD}, 100 \mathrm{MHz}\right): 159.9,146.4,144.0,140.2,137.6,103.6,75.8,68.5,68.4,63.2,56.9,46.3$, 37.7. ${ }^{19} \mathrm{~F}$ NMR ( $\left.\mathrm{CD}_{3} \mathrm{OD}, 376 \mathrm{MHz}\right):-143.8$ to $-143.2(\mathrm{~m}),-155.2$ to $-155.3(\mathrm{~m}),-163.7$ to $-163.9(\mathrm{~m})$. HRMS calcd for $\mathrm{C}_{15} \mathrm{H}_{16} \mathrm{~F}_{5} \mathrm{NO}_{6}+\mathrm{H}^{+}(\mathrm{M}+\mathrm{H})^{+}:$402.0976, found: 402.0974 .

\subsubsection{Methyl 3-Deoxy-3-C-(3-Methoxybenzamidomethyl)- $\beta$-D-Galactopyranoside 7h}

Compound $7 \mathrm{~h}$ (TLC, DCM/MeOH, 10:1, $\mathrm{R}_{\mathrm{f}} 0.42$ ) was prepared according to the general procedure 3.12 from the amide $22 \mathrm{~h}(28 \mathrm{mg}, 0.03 \mathrm{mmol})$. Obtained as a colorless oil in $66 \%$ yield $(10.3 \mathrm{mg}$, $0.03 \mathrm{mmol}$ ) from flash column chromatography (DCM:MeOH 20:1-10:1). $[\alpha]_{\mathrm{D}}^{25}-9.5\left(\mathrm{c} 0.5, \mathrm{CH}_{3} \mathrm{OH}\right)$. ${ }^{1} \mathrm{H}$ NMR (CD $\left.{ }_{3} \mathrm{OD}, 400 \mathrm{MHz}\right): 8.47(\mathrm{t}, J 5.2 \mathrm{~Hz}, \mathrm{CONH}), 7.38-7.33(\mathrm{~m}, 3 \mathrm{H}, \mathrm{ArH}), 7.08(\mathrm{~m}, 1 \mathrm{H}, \mathrm{ArH}), 4.47$ (d, 1H, J 7.2 Hz, H-1), 3.94 (td, 1H, J 5.6 Hz, J 2.0 Hz, H-5), 3.88-3.85 (m, 2H, H-2, H-4), 3.84 (s, 3H, $\left.\mathrm{OCH}_{3}\right), 3.78(\mathrm{~d}, 2 \mathrm{H}, J 5.6 \mathrm{~Hz}, \mathrm{H}-6 \mathrm{a}, \mathrm{H}-6 \mathrm{~b}), 3.66-3.62\left(\mathrm{~m}, 2 \mathrm{H}, \mathrm{CH}_{2} \mathrm{NN}\right), 3.53\left(\mathrm{~s}, 3 \mathrm{H}, \mathrm{OCH}_{3}\right), 2.41-2.35$ (m, 1H, H-3). ${ }^{13} \mathrm{C}$ NMR (CD $\left.{ }_{3} \mathrm{OD}, 100 \mathrm{MHz}\right): 170.3,161.3,137.0,130.7,120.3,118.5,113.6,103.7,75.9,70.0$, 68.6, 63.1, 56.9, 55.9, 46.4, 37.8. HRMS calcd for $\mathrm{C}_{16} \mathrm{H}_{23} \mathrm{NO}_{7}+\mathrm{H}^{+}(\mathrm{M}+\mathrm{H})^{+}: 342.1553$, found: 342.1555 . 
3.12.16. Methyl 3-Deoxy-3-C-(p-Toluamidomethyl)- $\beta$-D-Galactopyranoside 7i

Compound $7 \mathbf{i}\left(\mathrm{TLC}, \mathrm{DCM} / \mathrm{MeOH}, 10: 1, \mathrm{R}_{\mathrm{f}} 0.48\right.$ ) was prepared according to the general procedure 3.12 from the amide $22 \mathbf{i}(32 \mathrm{mg}, 0.05 \mathrm{mmol})$. Obtained as a colorless oil in $53 \%$ yield ( $11.9 \mathrm{mg}, 0.04 \mathrm{mmol})$ from flash column chromatography (DCM:MeOH 20:1-10:1). [ $\alpha]_{\mathrm{D}}^{25}-4.8\left(\mathrm{c} 0.5, \mathrm{CH}_{3} \mathrm{OH}\right) .{ }^{1} \mathrm{H}$ NMR (CD $\left.\mathrm{CD}_{3} \mathrm{OD}, 400 \mathrm{MHz}\right): 7.72-7.69(\mathrm{~m}, 2 \mathrm{H}, \mathrm{ArH}), 7.27(\mathrm{~d}, 2 \mathrm{H}, J 8.0 \mathrm{~Hz}, \mathrm{ArH}), 4.47(\mathrm{~d}, 1 \mathrm{H}, J 7.2 \mathrm{~Hz}, \mathrm{H}-1)$, $3.94(\mathrm{td}, 1 \mathrm{H}, J 5.6 \mathrm{~Hz}, J 2.0 \mathrm{~Hz}, \mathrm{H}-5), 3.88-3.85$ (m, 2H, H-2, H-4), 3.77 (d, 2H, J 5.6 Hz, H-6a, H-6b), 3.66-3.62 (m, 2H, CH $\left.\mathrm{CH}_{2} \mathrm{NN}\right), 3.53\left(\mathrm{~s}, 3 \mathrm{H}, \mathrm{OCH}_{3}\right), 2.39-2.34\left(\mathrm{~m}, 1 \mathrm{H}, \mathrm{H}-3, \mathrm{CH}_{3}\right) .{ }^{13} \mathrm{C} \mathrm{NMR}\left(\mathrm{CD}_{3} \mathrm{OD}\right.$, $100 \mathrm{MHz}):$ 170.4, 143.4, 132.7, 130.2, 128.2, 103.7, 76.0, 69.0, 68.7, 63.2, 56.9, 46.4, 37.7, 21.4. HRMS calcd for $\mathrm{C}_{16} \mathrm{H}_{23} \mathrm{NO}_{6}+\mathrm{H}^{+}(\mathrm{M}+\mathrm{H})^{+}$: 326.1604, found: 326.1603 .

\subsubsection{Methyl 3-Deoxy-3-C-(3,5-Dimethoxybenzamidomethyl)- $\beta$-D-Galactopyranoside $7 \mathbf{j}$}

Compound $7 \mathbf{j}$ (TLC, DCM/MeOH, 10:1, $\mathrm{R}_{\mathrm{f}} 0.43$ ) was prepared according to the general procedure 3.12 from the amide $22 \mathrm{j}(24 \mathrm{mg}, 0.04 \mathrm{mmol})$. Obtained as a colorless oil in $62 \%$ yield $(10 \mathrm{mg}, 0.03 \mathrm{mmol})$ from flash column chromatography (DCM:MeOH 20:1-9:1). [ $\alpha]_{\mathrm{D}}^{25}-25.7$ (c $\left.0.5, \mathrm{CH}_{3} \mathrm{OH}\right) .{ }^{1} \mathrm{H}$ NMR $\left(\mathrm{CD}_{3} \mathrm{OD}, 400 \mathrm{MHz}\right): 6.96(\mathrm{~d}, 1 \mathrm{H}, J 2.0 \mathrm{~Hz}, \mathrm{ArH}), 6.63(\mathrm{t}, 1 \mathrm{H}, J 2.0 \mathrm{~Hz}, \mathrm{ArH}), 4.47\left(\mathrm{~d}, 1 \mathrm{H}, J_{1,2} 7.2 \mathrm{~Hz}, \mathrm{H}-1\right)$, $3.94(\mathrm{td}, 1 \mathrm{H}, J 5.6 \mathrm{~Hz}, J 2.0 \mathrm{~Hz}, \mathrm{H}-5), 3.88-3.85(\mathrm{~m}, 2 \mathrm{H}, \mathrm{H}-2, \mathrm{H}-4), 3.82\left(\mathrm{~s}, 6 \mathrm{H}, 2 \times \mathrm{OCH}_{3}\right), 3.77(\mathrm{~d}, 2 \mathrm{H}, J$ $6.0 \mathrm{~Hz}), 3.67-3.57\left(\mathrm{~m}, 2 \mathrm{H}, \mathrm{CH}_{2} \mathrm{NH}\right), 3.53\left(\mathrm{~s}, 3 \mathrm{H}, \mathrm{OCH}_{3}\right), 2.40-2.34(\mathrm{~m}, 1 \mathrm{H}, \mathrm{H}-3) .{ }^{13} \mathrm{C} \mathrm{NMR}\left(\mathrm{CD}_{3} \mathrm{OD}\right.$, $100 \mathrm{MHz}$ ): 170.2, 162.4, 137.6, 106.1, 104.5, 103.7, 75.9, 69.0, 68.6, 63.1, 56.8, 56.0, 46.4, 37.8. HRMS calcd for $\mathrm{C}_{17} \mathrm{H}_{25} \mathrm{NO}_{8}+\mathrm{H}^{+}(\mathrm{M}+\mathrm{H})^{+}$: 372.1658, found: 372.1663 .

\subsubsection{Methyl 3-Deoxy-3-C-(3-Trifluoromethylbenzamidomethyl)- $\beta$-D-Galactopyranoside 7k}

Compound 7k (TLC, DCM/MeOH, 10:1, $\mathrm{R}_{\mathrm{f}} 0.51$ ) was prepared according to the general procedure 3.12 from the amide 22k ( $25 \mathrm{mg}, 0.04 \mathrm{mmol})$. Obtained as a colorless oil in $66 \%$ yield $(11.2 \mathrm{mg}$, $0.03 \mathrm{mmol}$ ) from flash column chromatography (DCM:MeOH 20:1-10:1). $[\alpha]_{\mathrm{D}}^{25}-3.9\left(\mathrm{c} 0.6, \mathrm{CH}_{3} \mathrm{OH}\right)$. ${ }^{1} \mathrm{H}$ NMR (CD $\left.{ }_{3} \mathrm{OD}, 400 \mathrm{MHz}\right): 8.13(\mathrm{~s}, 1 \mathrm{H}, \mathrm{ArH}), 8.08(\mathrm{t}, 1 \mathrm{H}, J 8.0 \mathrm{~Hz}, \mathrm{ArH}), 7.85(\mathrm{~d}, 1 \mathrm{H}, J 8.0 \mathrm{~Hz}, \mathrm{ArH})$, $7.68(\mathrm{t}, 1 \mathrm{H}, J 8.0 \mathrm{~Hz}, \mathrm{ArH}), 4.47$ (d, 1H, J1,2 $7.2 \mathrm{~Hz}, \mathrm{H}-1), 3.95(\mathrm{td}, 1 \mathrm{H}, J 6.0 \mathrm{~Hz}, J 2.0 \mathrm{~Hz}, \mathrm{H}-5), 3.89-3.86$ (m, 2H, H-2, H-4), 3.79 (dd, 1H, J6a,6b 12.0 Hz, J5,6a $6.0 \mathrm{~Hz}, \mathrm{H}-6 \mathrm{a}), 3.76$ (dd, 1H, J6a,6b $12.0 \mathrm{~Hz}, J_{5,6 \mathrm{~b}}$ $6.0 \mathrm{~Hz}, \mathrm{H}-6 \mathrm{~b}), 3.69$ (dd, $\left.1 \mathrm{H}, J 13.6 \mathrm{~Hz}, J 5.6 \mathrm{~Hz}, \mathrm{CH}_{2} \mathrm{NH}\right), 3.63\left(\mathrm{dd}, 1 \mathrm{H}, J 13.6 \mathrm{~Hz}, J 9.2 \mathrm{~Hz}, \mathrm{CH}_{2} \mathrm{NH}\right), 3.54$

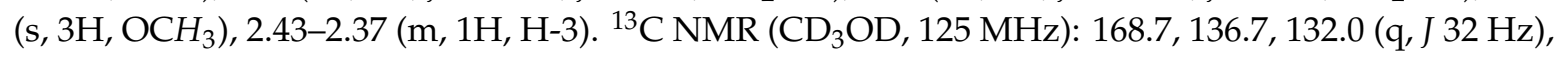
131.9, 130.6, $129.2(\mathrm{q} J 3.6 \mathrm{~Hz}), 125.4(\mathrm{q}, J 270 \mathrm{~Hz}), 125.1$ (q, J 4.0 Hz), 103.7, 75.9, 68.9, 68.6, 63.1, 56.9, 46.5, 37.8. ${ }^{19} \mathrm{~F} \mathrm{NMR}\left(\mathrm{CD}_{3} \mathrm{OD}, 376 \mathrm{MHz}\right):-64.2$. HRMS calcd for $\mathrm{C}_{16} \mathrm{H}_{20} \mathrm{~F}_{3} \mathrm{NO}_{6}+\mathrm{H}^{+}(\mathrm{M}+\mathrm{H})^{+}: 380.1321$, found: 380.1321 .

\subsubsection{Methyl 3-Deoxy-3-C-(4-Phenylbenzamidomethyl)- $\beta$-D-Galactopyranoside 71}

Compound 71 (TLC, DCM/MeOH, 10:1, $\mathrm{R}_{\mathrm{f}} 0.54$ ) was prepared according to the general procedure 3.12 from the amide 221 ( $39 \mathrm{mg}, 0.06 \mathrm{mmol})$. Obtained as a colorless oil in $67 \%$ yield $(15.4 \mathrm{mg}, 0.04 \mathrm{mmol})$ from flash column chromatography (DCM:MeOH 20:1-12:1). $[\alpha]_{\mathrm{D}}^{25}-21.4\left(\mathrm{c} 0.7, \mathrm{CH}_{3} \mathrm{OH}\right) .{ }^{1} \mathrm{H}$ NMR (CD $\left.\mathrm{CD}_{3} \mathrm{OD}, 400 \mathrm{MHz}\right): 7.70$ (dd, 2H, J $\left.6.8 \mathrm{~Hz}, J 2.0 \mathrm{~Hz}, \mathrm{ArH}\right), 7.71(\mathrm{dd}, 2 \mathrm{H}, J 6.8 \mathrm{~Hz}, J 2.0 \mathrm{~Hz}, \mathrm{ArH}), 7.65$ (m, 2H, ArH), 7.48-7.44 (m, 2H, ArH), 7.40-7.35 (m, 1H, ArH), 4.49 (d, 1H, J1,2 7.2 Hz, H-1), 3.96 (td, 1H, J $6.0 \mathrm{~Hz}, J$ J $2.4 \mathrm{~Hz}, \mathrm{H}-5), 3.82-3.75$ (m, 2H, H-6a, H-6b), 3.73-3.62 (m, 2H, $\left.\mathrm{CH}_{2} \mathrm{NH}\right), 3.54\left(\mathrm{~s}, 3 \mathrm{H}, \mathrm{OCH}_{3}\right)$, 2.44-2.38 (m, 1H, H-3). ${ }^{13} \mathrm{C}$ NMR ( $\left.\mathrm{CD}_{3} \mathrm{OD}, 100 \mathrm{MHz}\right): 170.1,145.7,141.2,134.2,130.0,129.1,128.8$, $128.11,128.07,103.7,76.0,69.0,68.7,63.2,56.9,46.4,37.8$. HRMS calcd for $\mathrm{C}_{21} \mathrm{H}_{25} \mathrm{NO}_{6}+\mathrm{H}^{+}(\mathrm{M}+\mathrm{H})^{+}$: 388.1760, found: 388.1761 .

\subsubsection{Methyl 3-Deoxy-3-C-(Diphenylphosphonamidomethyl)- $\beta$-D-Galactopyranoside 8}

Compound 8 (TLC, DCM/MeOH, 10:1, $\mathrm{R}_{\mathrm{f}}$ 0.45) was prepared according to the general procedure 3.12 from the amide 23 ( $43 \mathrm{mg}, 0.06 \mathrm{mmol})$. Obtained as a colorless oil in $50 \%$ yield $(13.3 \mathrm{mg}, 0.03 \mathrm{mmol})$ from flash column chromatography (DCM:MeOH 15:1-9:1). [ $\alpha]_{\mathrm{D}}^{25}-18.6\left(\mathrm{c} 0.7, \mathrm{CH}_{3} \mathrm{OH}\right) .{ }^{1} \mathrm{H}$ NMR $\left(\mathrm{CD}_{3} \mathrm{OD}, 400 \mathrm{MHz}\right): 7.40(\mathrm{t}, 4 \mathrm{H}, J 8.0 \mathrm{~Hz}, \mathrm{ArH}), 7.29-7.21(\mathrm{~m}, 6 \mathrm{H}, \mathrm{ArH}), 4.36(\mathrm{~d}, 1 \mathrm{H}, J 7.2 \mathrm{~Hz}, \mathrm{H}-1), 3.90$ 
(dd, 1H, J 4.0 Hz, J 2.0 Hz, H-4), 3.83 (dd, 1H, J 7.2 Hz, J 5.6 Hz, H-2), 3.79-3.76 (m, 1H, H-5), 3.71 (dd, $\left.1 \mathrm{H}, J_{5,6 \mathrm{a}} 10.4 \mathrm{~Hz}, J_{6 \mathrm{a}, 6 \mathrm{~b}} 4.4 \mathrm{~Hz}, \mathrm{H}-6 \mathrm{a}\right), 3.71$ (dd, 1H, J5,6b $\left.10.8 \mathrm{~Hz}, J_{6 \mathrm{a}, 6 \mathrm{~b}} 4.4 \mathrm{~Hz}, \mathrm{H}-6 \mathrm{~b}\right), 3.51$ (s, $\left.3 \mathrm{H}, \mathrm{OCH}_{3}\right)$, 3.50-3.44 (m, $\left.1 \mathrm{H}, \mathrm{CH}_{2} \mathrm{NH}\right), 3.17-3.08\left(\mathrm{~m}, 1 \mathrm{H}, \mathrm{CH}_{2} \mathrm{NH}\right), 2.28-2.22(\mathrm{~m}, 1 \mathrm{H}, \mathrm{H}-3) .{ }^{13} \mathrm{C}$ NMR $\left(\mathrm{CD}_{3} \mathrm{OD}\right.$, $100 \mathrm{MHz}$ ): 152.2 (dd, J 6.2 Hz, J $2.7 \mathrm{~Hz}), 130.9,126.3$ (d, J 3.1 Hz), 121.4 (dd, J 4.6 Hz, J 11.1 Hz), 103.6, 75.7, 68.7, 68.1, 63.2, 56.8, $47.4(\mathrm{~d}, 5.7 \mathrm{~Hz}), 39.2 .{ }^{31} \mathrm{P} \mathrm{NMR}\left(\mathrm{CD}_{3} \mathrm{OD}, 162 \mathrm{MHz}\right)$ : -1.0. HRMS calcd for $\mathrm{C}_{20} \mathrm{H}_{26} \mathrm{PNO}_{8}+\mathrm{H}^{+}(\mathrm{M}+\mathrm{H})^{+}: 440.1474$, found: 440.1470 .

\subsection{Methyl 2,3-Di-O-Acetyl- $\beta$-D-Gulopyranoside $\mathbf{2 5}$}

Compound 24 (300 mg, $0.82 \mathrm{mmol}$ ) was dissolved in $80 \%$ aqueous $\mathrm{AcOH}(5 \mathrm{~mL})$ and the solution was stirred at $80^{\circ} \mathrm{C}$ for $2 \mathrm{~h}$. When the TLC (TLC, heptane/EtOAc, 1:2, $\mathrm{R}_{\mathrm{f}} 0.39$ ) showed complete consumption of the starting material, the solvents were evaporated under reduced pressure and co-evaporated twice with toluene $(10 \mathrm{~mL})$. Then, the crude was purified via flash chromatography (Heptane/EtOAc, 3:1-1:2) to obtain pure compound $25(191 \mathrm{mg}, 0.69 \mathrm{mmol}, 84 \%)$ as a white foam. $[\alpha]_{\mathrm{D}}^{25}$ -30.4 (c 0.8, $\left.\mathrm{CHCl}_{3}\right) .{ }^{1} \mathrm{H}$ NMR ( $\left.\mathrm{CDCl}_{3}, 400 \mathrm{MHz}\right): 5.35$ (t, $\left.1 \mathrm{H}, J_{2,3} 3.6 \mathrm{~Hz}, \mathrm{H}-3\right), 5.10$ (dd, $1 \mathrm{H}, J_{1,2} 8.0 \mathrm{~Hz}$, $\left.J_{2,3} 3.6 \mathrm{~Hz}, \mathrm{H}-2\right), 4.68$ (d, 1H, J 8.0 Hz, H-1), 3.93-3.89 (m, 4H, H4, H-5, H-6a, H-6b), 3.52 (s, 3H, OCH , ,

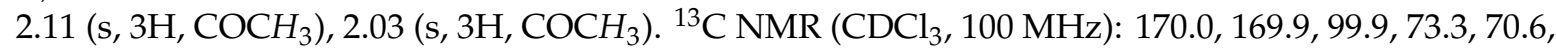
69.0, 68.4, 62.8, 56.9, 20.98, 20.95. HRMS calcd for $\mathrm{C}_{11} \mathrm{H}_{18} \mathrm{O}_{8}+\mathrm{Na}^{+}(\mathrm{M}+\mathrm{Na})^{+}:$301.0899, found: 301.0898.

\subsection{Methyl $\beta$-D-Gulopyranoside 9}

Compound 25 (120 mg, $0.43 \mathrm{mmol})$ was dissolved in $\mathrm{MeOH}(3 \mathrm{~mL})$. NaOMe (1.0 mL, $0.5 \mathrm{M}$ in $\mathrm{MeOH}$ ) was added and the solution was stirred at room temperature for $2 \mathrm{~h}$ (TLC, DCM/MeOH, 5:1, $\mathrm{R}_{\mathrm{f}}$ 0.3). The solution was neutralized with DOWEX $50 \mathrm{~W} \mathrm{H}^{+}$resin, filtered and the solvents were evaporated under reduced pressure and the crude was purified via flash chromatography (DCM/MeOH, 7:1-3:1) to obtain pure compound $9(46 \mathrm{mg}, 0.23 \mathrm{mmol}, 55 \%)$ as a colorless oil. $[\alpha]_{\mathrm{D}}^{25}$ -19.2 (c 0.9, $\left.\mathrm{CH}_{3} \mathrm{OH}\right) .{ }^{1} \mathrm{H}$ NMR $\left(\mathrm{D}_{2} \mathrm{O}, 400 \mathrm{MHz}\right): 4.60\left(\mathrm{~d}, 1 \mathrm{H}, J_{1,2} 8.4 \mathrm{~Hz}, \mathrm{H}-1\right), 4.05\left(\mathrm{t}, 1 \mathrm{H}, J_{3,4} 3.6 \mathrm{~Hz}\right.$, H-4), 4.00-3.96 (m, 1H, H-5), 3.80 (dd, $\left.1 \mathrm{H}, J_{3,4} 3.6 \mathrm{~Hz}, J_{4,5} 1.2 \mathrm{~Hz}, \mathrm{H}-4\right), 3.75$ (dd, $1 \mathrm{H}, J_{6 \mathrm{a}, 6 \mathrm{~b}} 12.0 \mathrm{~Hz}, J_{5,6 \mathrm{a}}$ $6.4 \mathrm{~Hz}, \mathrm{H}-6 \mathrm{a}), 3.76$ (dd, 1H, J Ja,6b $\left.12.0 \mathrm{~Hz}, J_{5,6 \mathrm{a}} 4.8 \mathrm{~Hz}, \mathrm{H}-6 \mathrm{~b}\right), 3.76$ (dd, $1 \mathrm{H}, J_{1,2} 8.4 \mathrm{~Hz}, J_{2,3} 3.6 \mathrm{~Hz}, \mathrm{H}-2$ ), $3.56\left(\mathrm{~s}, 3 \mathrm{H}, \mathrm{OCH}_{3}\right) .{ }^{13} \mathrm{C}$ NMR $\left(\mathrm{D}_{2} \mathrm{O}, 100 \mathrm{MHz}\right): 101.5,73.8,71.1,69.3,68.0,61.0,56.9$. HRMS calcd for $\mathrm{C}_{7} \mathrm{H}_{14} \mathrm{O}_{6}+\mathrm{Na}^{+}(\mathrm{M}+\mathrm{Na})^{+}: 217.0688$, found: 217.0687 .

\subsection{Methyl 3-Azido-2,4,6-Tri-O-Benzoyl-3-Deoxy- $\beta$-D-Gulopyranoside 29}

Triflic anhydride $(235 \mu \mathrm{L}, 1.4 \mathrm{mmol})$ was added dropwise to a stirred solution of $\mathbf{2 6}$ (400 $\mathrm{mg}$, $1.4 \mathrm{mmol})$ in DCM $(10 \mathrm{~mL})$ and pyridine $(451 \mu \mathrm{L}, 5.6 \mathrm{mmol})$ at $-30{ }^{\circ} \mathrm{C}$ and under $\mathrm{N}_{2}$ atmosphere after which the reaction was allowed to reach rt under $2 \mathrm{~h}$. $\mathrm{BzCl}(179 \mu \mathrm{L}, 1.54 \mathrm{mmol})$ was added and the reaction was stirred for another $2 \mathrm{~h}$ before the reaction was diluted with DCM $(25 \mathrm{~mL})$ and washed with saturated $\mathrm{NaHCO}_{3}(2 \times 25 \mathrm{~mL})$. The combined aqueous phases were extracted with DCM $(40 \mathrm{~mL})$. The pooled organic phases were dried over $\mathrm{MgSO}_{4}$ and concentrated to give crude 27. Sodium azide $(637 \mathrm{mg}, 9.8 \mathrm{mmol})$ was added to the crude $27(\leq 1.4 \mathrm{mmol})$ in DMF $(15 \mathrm{~mL})$ and the reaction was stirred overnight at $70{ }^{\circ} \mathrm{C}$ under $\mathrm{N}_{2}$ atmosphere. The reaction was concentrated to give crude 28 , which was dissolved in $90 \% \mathrm{AcOH}(20 \mathrm{~mL})$ and heated at $80^{\circ} \mathrm{C}$ for $3 \mathrm{~h}$. The solvent was evaporated in vacuo and co-evaporated with toluene to remove the residual $\mathrm{AcOH}$. The residue was dissolved in pyridine (15 $\mathrm{mL})$, into the solution catalytic amount of DMAP and benzoyl chloride ( $488 \mu \mathrm{L}, 4.2 \mathrm{mmol})$ was added subsequently. The solution was stirred at room temperature for $4 \mathrm{~h}$ when TLC (heptane/EtOAc, 4:1, $\mathrm{R}_{\mathrm{f}} \mathrm{0.48}$ ) showed complete conversion of the starting material to a faster moving spot. The solvents were evaporated in vacuo and co-evaporated with toluene to remove residual pyridine. The solid residue thus obtained was dissolved in EtOAc $(50 \mathrm{~mL})$ and washed with $1 \mathrm{~N} \mathrm{HCl}(50 \mathrm{~mL})$, followed by saturated $\mathrm{NaHCO}_{3}$ and brine $(50 \mathrm{~mL})$. The organic layer was collected, dried $\left(\mathrm{Na}_{2} \mathrm{SO}_{4}\right)$, filtered and evaporated in vacuo. The crude was purified by flash chromatography using heptane/EtOAc (6:1 to 5:2) as the eluent to afford pure compound $29(324 \mathrm{mg}, 0.61 \mathrm{mmol}, 43 \%$ over four steps) as a white amorphous mass. $[\alpha]_{\mathrm{D}}^{25}-45.3$ (c $\left.0.7, \mathrm{CHCl}_{3}\right) .{ }^{1} \mathrm{H} \mathrm{NMR}\left(\mathrm{CDCl}_{3}, 400 \mathrm{MHz}\right): 8.14-7.39$ (m, 15H, $\left.\mathrm{ArH}\right)$, 
$5.51\left(\mathrm{dd}, 1 \mathrm{H}, J_{1,2} 7.6 \mathrm{~Hz}, J_{2,3} 4.0 \mathrm{~Hz}, \mathrm{H}-2\right), 5.41\left(\mathrm{dd}, 1 \mathrm{H}, J_{3,4} 4.0 \mathrm{~Hz}, J_{3,4} 0.8 \mathrm{~Hz}, \mathrm{H}-4\right), 5.00(\mathrm{~d}, 1 \mathrm{H}, J 7.6 \mathrm{~Hz}$,

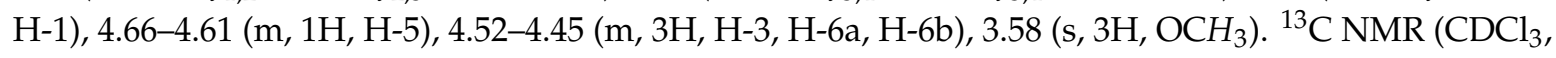
$100 \mathrm{MHz}): 166.0,165.3,165.2,133.8,133.6,133.2,130.02,129.98,129.7,129.5,129.0,128.7,128.6,128.5$, 128.4, 99.6, 70.3, 70.1, 69.5, 62.4, 60.1, 57.0. HRMS calcd for $\mathrm{C}_{28} \mathrm{H}_{25} \mathrm{~N}_{3} \mathrm{O}_{8}+\mathrm{NH}_{4}{ }^{+}\left(\mathrm{M}+\mathrm{NH}_{4}\right)^{+}$: 549.1985, found: 549.1989 .

\subsection{Methyl 3-Amino-2,4,6-Tri-O-Benzoyl-3-Deoxy- $\beta$-D-Gulopyranoside $\mathbf{3 0}$}

A solution of $29(201 \mathrm{mg}, 0.3784 \mathrm{mmol})$ in $\mathrm{MeOH}(7 \mathrm{~mL})$ was stirred with $\mathrm{Pd}(\mathrm{OH})_{2} / \mathrm{C}(10 \%$ wt., $1 \mathrm{mg}$ per $5 \mathrm{mg}$ of crude, $40 \mathrm{mg}$ ) under hydrogen atmosphere at room temperature for $2 \mathrm{~h}$. After the completion of the reaction (as indicated by TLC, heptane/EtOAc, 1:1, $\mathrm{R}_{\mathrm{f}} 0.26$ ), the reaction mixture was filtered through a Celite bed and washed with methanol. The filtrate was concentrated under reduced pressure and purified through flash column (heptane/EtOAc, 4:1-1:1) to get the desired compound as a white amorphous solid. Yield: $126 \mathrm{mg}(0.2494 \mathrm{mmol}, 66 \%)$. $[\alpha]_{\mathrm{D}}^{25}-39.9\left(\mathrm{c} 0.8, \mathrm{CHCl}_{3}\right) .{ }^{1} \mathrm{H} \mathrm{NMR}$ ( $\left.\mathrm{CDCl}_{3}, 400 \mathrm{MHz}\right): 8.13-7.38(\mathrm{~m}, 15 \mathrm{H}, \mathrm{ArH}), 5.38\left(\mathrm{dd}, 1 \mathrm{H}, J_{1,2} 7.2 \mathrm{~Hz}, J_{2,3} 4.0 \mathrm{~Hz}, \mathrm{H}-2\right), 5.29$ (dd, $1 \mathrm{H}, J_{3,4}$ $\left.4.4 \mathrm{~Hz}, J_{4,5} 2.4 \mathrm{~Hz}, \mathrm{H}-4\right), 5.11$ (d, 1H, J 7.2 Hz, H-1), 4.83-4.79 (m, 1H, H-5), 4.64 (dd, 1H, dd, 1H, J6a,6b $\left.11.2 \mathrm{~Hz}, J_{5,6 \mathrm{a}} 6.8 \mathrm{~Hz}, \mathrm{H}-6 \mathrm{a}\right), 4.51$ (dd, 1H, dd, $\left.1 \mathrm{H}, J_{6 \mathrm{a}, 6 \mathrm{~b}} 11.2 \mathrm{~Hz}, J_{5,6 \mathrm{~b}} 6.0 \mathrm{~Hz}, \mathrm{H}-6 \mathrm{~b}\right), 3.90\left(\mathrm{t}, 1 \mathrm{H}, J_{3,4}, J_{2,3}\right.$

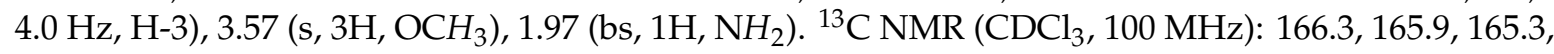
$133.7,133.5,133.2,130.1,129.9,129.8,128.69,128.67,128.5,99.3,72.1,71.7,70.2,63.3,57.1,50.6$. HRMS calcd for $\mathrm{C}_{28} \mathrm{H}_{27} \mathrm{NO}_{8}+\mathrm{H}^{+}(\mathrm{M}+\mathrm{H})^{+}$: 506.1815, found: 506.1817 .

\subsection{Methyl 3-Benzamido-2,4,6-Tri-O-Benzoyl-3-Deoxy- $\beta$-D-Gulopyranoside 31}

Compound 30 was dissolved in pyridine $(3 \mathrm{~mL})$, into the solution catalytic amount of DMAP and benzoyl chloride $(29 \mu \mathrm{L}, 0.2464 \mathrm{mmol})$ was added subsequently. The solution was stirred at room temperature for $3 \mathrm{~h}$ when TLC (heptane/EtOAc, 1:1, $\mathrm{R}_{\mathrm{f}} 4.8$ ) showed complete conversion of the starting material to a faster moving spot. The solvents were evaporated in vacuo and co-evaporated with toluene to remove residual pyridine. The solid residue thus obtained was dissolved in EtOAc $(7 \mathrm{~mL})$ and washed with $1(\mathrm{~N}) \mathrm{HCl}(5 \mathrm{~mL})$, followed by saturated $\mathrm{NaHCO}_{3}$ and brine $(5 \mathrm{~mL})$. The organic layer was collected, dried over $\mathrm{Na}_{2} \mathrm{SO}_{4}$, filtered and evaporated in vacuo. The crude was purified by flash chromatography using heptane/EtOAc (7:1 to 3:1) as the eluent to afford pure compound 31 (77 mg, $0.1265 \mathrm{mmol}, 77 \%)$ as a white amorphous solid. $[\alpha]_{\mathrm{D}}^{25}-48.8\left(\mathrm{c} 0.6, \mathrm{CHCl}_{3}\right) .{ }^{1} \mathrm{H} \mathrm{NMR}\left(\mathrm{CDCl}_{3}, 400 \mathrm{MHz}\right)$ : 8.11-7.29 (m, 20H, ArH), 6.60 (d, 1H, J3,NHCOPh $8.4 \mathrm{~Hz}, \mathrm{NHCOPh}), 5.96(\mathrm{dd}, 1 \mathrm{H}, J 10.8 \mathrm{~Hz}, J 6.0 \mathrm{~Hz}$, H-4), 5.55 (t, 1H, J 2.8 Hz, H-2), 5.34-5.29 (m, 1H, H-3), 4.99 (d, 1H, J1,2 2.8 Hz, H-1), 4.92 (dd, 1H, J6a,6b $\left.11.6 \mathrm{~Hz}, J_{5,6 \mathrm{a}} 5.6 \mathrm{~Hz}, \mathrm{H}-6 \mathrm{a}\right), 4.86$ (dd, $\left.1 \mathrm{H}, J_{6 \mathrm{a}, 6 \mathrm{~b}} 11.6 \mathrm{~Hz}, J_{5,6 \mathrm{~b}} 6.4 \mathrm{~Hz}, \mathrm{H}-6 \mathrm{a}\right), 4.77$ (dd, 1H, J6a,6b $12.4 \mathrm{~Hz}$, $\left.J_{4,5} 6.0 \mathrm{~Hz}, \mathrm{H}-5\right), 3.61$ (s, 3H, OCH $) .{ }^{13} \mathrm{C} \mathrm{NMR}\left(\mathrm{CDCl}_{3}, 100 \mathrm{MHz}\right): 167.4,166.8,166.2,165.5,133.9,133.8$, 133.7, 133.0, 131.7, 130.0, 129.9, 129.7, 129.6, 129.1, 128.7, 128.59, 128.57, 128.3, 127.0, 99.5, 72.4, 71.8, 68.4, 64.5, 60.4, 56.8, 46.3. HRMS calcd for $\mathrm{C}_{35} \mathrm{H}_{31} \mathrm{NO}_{9}+\mathrm{H}^{+}(\mathrm{M}+\mathrm{H})^{+}$: 610.2077, found: 610.2081.

\subsection{Methyl 3-Benzamido-3-Deoxy- $\beta$-D-Gulopyranoside 10}

Compound 31 ( $54 \mathrm{mg}, 0.0886 \mathrm{mmol})$ was dissolved in $\mathrm{MeOH}(2 \mathrm{~mL})$. NaOMe $(0.5 \mathrm{~mL}, 0.5 \mathrm{M}$ in $\mathrm{MeOH}$ ) was added and the solution was stirred at room temperature for $12 \mathrm{~h}$ (TLC, DCM/MeOH,

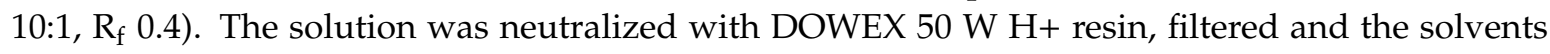
were evaporated under reduced pressure and the residue was purified by a short flash column using DCM-MeOH (9:1) to afford the compound $10(19.2 \mathrm{mg}, 0.0646 \mathrm{mmol}, 73 \%)$. $[\alpha]_{\mathrm{D}}^{25}-18.3\left(\mathrm{c} 0.6, \mathrm{CH}_{3} \mathrm{OH}\right)$. ${ }^{1} \mathrm{H}$ NMR (CD $\left.\mathrm{CD}_{3} \mathrm{OD}, 400 \mathrm{MHz}\right): 7.83$ (d, 2H, J 7.6 Hz, ArH), 7.57-7.44 (m, 3H, ArH), $4.70\left(\mathrm{~d}, 1 \mathrm{H}, J_{1,2}\right.$ $8.4 \mathrm{~Hz}, \mathrm{H}-1), 4.48-4.44(\mathrm{~m}, 1 \mathrm{H}, \mathrm{H}-3), 4.01$ (dd, 1H, J3,4 $\left.3.6 \mathrm{~Hz}, J_{4,5} 1.2 \mathrm{~Hz}, \mathrm{H}-4\right), 3.94$ (dd, $1 \mathrm{H}, J_{1,2} 7.6 \mathrm{~Hz}$, $\left.J_{2,3} 5.2 \mathrm{~Hz}, \mathrm{H}-2\right), 3.84\left(\mathrm{td}, 1 \mathrm{H}, J_{5,6 \mathrm{a}}, J_{5,6 \mathrm{a}} 6.0 \mathrm{~Hz}, J_{4,5} 1.6 \mathrm{~Hz}, \mathrm{H}-5\right), 3.77$ (dd, 1H, J6a,6b $11.2 \mathrm{~Hz}, J_{5,6 \mathrm{a}}$ $6.0 \mathrm{~Hz}, \mathrm{H}-6 \mathrm{a}), 3.74\left(\mathrm{dd}, 1 \mathrm{H}, J_{6 \mathrm{a}, 6 \mathrm{~b}} 11.2 \mathrm{~Hz}, J_{5,6 \mathrm{a}} 6.0 \mathrm{~Hz}, \mathrm{H}-6 \mathrm{~b}\right), 3.57\left(\mathrm{~s}, 3 \mathrm{H}, \mathrm{OCH}_{3}\right) .{ }^{13} \mathrm{C} \mathrm{NMR}\left(\mathrm{CD}_{3} \mathrm{OD}\right.$, $100 \mathrm{MHz}): 171.4,164.6,135.9,132.7,129.5,128.6,103.4,75.7,68.8,67.8,62.6,56.9,56.0$. HRMS calcd for $\mathrm{C}_{14} \mathrm{H}_{19} \mathrm{NO}_{6}+\mathrm{H}^{+}(\mathrm{M}+\mathrm{H})^{+}: 298.1291$, found: 298.1289 . 


\subsection{Expression Constructs, Expression, and Purification of Recombinant Galectins}

Human galectin-1 [25], galectin-2 [26], galectin-3 [27], galectin-4N [19], galectin-4C [19], galectin-8N [28], galectin-8C [28], galectin-9N [29], and galectin-9C [30], were expressed and purified as described earlier. Human galectin-7 was expressed using a pET3c plasmid in E. coli BL21-star. The plasmid containing expression optimized DNA encoding the full human galectin-7 sequence (NCBI Reference Sequence: NP_002298.1) was obtained from GenScript (Piscataway, NJ, USA). Bacterial culture and induction, and galectin purification was essential as described for galectin-3 expressed with the same vector [27]; a typical yield was $1.5-2 \mathrm{mg} / \mathrm{L}$ culture. Lactose was removed by chromatography on a PD-10 column (Amersham Biosciences) with repeated ultrafiltration with Centriprep (Amicon).

\subsection{Fluorescence Polarization Assay}

Fluorescence polarization experiments were carried out either with a POLARStar plate reader and FLUOstar Galaxy software or with a PheraStarFS plate reader and PHERAstar Mars version 2.10 R3 software (BMG, Offenburg, Germany). The dissociation constant $\left(\mathrm{K}_{\mathrm{d}}\right)$ values were determined in PBS as described earlier [18,19]. Specific conditions for galectin-1, 2, 3, 4N, 4C, 8N, 8C, 9N, and 9C were kept as reported [29]. Experiments were performed at room temperature with human galectin-7 at $5 \mu \mathrm{M}$ and the fluorescent probe $\beta$-D-galactopyranosyl-(1-4)-2-acetamido-2-deoxy- $\beta$-d-glucopyranosyl-(1-3)- $\beta$-dgalactopyranosyl-(1-4)-(N1-fluorescein-5-yl-carbonylaminomethylcarbonyl)- $\beta$-D-glucopyranosylamine [29] at $0.02 \mu \mathrm{M}$. All the compounds in Table 1 except 32 were dissolved in a neat DMSO at $100 \mathrm{mM}$ and diluted in PBS to three to six different concentrations to be tested in duplicate. Average $K_{d}$ values and SEMs were calculated from 2-8 single-triple point measurements showing between $30 \%-70 \%$ inhibition.

\section{Conclusions}

In summary, we report the synthesis and discovery of 3-C-methyl-guloside derivatives as highly selective galectin-1 inhibitors with 3-C-benzamidomethyl-3-deoxy-gulosides being the most selective structural class. The reason for the exceptional galectin-1-selectivites discovered remains to be elucidated as molecular modelling failed to provide insight into this and experimental structural studies by X-ray diffraction or nmr spectroscopy are likely necessary. Although the galectin- 1 affinities are in the high- $\mu \mathrm{M}$ to low $\mathrm{mM}$ range, they are significantly higher affinity than that of simple galactosides, such as methyl $\beta$-D-galactopyranoside, and thus points towards a novel structural class and synthetic route towards the discovery of galectin- 1 inhibitors with high selectivity. This is important in light of the roles of galectin-1 in tumor progression and immune regulation [31,32].

Supplementary Materials: Supplementary materials can be found at http://www.mdpi.com/1422-0067/20/15/ 3786/s1.

Author Contributions: K.B.P. and M.M. contributed equally to the synthesis and characterization of all compounds. K.B.P wrote the major part of the manuscript. H.L. supervised and analyzed the result of the fluorescence polarization assay. U.J.N. conceived the study, analyzed the data and co-wrote the paper. The manuscript was written with contributions from all authors. All authors have given consent to the final version of the manuscript.

Funding: We thank the Swedish Research Council (Grant No. 621-2016-03667), a project grant awarded by the Knut and Alice Wallenberg Foundation (KAW 2013.0022), and Galecto Biotech AB, Sweden for financial support.

Acknowledgments: We thank Barbro Kahl-Knutson for excellent assistance with determining affinities by fluorescence polarization and Sofia Essén for excellent assistance with hrms and analytical hplc experiments.

Conflicts of Interest: H.L. and U.J.N. are shareholders in Galecto Biotech AB, Sweden, a company developing galectin inhibitors. 


\section{Abbreviations}

$\begin{array}{ll}\text { Ac } & \text { Acetyl } \\ \text { Bn } & \text { Benzyl } \\ \text { DCM } & \text { Dichloromethane } \\ \text { THF } & \text { Tetrahydrofuran } \\ \text { DMF } & \text { Dimethylformamide } \\ \text { DIPEA } & \text { Diisopropylethylamine } \\ \text { AcOH } & \text { AcOH } \\ \text { EtOAc } & \text { EtOAc } \\ \text { TLC } & \text { Thin layer chromatography } \\ \text { HPLC } & \text { High-performance liquid chromatography } \\ \text { HRMS } & \text { High resolution mass spectrometry } \\ \text { DMSO } & \text { Dimethylsulfoxide } \\ \text { MM } & \text { Micromolar } \\ \text { mM } & \text { Milimolar } \\ \text { 9-BBN } & \text { 9-Borabicyclo[3.3.1]nonane } \\ \text { DMAP } & \text { 4-Dimethylaminopyridine }\end{array}$

\section{References}

1. Lella, S.D.; Sundblad, V.; Cerliani, J.P.; Guardia, C.M.; Estrin, D.A.; Vasta, G.R.; Rabinovich, G.A. When Galectins Recognize Glycans: From Biochemistry to Physiology and Back Again. Biochemistry 2011, 50, 7842-7857. [CrossRef] [PubMed]

2. Yang, R.-Y.; Rabinovich, G.A.; Liu, F.-T. Galectins: Structure, function and therapeutic potential. Expert Rev. Mol. Med. 2008, 10, e17. [CrossRef] [PubMed]

3. Johannes, L.; Jacob, R.; Leffler, H. Galectins at a glance. J. Cell Sci. 2018, 131, 1-9. [CrossRef] [PubMed]

4. Rabinovich, G.A.; Croci, D.O. Regulatory Circuits Mediated by Lectin-Glycan Interactions in Autoimmunity and Cancer. Immunity 2012, 36, 322-335. [CrossRef]

5. Rabinovich, G.A.; Toscano, M.A. Turning "sweet" on immunity: Galectin-glycan interactions in immune tolerance and inflammation. Nat. Rev. Immunol. 2009, 9, 338-352. [CrossRef]

6. Costa, A.F.; Gomes, A.M.; Kozlowski, E.O.; Stelling, M.P.; Pavão, M.S.G. Extracellular galectin-3 in tumor progression and metastasis. Front Oncol. 2014, 4, 1-9.

7. Cousin, J.M.; Cloninger, M.J. The Role of Galectin-1 in Cancer Progression, and Synthetic Multivalent Systems for the Study of Galectin-1. Int. J. Mol. Sci. 2016, 17, 1566. [CrossRef]

8. Chang, W.-A.; Tsai, M.-J.; Kuo, P.-L.; Hung, J.-Y. Role of galectins in lung cancer. Oncol Lett. 2017, 14, 5077-5084.

9. Diao, B.; Liu, Y.; Zhang, Y.; Xie, J.; Gong, J. The role of galectin-3 in the tumorigenesis and progression of pituitary tumors. Oncol. Lett. 2018, 15, 4919-4925. [CrossRef]

10. Califice, S.; Castronovo, V.; Brule, F.V.D. Galectin-3 and cancer. Int. J. Oncol. 2004, 25, 983-992.

11. Laaf, D.; Bojarová, P.; Elling, L.; Kren, V. Galectin-Carbohydrate Interactions in Biomedicine and Biotechnology. Trends Biotechnol. 2019, 37, 402-415. [CrossRef] [PubMed]

12. Notz, W.; Hartel, C.; Waldscheck, B.; Schmidt, R.R. De Novo Synthesis of a Methylene-Bridged Neu5Ac-r-(2,3)-Gal C-Disaccharide. J. Org. Chem. 2001, 66, 4250-4260. [CrossRef] [PubMed]

13. Manickam, G.; Ghoshal, A.; Subramaniam, P.; Li, Y. More Efficient Palladium Catalyst for Hydrogenolysis of Benzyl Groups. Synthetic Commun. 2006, 36, 925-928.

14. Sörme, P.; Kahl-Knutson, B.; Wellmar, U.; Nilsson, U.J.; Leffler, H. Fluorescence Polarization to Study Galectin-Ligand Interactions. Methods Enzymol. 2003, 362, 504-512. [PubMed]

15. Sörme, P.; Kahl-Knutson, B.; Huflejt, M.U.; Nilsson, U.J.; Leffler, H. Fluorescence polarization as an analytical tool to evaluate galectin-ligand interactions. Anal. Biochem. 2004, 334, 36-47.

16. Cumpstey, I.; Carlsson, S.; Leffler, H.; Nilsson, U.J. Synthesis of a phenyl thio- $\beta$-D-galactopyranoside library from 1,5-difluoro-2,4-dinitrobenzene: Discovery of efficient and selective monosaccharide inhibitors of galectin-7. Org. Biomol. Chem. 2005, 3, 1922-1932. [CrossRef] [PubMed] 
17. Öberg, C.-T.; Blanchard, H.; Leffler, H.; Nilsson, U.J. Protein subtype-targeting through ligand epimerization: Talose-selectivity of galectin-4 and galectin-8. Bioorg. Med. Chem. Lett. 2008, 18, 3691-3694. [CrossRef]

18. Pal, K.B.; Mahanti, M.; Huang, X.; Persson, S.; Sundin, A.P.; Zetterberg, F.R.; Oredsson, S.; Leffler, H.; Nilsson, U.J. Quinoline-galactose hybrids bind selectively with high affinity to a galectin-8 N-terminal domain. Org. Biomol. Chem. 2018, 16, 6295-6305. [CrossRef] [PubMed]

19. Mandal, S.; Rajput, V.K.; Sundin, A.P.; Leffler, H.; Mukhopadhyay, B.; Nilsson, U.J. Galactose-amidine derivatives as selective antagonists of galectin-9. Can. J. Chem. 2016, 94, 936-939. [CrossRef]

20. Tolnai, G.L.; Nilsson, U.J.; Olofsson, B. Efficient O-Functionalization of Carbohydrates with Electrophilic Reagents. Angew. Chem. Int. Ed. Engl. 2016, 55, 11226-11230. [CrossRef]

21. Peterson, K.; Kumar, R.; Stenström, O.; Verma, P.; Verma, P.R.; Håkansson, M.; Kahl-Knutsson, B.; Zetterberg, F.; Leffler, H.; Akke, M.; et al. Systematic Tuning of Fluoro-galectin-3 Interactions Provides Thiogalactoside Derivatives with Single-Digit nM Affinity and High Selectivity. J. Med. Chem. 2018, 61, 1164-1175. [CrossRef]

22. Öberg, C.T.; Noresson, A.-L.; Delaine, T.; Larumbe, A.; Tejler, J.; von Wachenfeldt, H.; Nilsson, U.J. Synthesis of 3-azido-3-deoxy- $\beta$-D-galactopyranosides. Carbohydr. Res. 2009, 344, 1282-1284.

23. Zemplén, G. Abbau der reduzierenden Biosen, I. Direkte Konstitutionsermitt-lung der cellobiose. Ber. Dtsch. Chem. Ges. 1926, 59, 1254.

24. Wong, C.-H.; Maris-Varas, F.; Hung, S.-C.; Marron, T.G.; Lin, C.-C.; Gong, K.W.; Weitz-Schimidt, G. Small Molecules as Structural and Functional Mimics of Sialyl Lewis X Tetrasaccharide in Selectin Inhibition: A Remarkable Enhancement of Inhibition by Additional Negative Charge and/or Hydrophobic Group. J. Am. Chem. Soc. 1997, 119, 8152-8158. [CrossRef]

25. Salomonsson, E.; Larumbe, A.; Tejler, J.; Tullberg, E.; Rydberg, H.; Sundin, A.; Khabut, T.; Frejd, T.; Lobsanov, Y.D.; Rini, J.M.; et al. Monovalent Interactions of Galectin-1. Biochemistry 2010, 49, 9518-9532. [CrossRef]

26. Gitt, M.A.; Massa, S.M.; Leffler, H.; Barondes, S.H. Isolation and expression of a gene encoding L-14-II, a new human soluble lactose-binding lectin. J. Biol. Chem. 1992, 267, 10601-10606.

27. Massa, S.M.; Cooper, D.N.; Leffler, H.; Barondes, S.H. L-29, an endogenous lectin, binds to glycoconjugate ligands with positive cooperativity. Biochemistry 1993, 32, 260-267. [CrossRef]

28. Carlsson, S.; Öberg, C.T.; Carlsson, M.C.; Sundin, A.; Nilsson, U.J.; Smith, D.; Cummings, R.D.; Almkvist, J.; Karlsson, A.; Leffler, H. Affinity of galectin- 8 and its carbohydrate recognition domains for ligands in solution and at the cell surface. Glycobiology 2007, 17, 663-676. [CrossRef]

29. Öberg, C.T.; Carlsson, S.; Fillion, E.; Leffler, H.; Nilsson, U.J. Efficient and Expedient Two-Step Pyranose-Retaining Fluorescein Conjugation of Complex Reducing Oligosaccharides: Galectin Oligosaccharide Specificity Studies in a Fluorescence Polarization Assay. Bioconj. Chem. 2003, 14, 1289-1297. [CrossRef]

30. Delaine, T.; Collins, P.; MacKinnon, A.; Sharma, G.; Stegmayr, J.; Rajput, V.K.; Mandal, S.; Cumpstey, I.; Larumbe, A.; Salameh, B.A.; et al. Galectin 3-Binding Glycomimetics that Strongly Reduce Bleomycin-Induced Lung Fibrosis and Modulate Intercellular Glycan Recognition. ChemBioChem 2016, 17, 1759-1770. [CrossRef]

31. Méndez-Huergo, S.P.; Blidner, A.G.; Rabinovich, G.A. Galectins: Emerging regulatory checkpoints linking tumor immunity and angiogenesis. Curr. Opin. Immun. 2017, 45, 8-15. [CrossRef]

32. Kaltner, H.; Toegel, S.; Caballero, G.G.; Manning, J.C.; Ledeen, R.W.; Gabius, H.-J. Galectins: Their network and roles in immunity/tumor growth control. Histochem. Cell. Biol. 2016, 147, 239-256. [CrossRef]

(C) 2019 by the authors. Licensee MDPI, Basel, Switzerland. This article is an open access article distributed under the terms and conditions of the Creative Commons Attribution (CC BY) license (http://creativecommons.org/licenses/by/4.0/). 